University of Arkansas, Fayetteville

ScholarWorks@UARK

Graduate Theses and Dissertations

$5-2018$

\title{
Effect of a Skating Unit on Fitness in Fifth Grade Students
}

Eric Lange

University of Arkansas, Fayetteville

Follow this and additional works at: https://scholarworks.uark.edu/etd

Part of the Exercise Science Commons, and the Health and Physical Education Commons

\section{Citation}

Lange, E. (2018). Effect of a Skating Unit on Fitness in Fifth Grade Students. Graduate Theses and Dissertations Retrieved from https://scholarworks.uark.edu/etd/2642

This Dissertation is brought to you for free and open access by ScholarWorks@UARK. It has been accepted for inclusion in Graduate Theses and Dissertations by an authorized administrator of ScholarWorks@UARK. For more information, please contact scholar@uark.edu. 
Effect of a Skating Unit on Fitness in Fifth Grade Students

A dissertation submitted in partial fulfillment

of the requirements for the degree of

Doctor of Philosophy in Kinesiology

by

\author{
Eric Lange \\ University of Tulsa \\ Bachelor of Science in Health and Physical Education, 1994 \\ University of Tulsa \\ Master of Arts in Education, 1999
}

May 2018

University of Arkansas

This dissertation is approved for recommendation to the Graduate Council.

Dean Gorman, Ph.D.

Dissertation Director

Cathy Lirgg, Ph.D.

Committee Member
Jack Kern, Ph.D.

Committee Member

Wen-Juo Lo, Ph.D.

Committee Member 


\begin{abstract}
The purpose of this quantitative study investigates the effect of a skating unit on factors of cardiovascular fitness, static balance, explosive power, and agility in fifth graders. Methods: During a 6-weeks skating unit (twelve lesson), seventy-one students (ages 10-12; $M$ age $=10.34$ ) participated during regularly scheduled physical education classes. Three separate classes served as control group (C) ( $n=19 ; 8$ male; 11 female) and two experimental groups: roller skating (RS) ( $n=26 ; 11$ male; 15 female) and inline skating (IS) ( $n=26 ; 10$ male; 16 female). Control group had no access to roller or inline skates during class time of study. Control curriculum consisted of activities like soccer, dance, and softball; experimental specifically designed skating curriculum. A one-way analysis of variance (ANOVA) conducted separately on each of the four factors to investigate significance at the .05 level. Dependent variable was difference in means (posttest minus pretest) for PACER, Stork Balance, vertical jump, and Illinois Agility Run test scores. Results: ANOVA reported all non-significant except for balance factor. Tukey-Kramer post hoc reported non-significance in all pairwise comparisons except between RS and IS. Range for $\eta^{2}$ was between $4.1 \%-14.9 \%$. Exploratory analysis was conducted to investigate how males and females performed in each factor and reported all non-significant; $\eta^{2}$ range between $3.0 \%-15 \%$ for males and $2.4 \%-16 \%$ for females. All the associations were classified as low to medium except for male static balance (15\%), female static balance (16\%), and male explosive power (13.9\%) had demonstrated a strong or near strong association. Conclusions: Data suggests only static balance benefits a participant who RS compared to IS. Even though other factors reported non-significance, mean change illustrates improvements after intervention suggesting a skating unit could induce improvements in factors. Teacher questionnaire shares' skating was positive learning opportunity. Exploratory analysis reported non-significance.
\end{abstract}


However, $\eta 2$ suggests that if study had either a larger sample size or continued beyond 6-week intervention, could illustrate significance. A skating unit is a viable possibility. Further research warranted.

Keywords: skating unit, roller skating, inline skating, cardiovascular fitness, static balance, explosive power, agility. 
C2018 by Eric Lange

All Rights Reserved 


\section{ACKNOWLEDGEMENTS}

"The journey of a thousand miles begins with a single step" Lao Tzu.

Today, a journey of a thousand miles comes to an end for me and that is the completion of my studies at the University of Arkansas. Along this journey, I have had the privilege to be mentored and learn from some extraordinary faculty and have such strong support from family and friends.

First, I would like to thank my dissertation committee Dr. Dean Gorman, Dr. Cathy Lirgg, Dr. Jack Kern, and Dr. Wen-Juo Lo for the passing of their wisdom, support and mentorship throughout this process. I would also like to thank professors Dr. Paul Calleja and Dr. Ed Bengtson, and Ms. Janet Forbes for the sharing of their expertise over the last years. I wish to thank the many classmates that I had the honor to get to know, especially Maryann Mitts who started this journey at the same time as I. I want to thank my evaluation team Aerial Voskamp, Logan Bishop, and Sean Lombard (and dear friend) for their commitment and hard work. Finally, I want to thank some extraordinary people the Physical Education teacher, Instructional Assistant, Principal, and Dr. Robert Ferguson for their hard work and opening their school to me and the evaluation team to make this study possible.

Finally, to the many family and friends who made this journey possible. To my wife Denise, thank you so much for your love and support throughout this journey. It was through that support that helped make this possible. I want to thank my parents Tom and Peggy Lange, Jim Gelsomini, and Terry and Marilyn Gall for teaching the true meaning of hard work and grit and your words of encouragement. A special thanks to my other family Karen, Jerry and Sean Garkow for showing me what is possible and the hours tutoring me growing up. I want to thank the Alcorns (Byron, Melissa, Brandan, and Nate), Korens (Joel and Mike), the McDougals (Mac, 
Lisa, Brandon, Chase and Anna), the Turners (Mark, Brigid, Mahala, and Tyler), Harper McIntyre, and Joseph Bilhartz for all your assistance throughout this journey.

From the bottom of my heart, I want to thank each and every one of you for all you have done to help make this journey possible. 


\section{TABLE OF CONTENTS}

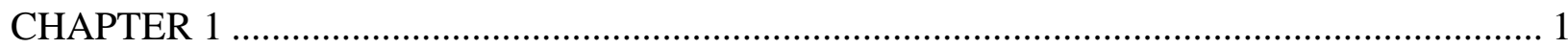

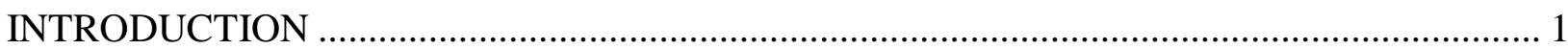

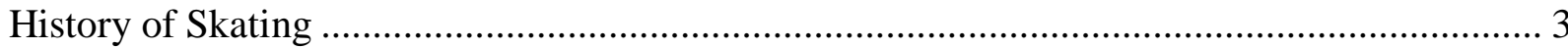

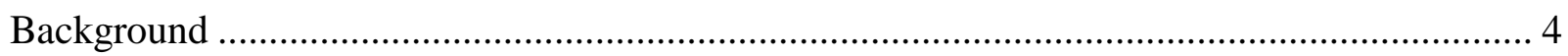

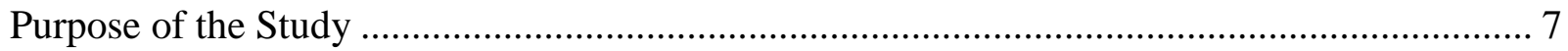

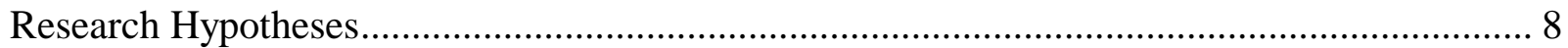

Assumptions, Delimitations, and Limitations ……………................................................. 8

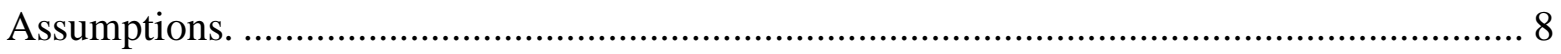

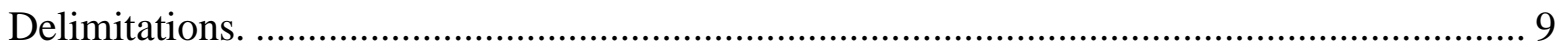

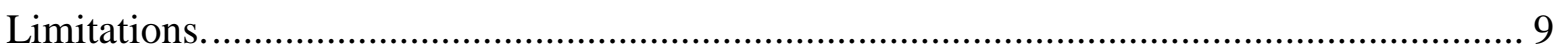

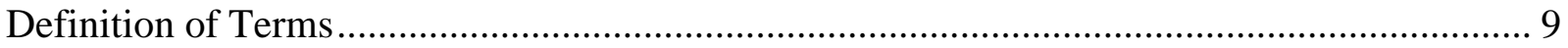

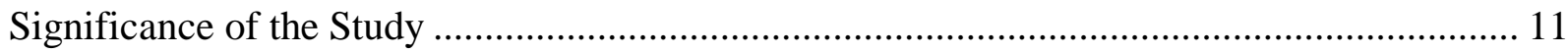

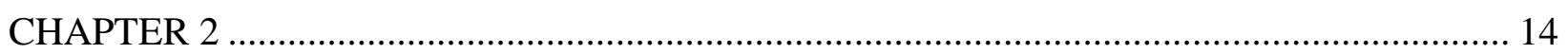

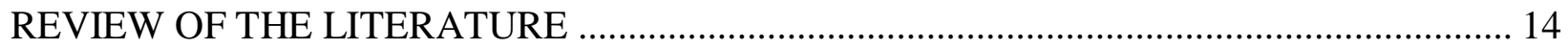

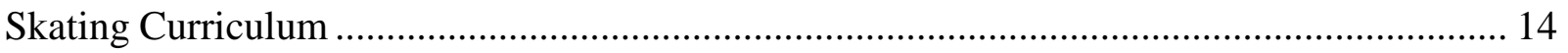

Non-Traditional Curriculum and Research .................................................................... 17

Skating and Cardiovascular Fitness …………………....................................................... 19

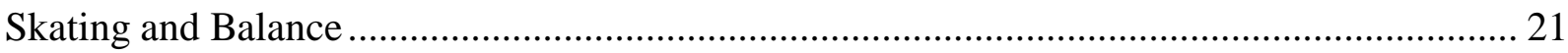

Skating and Explosive Power......................................................................................... 22

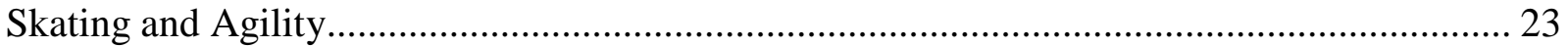

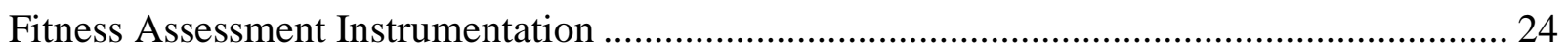

Progressive aerobic cardiovascular endurance run (PACER) ............................................ 25

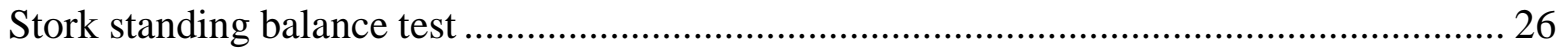

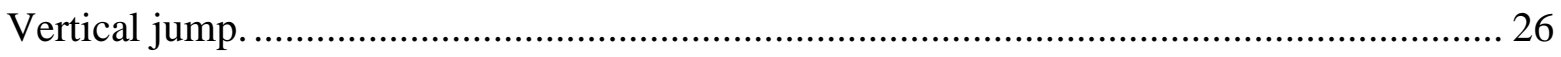

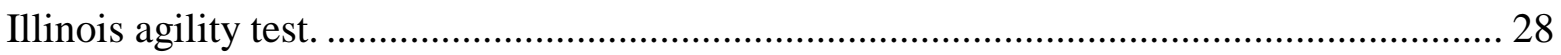

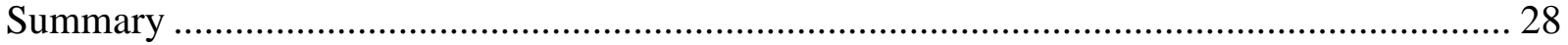

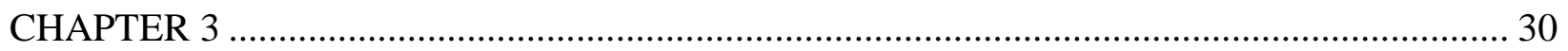

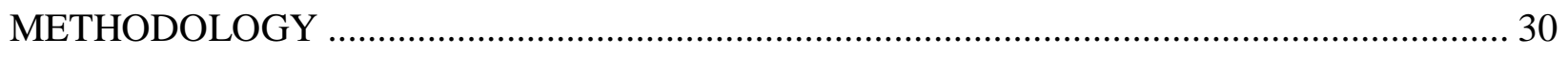

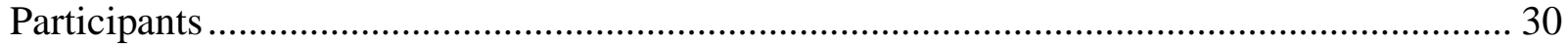




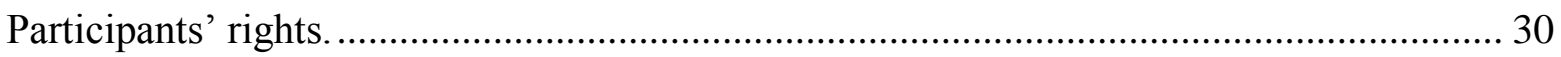

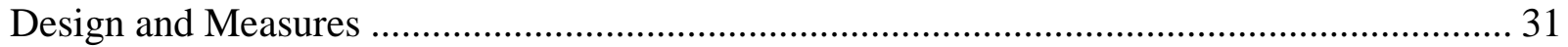

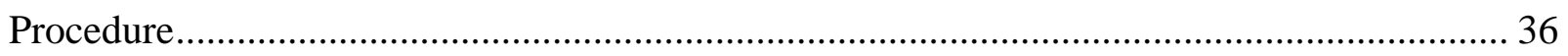

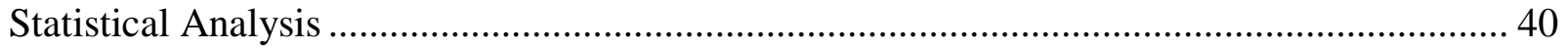

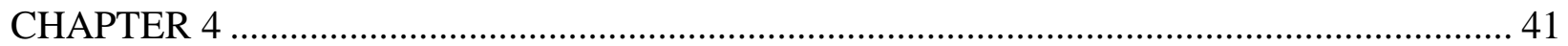

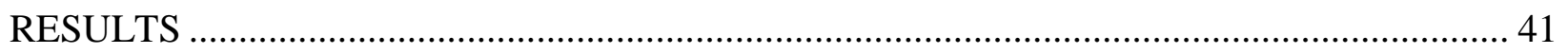

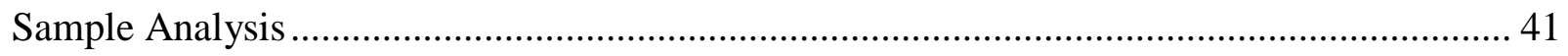

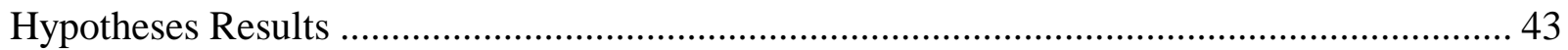

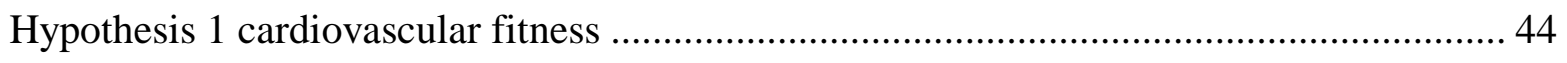

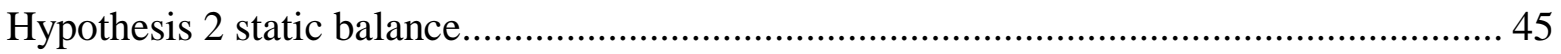

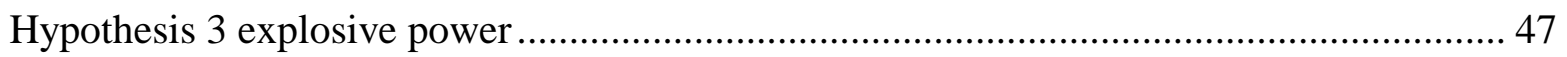

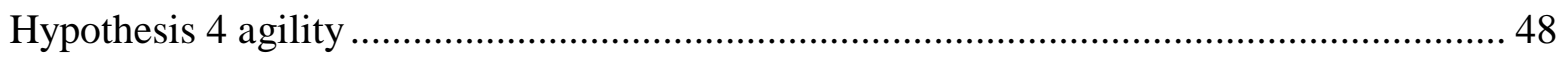

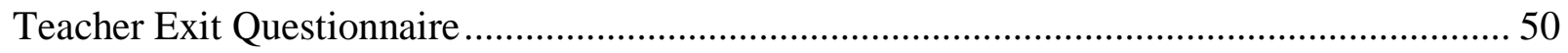

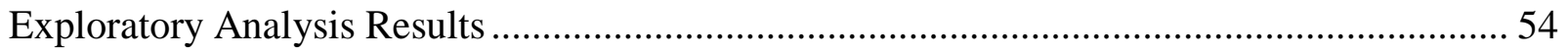

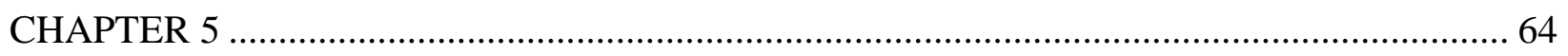

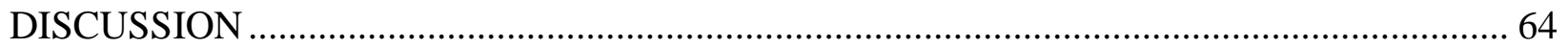

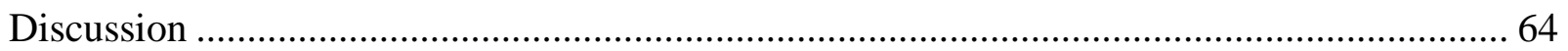

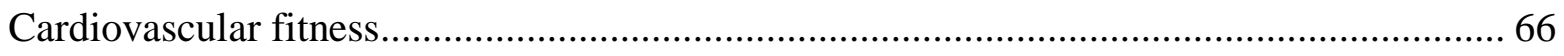

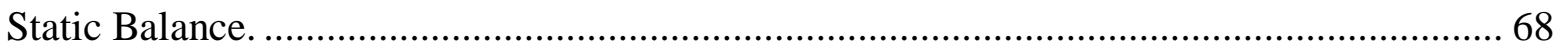

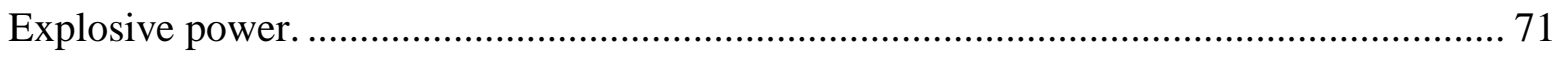

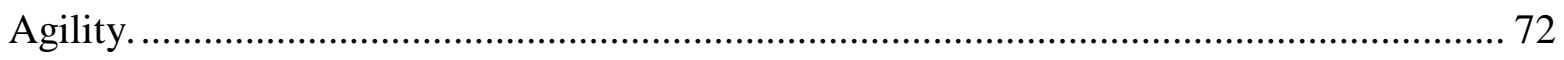

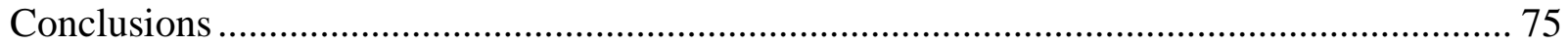

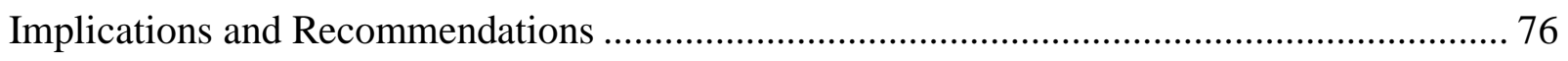

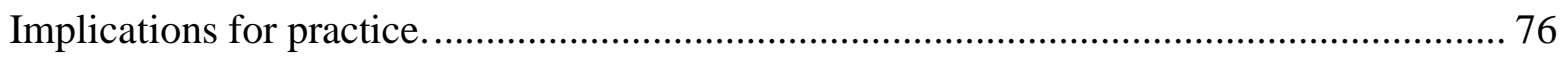

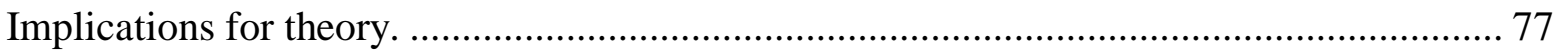

Recommendations for future research............................................................................. 77

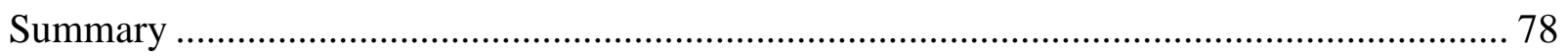

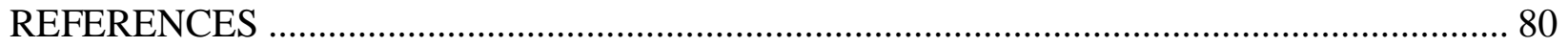

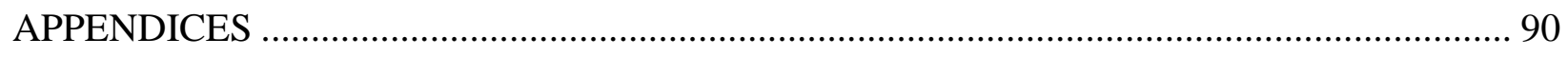

Appendix A: Institutional Review Board Approval Letter ......................................................... 90

Appendix B: Institutional Review Board Approval Modification ............................................. 91 
Appendix C: Consent for a Minor to Participate in a Research Study ................................. 92

Appendix D: Consent for a Minor to Participate in a Research Study Translated in Spanish.. 96 Appendix E: Fitness Evaluation Form ..................................................................... 101

Appendix F: Progressive Aerobic Cardiovascular Endurance Run (PACER) Scoring Sheet 102

Appendix G: Teacher Exit Questionnaire ….................................................................... 103

Appendix H: Skatetime Copyright Approval Letter and Email .......................................... 104

Appendix I: Skate in School Copyright Approval Letter and Email ................................... 106

Appendix J: Roller and Inline Skating Curriculum........................................................... 108

Appendix K: Enrichment Games and Descriptions .................................................... 133

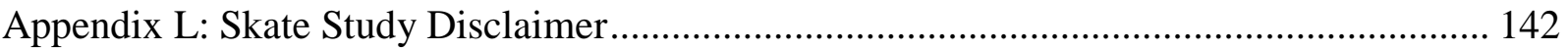




\section{LIST OF TABLES}

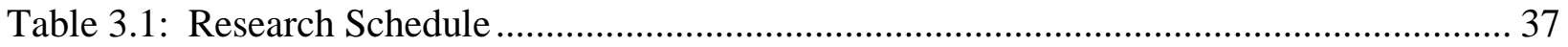

Table 3.2: Control Curriculum Overview …........................................................................ 38

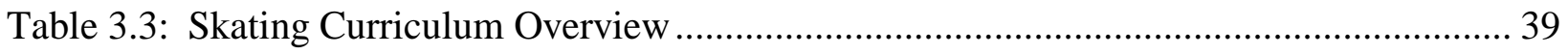

Table 4.1: Means and Standard Deviations for PACER laps ................................................ 45

Table 4.2: 95\% Confidence Intervals of Pairwise Differences in Mean Changes and Standard

Deviations for Modified Stork Standing Balance Test ........................................................ 47

Table 4.3: Means and Standard Deviations for Vertical Jump ............................................. 48

Table 4.4: Means and Standard Deviations for Illinois Agility Test ..................................... 49

Table 4.5: Means and Standard Deviations for Male PACER in laps ..................................... 56

Table 4.6: Means and Standard Deviations for Feale PACER in laps.....................................5 57

Table 4.7: Means and Standard Deviations for Male Modified Stork Standing Balance Test.... 58

Table 4.8: Means and Standard Deviations for Female Modified Stork Standing Balance Test 59

Table 4.9: Means and Standard Deviations for Male Vertical Jump ....................................... 60

Table 4.10: Means and Standard Deviations for Female Vertical Jump .................................. 61

Table 4.11: Means and Standard Deviations for Male Illinois Agility Test ............................. 62

Table 4.12 :Means and Standard Deviations for Female Illinois Agility Test .......................... 63 


\section{LIST OF FIGURES}

Figure 3.1: Modified Stork Standing Balance Test pose ........................................................... 32

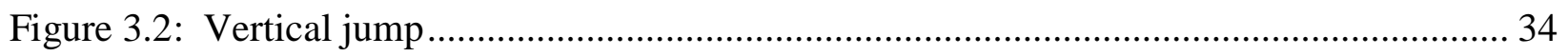

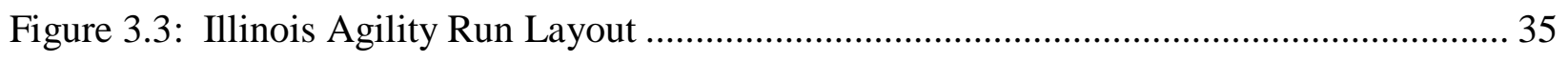

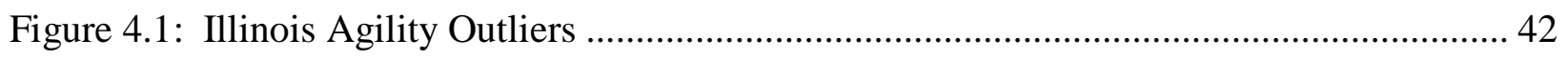

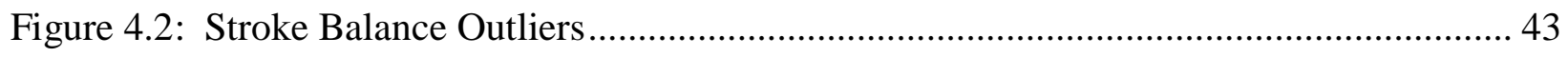

Figure 4.3: Changes in PACER laps.............................................................................. 45

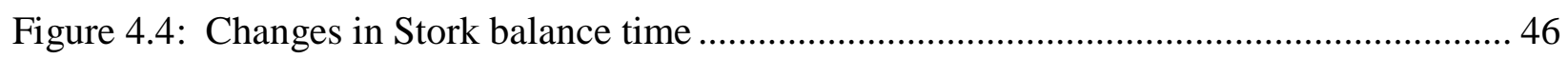

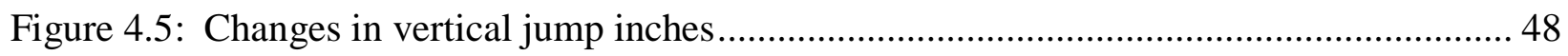

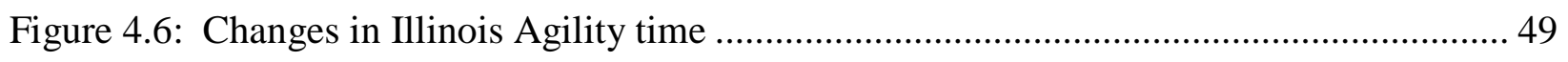

Figure 4.7: Changes in male PACER laps ........................................................................ 56

Figure 4.8: Changes in female PACER laps........................................................................... 57

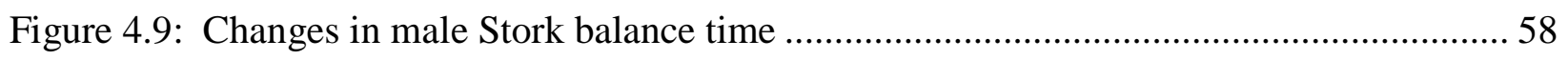

Figure 4.10: Changes in female Stork balance time …………………………………......... 59

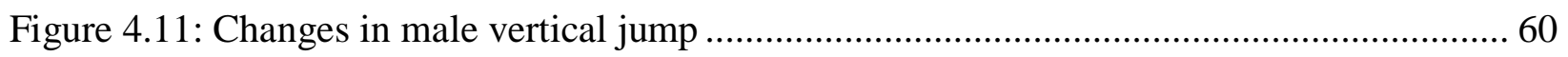

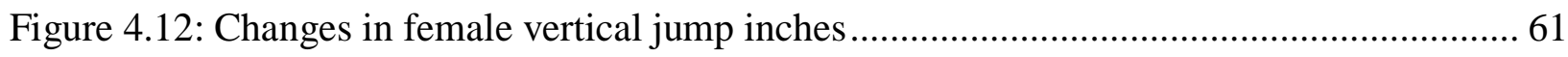

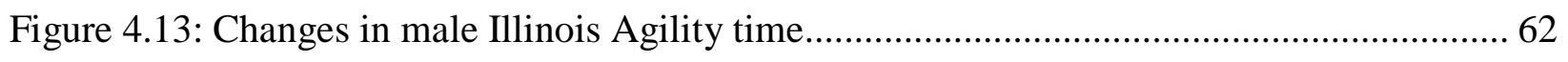

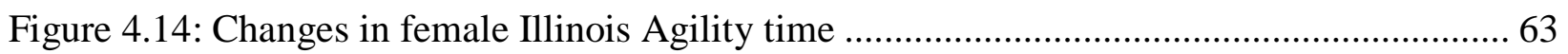




\section{CHAPTER 1}

\section{INTRODUCTION}

"In physical education, many teachers have been stagnant for too long, sticking to their favored team sports and staying in their own comfort zone" (Nguyen, 2015, p. 35). It is time for physical education teachers to begin to look beyond the traditional classroom curriculum of activities like football and soccer and look at implementing non-traditional activities into schools to have a positive impact on students' health and create lifelong behaviors into adulthood (Schwab \& Dustin, 2014). Skating is one such non-traditional activity that can be utilized by physical education teachers that not only provides many health benefits, but is also an enjoyable activity.

Skating is a general term used to describe several different forms, two of which are roller skating and inline skating. Roller skating and inline skating are stylish and fun forms of exercise (Gold, 2006) suitable for all ages and experience levels. Skating is a form of transportation where participants use their physicality to propel themselves in a given direction. The motor ability required to skate makes this activity an ideal form of exercise for children. Skating's many health benefits includes cardiovascular fitness (Roller Skating Association International [RSA], 2015b), caloric burn (Whitney \& Rolfes, 2016), and demands high motor ability (Rinne, Miilunpalo, \& Heinonen, 2007).

Throughout the years, skating has evolved and allows participants' to participant in specialized activities like speed skating, roller and inline hockey, trick skaters, and artistic skating (figure skating, dance, freestyle, and precision teams). Skating's diversity allows for physical education teachers to modify traditional games, like basketball and team handball 
(McManama, 2014; Skatetime 2013a), by having participants wear skates while participating in activities to add an additional level of complexity and enjoyment. However, most skaters are recreational skaters who are just looking for an enjoyable stress free activity to spend time with one's self or to socialize with peers. The diversity of this activity has led to many cities to invest in specially designed skate parks, boardwalks, paved trails, and skating rinks for skaters to skate in a safe environment free from the hazards of the road. However, most skaters enjoy the freedom of skating on the streets and sidewalks in their neighborhood that provides unique opportunities to perform tricks.

This chapter will provide a general overview about skating for this study. Specifically, Chapter 1 will provide the reader some background information of what a skating unit can provide its participants, the purpose for this study, a series of four research hypotheses that will be investigated, and finally why a skating unit is significant for physical education teachers. Additionally, several potential assumptions, delimitations, and limitations will need to be considered in conducting this study. Furthermore, a list of definitions is provided to assist comprehension for the reader as they read through this study. In future chapters, Chapter 2, provides an in-depth review of literature related to skating and curriculum, cardiovascular fitness, balance tests, vertical jump, and agility. Additionally, a review of the fitness assessment instruments will be investigated to be administered in this study. Chapter 3 provides details about the methodology. The methodology specifically addresses areas like the participants, the design and measures of fitness assessment instrumentation, procedure, and statistical analysis. In Chapter 4, the results, will report the findings of the analysis and determine the hypotheses significance defined later in this chapter. Finally, in Chapter 5, a discussion of the impacts of a skating unit on the four fitness factors (cardiovascular, static balance, explosive power, and 
agility), conclusions, limitations, and future recommendations for research on the effect of a skating unit on fitness in fifth graders.

\section{History of Skating}

Skating has been around for centuries. Ice skating is one of the earliest recorded forms of skating where Northern Europeans used bone to create a blade to glide on ice surfaces. Later, blades made bones were replaced with metal that allowed for better reliability and increased speed (Brokaw, 1939; Formenti \& Minetti, 2007). In 1760, Joseph Merlin is credited with the first recorded invention of a skate with wheels and in 1819 Monsieur Petitbled was the first to patent a similar version made from metal and wood (McManama, 2014). In 1863, the first form of rollers skates took shape when James Plimpton created a skate that placed wheels in a side by side pattern located on the front and rear of the skating platform that laid the foundation for our modern roller skate sometimes called quad skates (National Museum of Roller Skating, 2016). Even though the design of inline skates has been in existence for several centuries, it was not until 1980's when two brothers, Scott and Brennan Olsen, created the modern inline skate (Inline Skating Resource Center, n.d.b). Today, with the advent of modernization, roller skating and inline skating wheels are made from polyurethane rather than bone, wood, metal, and ivory to provide a smoother ride. The boot is made of molded plastic, other synthetic and natural materials, and foam to provide the user with a comfortable form fit that allows users to skate for hours free from foot discomfort (McManama, 2014). Throughout history, man used roller skating and inline skating as a fun substitute to ice skating when ice was unavailable during certain times of the year. With designs from visionaries like Joseph Merlin, Monsieur Petitbled, James Plimpton, and the Olson brothers, a person can enjoy skating all year long providing schools an opportunity to adopt skating as part of their curriculum. 


\section{Background}

Why a skating unit? One reason for a skating unit is to address the rapid increase in obesity in children. Obesity is one of the fastest increasing health epidemics facing our nation. Skinner, Perrin, and Skelton (2016) reported that children from a 2013-2014 sample population found $33.4 \%$ were classified as overweight or obese and a recent report by the Global Burden of Disease (GBD) 2015 Obesity Collaborators (2017), concluded that United States children has one of the worst obesity rates when compared to other countries around the world. This rapid increase in obesity is a contributing factor to chronic diseases like heart disease and diabetes and has placed a significant burden on the cost of health care. The annual medical cost of obesity had risen to an estimated $\$ 147$ billion in 2008 (Finkelstein, Trogdon, Cohen, \& Dietz, 2009; Kim $\&$ Basu, 2016). Due to this alarming statistics, it is imperative for local, national, and world leaders to find ways to decrease the obesity epidemic by reasserting a higher importance of physical education in our schools.

One contributing factor to obesity is the lack of time in schools devote to physical education classes between 2 and 19 years of age. The Society of Health and Physical Educators (SHAPE) recommends that schools schedule class time daily throughout the entire academic year that ensures students participate in physical activities that promote healthy lifestyles that can combat the obesity epidemic. SHAPE $(2014 ; 2016)$ recommends that elementary school students receive a minimum equivalent of 150 minutes per week and spend at least $50 \%$ of class time in moderate to vigorous physical activity during the academic year. Additionally, SHAPE (2014; 2016) recommends that middle school and high school students participate in at least 225 minutes per week during the school year every year they are attending school. Furthermore, schools need to provide at a minimum of 30-60 minutes of physical education class time daily 
and that school examine a broad range of activities that are fun and diverse in nature to maintain participant interest (SHAPE, 2014). A unit that includes roller skating and/or inline skating provides educators one such innovative activity that is fun and challenging that can help reduce or prevent obesity. It is through the fundamental skills learned in school that allows students to go beyond what was learned in the classroom and be able to utilize skating to meet daily aerobic needs at home.

How can a skating unit in schools help students? There are several health benefits to those who actively participate in roller skating and/or inline skating. Similar to the recommendation by SHAPE $(2014,2016)$, the American Heart Association (AHA, 2014) recommends that adults participate in 30 minutes of moderate aerobic activity five days weekly (150 minutes weekly) and children receive a minimum of 60 minutes of moderate to vigorous aerobic activity daily. Skating is considered to be an aerobic type of activity and regular participation in this physical activity promotes health lifestyle that can reduce the incidence of chronic debilitating illnesses like hearth disease, cancer, type 2 diabetes, and osteoporosis in adults (SHAPE, 2016). In children, skating can reduce the onset of obesity and chronic diseases contributing to a healthier quality of life as adults. Menschik, Ahmed, Alexander, and Blum (2008) found that adolescents who participated in activities such as inline skating, roller skating, skateboarding, and bicycling reduced the risk of being overweight later in life by $48 \%$ when performed at least four times per week.

In addition to SHAPE $(2014,2016)$ and the AHA (2014), The Roller Skating Association International (RSA, 2015) claims that roller skating can (1) strength cardiovascular fitness, (2) is an aerobic activity that can provide health benefits similar to walking and jogging, (3) increases 
caloric burn, (4) increases muscle strength, and (5) is less impactful or stressful on the body when compared to jogging. Since skating is a comparable aerobic activity to walking, a 142 pound individual who walks about $4.0 \mathrm{mph}$ (Franklin, 2016) can burn anywhere from 0.0350.048 kcals/pound per minute (Whitney \& Rolfes, 2016) when skating. Furthermore, a study by Rinne et al. (2007) found that skating requires a high level of motor ability in the areas of orientation, kinesthetic differentiation, balance, reaction ability, and a sense of rhythm. The physiological benefits gained by those who participate during a skating unit illustrates the significance for schools and school districts to find the means to implement this type of activity into their curriculum.

Skating not only has several health benefits, but is a fun activity for both boys and girls. Studies by Fromel et al. (2017) and Wilson, Williams, Evans, Mixon, and Rheaume, (2005) found that children, both boys and girls, rate skating as one of their top choices of activities to participate in that not only promotes a healthy lifestyle, but allows students engage with peers on a social level. Physical education courses reinforce the development of soft skills like social development and interaction and a skating unit provides such a platform for children learn how to become socially responsible meeting one of the five standards developed by SHAPE (2013).

Where might a physical education teacher find resources for a skating unit? Skatetime (Skatetime Chicago, Rockford, IL) and Skate in School (Skate in School Minneapolis, MN \& Rollerblade, West Lebanon, NH) are two such resources that allows schools to rent or purchase equipment and also provides a curriculum for physical education teachers. Skatetime provides an opportunity for schools that may not have the funding to purchase equipment to rent roller skates and protective gear such as helmets, wrist guards, and knee and elbow pads. Skatetime's 
(2013a, 2013b, 2017) curriculum provides a sequence of activities and games that allows for beginner skaters to grow through the lesson and non-beginners to have an opportunity to develop and master previously learned skills. Skate in School provides opportunities for schools or districts to purchase inline skates and equipment. Skate in School partnered with the National Association for Sport and Physical Education (NASPE) to develop curricula for beginner and intermediate skaters that follow the K-12 Physical Education National Physical Education Standards. Their curriculum provides lesson objectives, vocabulary, an activity for the day, and further provides educators assessment examples and strategies/tips (Skate in School, 2016a, 2016b). Both of these companies provide a service that helps provide physical education teachers the tools needed to provide quality skating instruction for students.

In summary, a skating unit has been found to be beneficial for those who participate in this physical activity. First, this aerobic activity promotes a lifelong healthy lifestyle that can reduce the impact of obesity and the incidence of chronic diseases like heart disease and diabetes. Secondly, skating has been found to promote physiological changes that strengths the cardiovascular system, muscular systems, and can directly impact motor ability. Finally, students find skating to be a fun social activity that can be done beyond the physical education classroom.

\section{Purpose of the Study}

The purpose of this quantitative study seeks to investigate the effect of a skating unit on cardiovascular fitness, static balance, explosive power, and agility in fifth grade students in a northwestern Arkansas school district. 


\section{Research Hypotheses}

This quantitative study will use a pretest posttest design to investigate the effects of a skating unit on a fifth grade student's fitness. Specifically, this study will address the following hypotheses:

(1) Does the mean change in the PACER scores differ among the three experimental populations: those in the control, those who roller skate, and those who inline skate?

(2) Does the mean change in the static balance scores differ among the three experimental populations: those in the control, those who roller skate, and those who inline skate?

(3) Does the mean change in the vertical jump scores differ among the three experimental populations: those in the control, those who roller skate, and those who inline skate?

(4) Does the mean change in the agility scores differ among the three experimental populations: those in the control, those who roller skate, and those who inline skate?

\section{Assumptions, Delimitations, and Limitations}

Assumptions. There are several assumptions that the researcher needs to address. The following assumptions were made during this study:

(1) it is assumed that all the participants will do their best on the pre and posttests;

(2) it is assumed that all participates will not be absent from school during the pretesting, post testing, and intervention periods of this study;

(3) it is assumed that participants will participate at their best during the activities during the activities scheduled for the control and experimental groups during the life of the study. 
Delimitations. Two delimitations have been identified for this study.

(1) Participants are from a small elementary school, so the findings for this study cannot be generalized for other fifth grade populations.

(2) The activities of the control group will follow the regularly scheduled activities determined by the physical education teacher and not specifically designed for this study. The curriculum included activities and time spent in the following; the completion of a softball unit (3 lessons, 25\%), dance unit (5 lessons, 41.7\%), exercise stations with activities such as dancing and soccer skills (1 lesson, 8.3\%), beginning of a soccer unit (2 lessons, $16.7 \%$ ), and finally a skills station that included activities like soccer and jump roping (1 lesson, 8.3\%) during the six week intervention period.

Limitations. Pretest posttest designs require participants to perform at their "best" during the testing time periods which could negatively impact the results when a participant under performs when not feeling well or has low performing day.

\section{Definition of Terms}

To ensure understanding for the reader, the following definitions will be used for the purposes of this research study:

American National Standards Institute (ANSI). Set of safety standards and certifies equipment (Skate in School, 2016a).

Ice skates. A pair of boots with a metal blade attached used to glide and propel skaters on ice surfaces. 
Inline skates. A pair of boots where a frame with wheels are attached and aligned in a straight line used to glide and propel on various indoor and outdoor surfaces.

National Association for Sport and Physical Education (NASPE). One of five nonprofit organizations part of the American Alliance for Health, Physical Education, Recreation, and Dance (AAHPERD) now known as Society of Health and Physical Educators (SHAPE). NASPE creates standards for the physical education community (Play and Playground Encyclopedia, 2017a).

Non-Traditional Curriculum. Activities not performed in a traditional classroom such as bicycling, skating (ice, roller, or inline), rock climbing, and hiking.

Roller skates. Also known as "quad" skates or "quads" are a pair of boots attached to a frame with multiple wheels in a "box" pattern used to glide and propel on various indoor and outdoor surfaces.

Roller Skating Association International (RSA). The international governing body for roller skating (Roller Skating Association International, 2015).

Society of Health and Physical Educators (SHAPE). National organization of physical education, sport, dance, and school health professionals. SHAPE creates standards that govern physical education professionals through research, conferences, and workshops that promotes health in society (Play and Playground Encyclopedia, 2017b).

Traditional Curriculum. Activities performed in a traditional classroom such as soccer, football, softball, and basketball. 


\section{Significance of the Study}

To date, a review of literature has produced minimal studies regarding the impacts of a skating unit on school aged children. While one study was conducted in Germany (Muehlbauer, Kuehnen, \& Granacher, 2013) yet no such study has been conducted in the United States to date. The findings by Muehlbauer et al., (2013), while found to illustrate a significance in increasing a child's balance and explosive power, suggest that further studies need to be conducted to measure other fitness variables like cardiovascular fitness and agility and to evaluate if similar significance can be replicated in balance and explosive power with the limited access that children have to physical education in the United States. If the findings are found to be significant in those additional factors, this study would illustrate the importance a skating unit on fitness of children in the United States.

Additionally, a skating unit (roller skating and/or inline skating) provides a platform that allows physical education professionals to meet all five of the Society of Health and Physical Educators (SHAPE) National Physical Education Standards. The SHAPE Standards are as follows and examples of how might a physical education teacher utilize that standard in a skating unit. Standard (1) "the physically literate individual demonstrates competency in a variety of motor skills and movement patterns" (SHAPE, 2013) through demonstrating different techniques to propel oneself forward and backwards along with the different types of turns and stops to reduce injuries from falls by increasing balance. Standard (2) "the physically literate individual applies knowledge of concepts, principles, strategies and tactics related to movement and performance" (SHAPE, 2013) can be demonstrated through concepts by explaining the science behind how to turn, the use of speed control in slalom and obstacle courses, and the understanding of braking distances on various types of surfaces. Standard (3) "the physically 
literate individual demonstrates the knowledge and skills to achieve and maintain a healthenhancing level of physical activity and fitness" (SHAPE, 2013) through describing the health benefits of skating on cardiovascular fitness, muscle strength and endurance, and balance. Standard (4) "the physically literate individual exhibits responsible personal and social behavior that respects self and others" (SHAPE, 2013) working to reduce falls and supporting and helping each other when one does. Finally, Standard (5) "the physically literate individual recognizes the value of physical activity for health, enjoyment, challenge, self-expression and/or social interaction" (SHAPE, 2013) by challenging one's self to stretch themselves to improve their skating skills or to get together with friends and classmates to share how skating has impacted them. These are a few ways in how a skating unit can be used to meet the National Physical Education Standards.

Beyond the physical education classroom, a skating unit can be used in conjunction with other disciplines like math and science. Howard-Shaughnessy and Sluder (2015) uses roller skating to teach math and science skills by calculating heart rates, building of molecules structures, nutritional effects required for skating, and geography skills needed to identify landmarks, states, and capitals. The U.S. Department of Education (2017) is pushing schools to find innovative ways to implement Science Technology Engineering and Math (STEM) curriculum/programs to further develop math, science, and computer skills to meet an increasing job market in STEM programs. A skating unit allows for educators to integrate instruction in math, science, social studies, language and visual arts, and music and dance (Skate in School, 2016a). Additionally, the Roller Skating Association International (RSA) has worked with many United States skating rinks to provide a STEM curriculum where students can learn the "real world" application of physics, math, and engineering with skating as the vessel for learning. 
These examples demonstrate how a skating unit can be used to induce learning beyond the physical education classroom into other disciplines like math and science.

Finally, a skating unit provides many health benefits to its participants. The RSA (2015) claims roller skating is an aerobic activity that is good for heart health, the development of lower body strength, caloric burn, and is less impacting on the body when compared to the impact on the body in running. In addition, the Inline Skating Resource Center (formally the International Inline Skating Association, n.d.a) reports similar findings to the RSA (2015), but also reports anaerobic health benefits and greater caloric burn when skating at a high intensity pace. With many Physical Education courses meeting 45-50 minutes two times per week, skating provides an opportunity for the skills learned in class to be utilized beyond the classroom in environments like neighborhoods, parks, and specially designed trails. It is the responsibility of physical education teachers to develop lifelong skills that can be utilized beyond school aged years in maintaining a healthy lifestyle into adulthood and a skating unit provides students that opportunity. 


\section{CHAPTER 2}

\section{REVIEW OF THE LITERATURE}

The purpose of this chapter is to review existing research and provide an overview of skating and fitness assessment instrumentation. Specifically, this chapter will provide information about skating curriculum development and skating's effects on cardiovascular fitness, balance, explosive power, and agility. Finally, this chapter will explore the various types of fitness assessment instruments that will be administered during this study on the effects of a skating unit on fitness in fifth grade students.

Even though the primary focus of this review of literature is on roller skating and inline skating, but may be limited in scope. As a result, the review of literature will be broadened to include ice skating due to its similarity to roller skating and inline skating.

\section{Skating Curriculum}

In this section, the researcher discusses the findings of the review of literature related to skating curriculum. To date, there are several resources online and in publications that are accessible for educators to use for a skating unit. The first two sources, Skatetime and Skate in School, have created curriculum that can be used or easily adapted for school settings. Skatetime (2013a, 2013b, 2017) developed an instructor's manual and several resource manuals for teachers to use during their in school skating activities. Skatetime (2017) provides a five day curriculum where students learn basic skills like safety, how to fall and recover, forward and backward movement, and turning and progress to more advanced skills like cone weaving, obstacle courses, and dancing to music. Finally, Skatetime (2013a, 2013b) provides two game packets to further refine a participant's skating skills and enrich learning. Skate in School, in 
collaboration with Rollerblade (Rollerblade USA, West Lebanon, $\mathrm{NH}$ ), is another company that provides curriculum for skating. Even though their curriculum is designed for inline skating, it can be easily adapted to meet the needs of a roller skating unit. Skate in School partnered with the National Association for Sport and Physical Education (NASPE) and developed a curriculum that meets the Society of Health and Physical Educators (SHAPE) K-12 Physical Education National Physical Education Standards. Skate in School (2016a, 2016b) contains twenty beginning and intermediate lessons along with eight enrichment activities that allows for beginners to learn the fundamental skills of skating and for intermediate skaters to further refine and master previously learned skills. To assist physical education teachers, each lesson contains learning objectives, needed equipment, vocabulary, a warm-up, lesson of the day, and closure (Skate in School, 2016a, 2016b). Additionally, Skate in School (2016a, 2016b) curriculum also provides assessment examples and strategy tips for teachers as they work through the curriculum. Finally, Skate in School provides enrichment activities that not only develop physical skills, but also provides opportunities for students to work on goal setting, social development, motivation, and teamwork all of which meet or exceed the National Physical Education Standards. Both Skatetime and Skate in School provide helpful resources for teachers.

Skating can also be used as a vessel to cross discipline. Howard-Shaughnessy and Sluder (2015) developed a curriculum that is "designed to meet specific National Standards and interdisciplinary goals, as well as to provide fun cardiovascular physical activity for students" (p. 28). Students participate in a week long curricula that has five activities that allows students to develop math, reading, writing, science, nutrition, and geography skills. Upon completion of the week long curriculum, students wrote a one-page summary of their experience. In those summaries, students reported that they had a fun experience, had more interaction and 
cooperation even with those who do not like physical education, and reported that skating seemed more "beneficial in socialization, teamwork, and cohesion" (Howard-Shaughnessy \& Sluder, 2015, p. 31). Skate in School (2016a) also recognizes the important of interdisciplinary curriculum and encourages integrating skating with subjects like math and science, social studies, language arts, visual arts, and music and dance (p. 5) to further learning. Finally, RSA (2015) offers Science Technology Engineering and Math (STEM) programs through their associated skating rinks. These programs are designed to get children interested in math and science. It is important to note, that these programs are typically for profit. This requires the schools and or the children to raise funds to participate in this program.

Finally, skating curricula can be found through other publications at local bookstores or ordered on-line. It is important to note that these resources would require the physical education teacher to drastically modify the curriculum to meet National Physical Education Standards and student needs. Jerre McManama (2014) authored the Physical Education Activity Handbook that is filled with several different activities for physical education teachers designed to introduce the fundamental skills required of beginning and intermediate skaters. McManama (2014) shares a sequenced curriculum that allows for a first time beginner to learn the foundational skills needed to skate. For the intermediate skater, the curriculum allows for refinement of those skills to increase mastery through repetition. It is important to note that the curriculum is designed for inline skating, but can be easily adapted for roller skating. Furthermore, in the 1990's, several "how to" books were authored to introduce participants to inline skating. These "how to" books by Liz Miller (2003) provided several step-by-step lessons for beginners, Suzanne Nottingham (1997) created several workouts targeting various training zones for advanced skaters, and Powell and Svensson (1998) expanded on inline skates activities like hockey and aggressive 
skating. All of these publications can be adapted to meet student needs in a physical education class.

To summarize the literature review on skating curriculum, there are resources that are accessible for educators. However, curriculum is limited and only Skatetime and Skate in School provides a curriculum that is designed around a skating (roller and inline) for schools. STEM curriculum is offered for educators to use across a discipline that intertwines subjects like math and science. Finally, physical education teachers have access to many publications that give suggestions and training programs for participants. But, these resources would have to be drastically modified to meet student needs. Remember, only Skate in School curriculum provides objectives that meet National Physical Education Standards for professionals to conduct for a skating unit.

\section{Non-Traditional Curriculum and Research}

After a limited review of literature on curriculum for skating, the search was expanded to include other non-traditional activities. Many of these non-traditional activities are viable alternatives for physical education teachers (Nguyen, 2015) to consider when developing a curriculum for the year. Physical education teachers sought to incorporate activities like bicycling, rock climbing, and water activities into their classroom which further exposes students to new activities. This section will address specifically some examples of non-traditional curriculum and the research that demonstrates the merit of these activities when incorporated in the classroom.

The search for non-traditional activities produced several example of curriculum to aid in the implementation of non-traditional activities in the physical education setting. The intent of 
these activities is to get professionals thinking outside the box (Schwab, \& Dustin, 2014) when it comes to introducing new curriculum. These activities sometimes referred to as "Outdoor Adventures Education," like bicycling, kayaking, hiking, and camping, and deemed as lowimpact on the body and promote healthy lifelong skills (Schwab, \& Dustin, 2014). Nguyen (2015) further expands on this by developing a multi-week curriculum, designed around Society of Health and Physical Educators (SHAPE) standards, exposing students to activities such as camping, hiking and backpacking, road and mountain bicycling, bouldering and rock climbing, snow skiing and snowboarding, and water sports like paddle boarding and kayaking. Additionally, students are also taught basic survival and safety skills for unexpected occurrences that may arise when participating in said activities. Another example of a non-traditional activity would be the use of a bicycling curriculum. One such curriculum was developed by the Bicycle Coalition of the Ozarks (n.d.) that provides a multi-unit design for grades 3-5 based on the State of Arkansas's Physical Education standards. The curriculum specifically addresses the standards of personal and social behavior, safety, motor skills, health, nutrition and others. Todd and Medina (2013) created a curriculum for canoeing designed for student with developmental disabilities like autism spectrum disorder, cerebral palsy, intellectual disabilities, and sensory impairments. The curriculum includes a check-list of skills like safety and the use of personal floatation devices, how to enter and exit a canoe, and paddling skills. Finally, in her text the Physical Education Activity Handbook, McManama (2014) provides curriculum on several activities like cycling, backpacking and camping, water activities like canoeing and kayaking, and snow activities like cross-country skiing, snowshoeing and snowboarding for physical education professionals. These examples of curriculum demonstrate that physical education professionals have resources they can utilize within their "classrooms." 
Even though non-traditional curriculum is available for physical education professionals the research is limited in scope. Research on non-traditional activities like bicycling, rock climbing, and surfing illustrated their impacts on a participant's health. The first study was a bicycling study by Lirgg, Gorman, Merrie, and Hadadi (in press, 2018). Their study concluded that a multi-week bicycling unit with middle school students induced a significant change in a student balance, explosive power, and agility. Researchers in rock climbing also found that this activity is beneficial to students. A study by Watts, Ostrowski, (2014) found that rock climbing can produce energy expenditure levels in children similar to those who participated in activities like stair climbing, sports and game activities, and easy jogging. Additionally, rock climbing was found to improve a child's strength and gross and fine motor skills (Kozina et al., 2016; Mark, Jensen, Voigt, Nielsen, \& Lorentzen, 2017). Finally, research demonstrated that high school students could enhance their cardiovascular health by participating in surfing during physical education classes (Bravo, Cummins, Nessler, \& Newcomer, 2016). The research demonstrates that non-traditional activities like bicycling, rock climbing, and surfing are viable activities that can be incorporated into a physical education curriculum.

\section{Skating and Cardiovascular Fitness}

In this section, the researcher will share findings on skating and its effects on the cardiovascular system. One of the most recent research articles was by Orepic, Mikulic, Sorice, Ruzic, and Markovic (2013), where they investigated the physiological responses of inline skating. Orepic et al. (2013) concluded that inline skating can induce physiological changes in cardiovascular fitness in adults. Even though the participants in this study were young healthy adults, one could extrapolate that skating could produce similar cardiovascular effects with children; but further research needs to be conducted to explore if there is a similarity. 
Three studies performed in the 1990's demonstrated that skating, more specifically, inline skating, could induce physiological responses to the cardiovascular system comparable to that of running. The first study by Melanson, Freedson, and Jungbluth (1996) found that after a 9-week inline skating training program, skating could induce improvements in cardiovascular fitness similar to running in $\mathrm{VO}_{2 \max }$ and training volume and intensity in adults. Another study by Melanson, Freedson, Webb, Jungbluth, and Kozlowski (1996) concluded that the intensity required of skating (73-98\% of age-predicted $\mathrm{HR}_{\max }$ ) was similar to that of running (66-97\%) which further illustrates the physiological changes that occurs while skating. Finally, a study by Wallick et al. (1995) concluded that inline skating physiological responses are similar to treadmill running for cardiovascular fitness. These studies demonstrate that skating allows participants the ability to train in both aerobic and anaerobic training zones to improve cardiovascular fitness. Remember, that the American Heart Association (AHA, 2014) recommends adults participate in 30 minutes of moderate aerobic activity five days a week for at least 150 minutes weekly and children receive a minimum of 60 minutes of moderate to vigorous aerobic activity daily. Since skating (at high intensities) can be classified as an aerobic activity and research has demonstrated that there are physiological cardiovascular responses comparable to running, skating is a healthy activity choice for participants.

To summarize the literature review for skating and cardiovascular fitness, we do find research that skating does induce significant change in cardiovascular fitness. However, it is important to note, that the research provided was conducted on adults and can be problematic to assume that adults and children would produce similar results. As a result of the literature review, cardiovascular fitness need to be investigated further to determine if a skating unit would induce similar finding in children. 


\section{Skating and Balance}

The literature review demonstrated that there are several studies that have investigated how skating can improve balance. Most of the research in this area revolves around how skating can reduce injuries from falls in children and older adults. One study by Muehlbauer et al. (2013) hypothesized that that inline skating would improve a child's balance. To measure balance, they selected children eleven to twelve years of age and performed a pretest posttest quantitative study using the Star Excursion Balance Test. The Star Excursion Balance Test is a balance test that measures both static and dynamic balance where students stand on one leg and reaches with the other to various points $360^{\circ}$ around them. Muehlbauer et al. (2013) confirmed significant improvement on posttest scores in all directions but one, which supported their hypothesis that a child's balance would improve after a 4-week skating intervention.

Since research was limited on roller and inline skating, the researcher expanded the search to include ice skating. The review produced two studies that questioned postural control in those who participated in ice skating activities. Keller et al. (2014) concluded that after a four week intervention with ice skating, a children's balance had significantly improvement. Another study by Lamoth and Heuvelen (2012) found that elderly adults who participated in ice skating were found to have greater postural stability then compared to non-skating elderly. Even though the research by Lamoth and Heuvelen (2012) was conducted on elderly adults, their research could be extrapolated to mean that those who participate in ice skating activities, regardless of age, could have a greater sense of balance then non-skating participants.

Finally, several studies addressed how ice skating could be used to improve the functional mobility of students with special needs. A study by Fragala-Pinkham, Dumas, Boyce, 
Peters, and Haley (2009) created a pilot study to see if a child with a disability could benefit from an ice skating program to induce positive results in balance and if so, implement this type of program in the future with other children. Students' ages 5 to 12 years, who were developmentally delayed, were selected to participate in the 6-week intervention. This study was qualitative in nature and relied on feedback from surveyed parents and coaches to determine the effectiveness of the program. Both parents and coaches observed participants balance and strength appeared to improve after the 6-week pilot program and that future studies could provide additional data on its effectiveness in using such a program with adapted students. A case study by Walsh and Scharf (2014) looked how an ice skating program affected a child with cerebral palsy. Even though the study was conducted on one child, five years of age, Walsh and Scharf (2014) concluded that the ice skating program improved this child's functional mobility in her lower body and stand independently without the use of assistance from crutches. A follow-up test performed four months after the skating program revealed a decline in functional mobility, but not to the degree of the pre-intervention period.

To summarize the literature review for skating and balance, research demonstrates that skating, specifically inline or ice skating can induce significant improvement in balance in children and adults. Research is limited on the effects of a roller skating unit and balance. This

review demonstrates that further investigation into the variable of skating's effect on balance will be examined in further detail throughout this study.

\section{Skating and Explosive Power}

After an extensive search related to skating's impact on explosive power, there appears to be only one study that directly investigates the impact of a skating unit on explosive power. 
Muehlbauer et al. (2013) hypothesized that explosive power would increase after a 4-week intervention. They concluded, that based upon pretest and posttest comparisons, there was a significance in children who participated in their four week program and such an activity could be used in physical education classes to improve students leg strength. Research by FragalaPinkham et al. (2009) indirectly found that students who participated in an adaptive ice skating program improved in leg strength. The qualitative study relied on questionnaires where parents and coaches shared their observations during the multi-week program. Other studies found that one of the byproducts in improving balance was that there was an increase in leg strength from skating (Lamoth \& van Heuvelen 2012; Walsh \& Scharf 2014) and/or balance training (Hrysomallis, 2011; Taube et al., 2007). As a result, skating appears to be linked, but further research would need to be conducted to verify the results.

To summarize the literature review for skating and explosive power, the extensive search produced little direct research. Muehlbauer et al. (2013) demonstrated that skating can improve vertical jumping power, while other research indirectly demonstrated that skating and balance training can develop lower leg power and explosive power. However, research finds that explosive power is better suited as a predictor of athletic potential in various sporting activities like hockey (Farlinger, Kruisselbrink, \& Fowles, 2007) and football (Teramoto, Cross, \& Willick, 2016).

\section{Skating and Agility}

A review of literature in investigating the effects of a skating unit on agility produced no credible studies. However, research by Hrysomallis (2011) demonstrated that those who participate in balance activities could improve their agility. Hrysomallis (2011) concluded that 
that by adding balance training could improve one's explosive power and agility time in physical education students. This demonstrates that even though there may be no direct research on skating improving agility, we do see that there are residual effects with balance training activities like with a skating unit.

Most of the research that exists related to skating and agility is how various off-ice and on-ice assessment variables could be used to predict skating potential. One such study was by Farlinger et al. (2007) which measured several off ice variables that included two agility tests, the Edgren side shuffle and the Hexagon test to determine if these assessment instruments could be used to project on-ice skating and agility. While the authors found the Edgren shuffle has a moderate correlation to the on-ice S test, but not for off-ice. Janot, Beltz, and Dalleck (2015) used the pro-agility test, but it was determined to not be a significant predictor of on-ice skating performance. A study by Geithner, Lee, and Bracko (2006) used agility in part of their study related to size of ice-hockey players and the positional demands for coaches to train.

To summarize the literature review for skating and agility, the extensive search produced no evidence on the effects of a skating unit on agility. The research did produce evidence that agility is being used to measure or predict on-ice athletic potential, but with mixed results.

\section{Fitness Assessment Instrumentation}

In this section of the review of literature, the researcher will investigate the various types of fitness assessment instruments that will be used to assess fitness in fifth grade students. Specifically, this review of literature will examine the reliability of the fitness instruments to determine their effectiveness in measuring cardiovascular fitness, balance, explosive power, and agility. 
Progressive aerobic cardiovascular endurance run (PACER). The Progressive Aerobic Cardiovascular Endurance Run also known as the PACER is a multi-stage run used to measure aerobic capacity (Cureton, Plowman, \& Mahar, 2013). The PACER has been researched extensively related to its reliability, validity, and age group norms. Léger and Lambert (1982) concluded that the 20-meter shuttle run test was a reliable and valid method to measure $\mathrm{VO}_{2 \max }$ in both male and female adults. This study laid the foundation of future studies, to not only investigate its usage on adults, but also on children. Léger, Mercier, Gadoury, and Lambert (1988) later revised their work to accommodate a broader age range from eight to nineteen years. FITNESSGRAM (The Cooper Institute, Dallas, TX) adopted the multi-stage run as part of their fitness evaluation program administered in many schools throughout the country. Further studies continued to examine the PACER's reliability and validity when compared to other commonly used cardiovascular fitness tests. One such study by Burns, Hannon, Allen, and Brusseau (2014) compared the convergent validity of the One-Mile Run/Walk and the PACER, concluding that the PACER demonstrated "convergent validity and strong relative accuracy” (p. 7) similar to the One-Mile Run/Walk. Additionally, research by Paradisis et al. (2014) determined that the multi-stage 20 -meter run can accurately predict $\mathrm{VO}_{2 \text { max }}$. A study by Vincent, Barker, Clarke, and Harrison (1999) on fifth-graders demonstrated that the PACER and OneMile Run/Walk have a high correlation between the two indicating that either assessment tool would be sufficient in measuring cardiovascular fitness. Additionally, Scott, Thompson, and Coe (2013) determined that the PACER produces physiological responses during exercise similar to a graded treadmill test on children aged ten to fifteen years. Finally, the PACER testretest reliability is a consistent tool to measure cardiovascular fitness on young children aged eight-eleven years (Guin et al., 2002; Mahar et al., 1997). 
To summarize the review of literature for the PACER, research demonstrates the PACER is a reliable and valid test to measure aerobic fitness in children and adults. Additionally, the PACER is well suited for test-retest environments which make it an ideal assessment tool for use in this study.

Stork standing balance test. The Stork Standing Balance Test is a commonly administered test to measure static balance in children and adult populations. A study by Panta, Arulsingh, Raj, Sinha, and Rahman (2015) concluded that the Stork and the Flamingo tests revealed a high association with each other making them ideal assessment tools to be used in a clinical setting. The Stork Standing Balance Test can also function in non-clinical settings like schools and/or on children. A study by Lirgg, Gorman, Merrie, and Hadadi (2018, in press) used the Stork Test to measure the effects of a bicycle unit in middle school students. Additionally, studies by Chaouachi, Othman, Hammami, Drinkwater, and Behm (2014), Forseth and Sigmundsson (2003), and Hammami et al. (2016) administered the Stork Test to assess balance in children that further demonstrates the assessments adaptability to work with all age populations.

To summarize the literature review for the Stork Standing Balance Test, these select studies demonstrate there is a high association with other static balance tests in clinical and nonclinical settings. The Stork Standing Balance Test demonstrates its versatility to measure many different age groups.

Vertical jump. The vertical jump test is used to measure explosive power in the lower limbs of the body. The vertical jump test can easily be conducted in the field or lab setting depending on the equipment used (Klavora, 2000) to measure the jump. The vertical jump test measures a person vertical jumping height (Wood, 2008b) through the use of various apparatuses 
or devices like taped rulers or chalk markings on a wall, the Vertec jumping apparatus (Sports Imports, Inc., Columbus, $\mathrm{OH})$, or through the use of electronic timing mats or cameras. In measuring vertical jumps, Leard et al. (2007) reported high correlations with the use of the Vertec, Just Jump (Probotics, Huntsville, AL) mat, and 3-camera system, but indicated that "accuracy of the Vertec depended on the ability of the subject to contact the vanes of the device at the peak of the jump" (p. 1298) and for the test administrator to accurately count the displacement by the participant. This study points out that the Vertec is a reliable device to measure explosive power, but it is important for the test administrator to understand the Vertec's disadvantages to increase the reliably of the results.

Test administrators can use many different jumping techniques to determine explosive power. An administrator can have participants perform the test by using various methods through counter movement (bending knees prior to jump), squat jump (knees already bent), off one-leg or two, with or without arm movement and others. Several studies have been conducted to determine the reliability and validity of the different types of vertical jump variations. A study by Rodríguez-Rosell, Mora-Custodio, Franco-Márquez, Yáñez-García, and González-Badillo (2016) concluded that the countermovement jump and Abalakov jump were found to be the most reliable tests to estimate "explosive force in soccer and basketball players" (p. 196). Additionally, Markovic, Dizdar, Jukic, and Cardinale (2004) concluded that the Sargent's jump and the countermovement jump vertical jump tests are reliable and valid tests to estimate lower body explosive power in college aged men.

To summarize the review of literature on the vertical jump, research demonstrates the vertical jump is a reliable fitness assessment tool to measure explosive power in participants and 
can be administered to assess children which make it an ideal assessment instrument for this study.

Illinois agility test. This Illinois Agility Test (Dawes et al., 2012) is a common test used to measure agility in sport. Several studies have been conducted in evaluating its effectiveness in measuring agility for athletes of any age. One such study was conducted by Raya et al. (2013) that compared the reliability in three common agility tests on servicemen: the Illinois Agility Test, Edgren Test and Side Step Test. The researchers concluded that they were able to establish reliability in these three agility tests and that any or all of these test could be used to measure agility in servicemen. Another study by Stewart, Turner, and Miller (2014) compared five of the commonly used agility tests on older teen physical education students. They concluded that comparing the Illinois, L-Run, Pro-Agility, T-test, and the 505 that these tests demonstrated "high intraday reliability" (Stewart, Turner, \& Miller, 2014) and that either could be used to measure agility. Finally, a study by Hachana et al. (2013) concluded the Illinois Agility Test is a reliable and valid test to measure agility in team sport athletes.

To summarize the review of literature on agility, these studies demonstrate the Illinois Agility Test is an effective tool in measuring agility due to its reliability and ability to be administered to different aged populations.

\section{Summary}

In summary, this chapter provided an extensive review of literature that produced mixed results. Literature related to skating (roller skating and inline skating) was limited in scope and only a few resources exist that provide a school based curriculum (Skatetime 2013a, 2013b, 2017; Skate in School, 2016a, 2016b) for educators to use without need of drastic modification to meet student and teacher needs. Research on the effects of a skating unit on fitness produced 
nothing related to roller skating and limited in scope related to inline skating (Melanson, Freedson, \& Jungbluth 1996; Melanson, Freedson, Webb, et. al., 1996; Muehlbauer et al., 2013, Orepic et al., 2013). However, an expanded literature review search to include ice skating did produce additional research (Fragala-Pinkham et al., 2009; Keller et al., 2014; Lamoth \& Heuvelen 2012; Walsh \& Scharf, 2014) that could be modified to meet the needs of a roller skating and/or inline skating unit. A review of literature search on the effect of a skating unit on various aspects of cardiovascular fitness, balance, explosive power, and agility produced limited results. However, the review of literature produced research demonstrating that these assessments are commonly used to predict athletic performance (Farlinger et al., 2007; Teramoto et al., 2016) in a given sport. Finally, the literature review produced numerous studies on the effectiveness of the fitness instrumentation and the reliability of the PACER, vertical jump, and Illinois Agility Run Test, but was limited as it related to the Stork Standing Balance Test. However, the Stork Standing Balance Test demonstrated its effectiveness as a tool to measure static balance and its ability to be administered to children (Hammami et al., 2016) and teens (Lirgg, 2018, in press). The limited research on the effect of a skating unit illustrates the need for further investigation. 


\section{CHAPTER 3}

\section{METHODOLOGY}

This chapter described the methodology of the effect of a skating unit on fitness in children. Specially, this chapter described the participants' characteristics, informed consent procedures, participant's rights, and data confidentiality. This chapter further detailed the procedure of the fitness assessment instrumentation protocol and how they were administered. Furthermore, the experimental design will provided a detailed description of the intervention for the control, roller skating, and inline skating groups. Finally, the statistical analysis detailed how each of the factors, levels, and dependent variables were analyzed for this study.

\section{Participants}

Eighty-two fifth grade students from a northwestern Arkansas elementary school were invited to participate in this study during the fall 2017 semester. Of the 82 students invited, 11 students $(13.4 \%)$ were removed due to non-participation, incomplete data, and/or left the school. During their regularly scheduled physical education classes, three separate classes $(n=71)$ served as the control group $(n=19 ; 8$ male; 11 female; mean age $=10.37)$ and two experimental groups: roller skating $(n=26 ; 11$ male; 15 female; mean age=10.31) and inline skating $(n=26 ; 10$ male; 16 female; mean age=10.35). For purposes of this study, students in the control group did not have access to the roller skates or inline skates during physical education classes.

Participants' rights. This study obtained Institutional Review Board approval (see Appendices A and B) and consent from the Principal, physical education teacher(s), student, and parent(s) or guardian(s) (see Appendices C and D for English and Spanish versions). The primary function of participants' rights was to protect the identity of those students who chose to 
participate in this study. Each student was assigned a unique identification number for coding purposes and data analysis with all personal information removed. This study was voluntary and a student, for any reason, could choose to decline to participate or withdraw from the study at any time, even after signing the informed consent. The physical education teacher(s) and fitness evaluation team assisted in data collection (pretest and posttest fitness tests) and the physical education teacher conducted the daily course curriculum, but did not have access to the data once the data was prepared for analysis. However, since the school district uses the PACER test as part of the FITNESSGRAM (The Cooper Institute, Dallas, TX) fitness testing, the participants pretest scores were used for the districts fitness testing during the fall semester. The student's posttest score was not used by the school for testing purposes.

\section{Design and Measures}

A pretest-posttest design was utilized for this study. To measure the fitness in children, the four instruments and protocol are described further in this section. Additionally, this section discussed the teacher's exit questionnaire upon completion of the study and how the data was collected and stored.

Cardiovascular fitness. The PACER (Léger \& Lambert, 1982; Léger et al., 1988) was administered to measure cardiovascular fitness. Cone lines were set up 20-meters apart in the gymnasium. The test began with participants lined up on one side of the course and when the audio track began, the subjects run to the other side of the course. A beep indicated the pace at which the subject needs to reach the ends of course. As the music continued, the pace increased and subjects continued to run until they could no longer maintain the pace for two ends. The total number of ends was determined by the total ends run minus the number of ends missed or not 
completed before the beep. The evaluator demonstrated the procedure, but gave no other instruction to the participant. Subject's total numbers of ends were recorded on the scoring sheet in Appendix E. A PACER scoring sheet was provided in Appendix F that could be used to assist evaluators in tracking ends completed.

a.

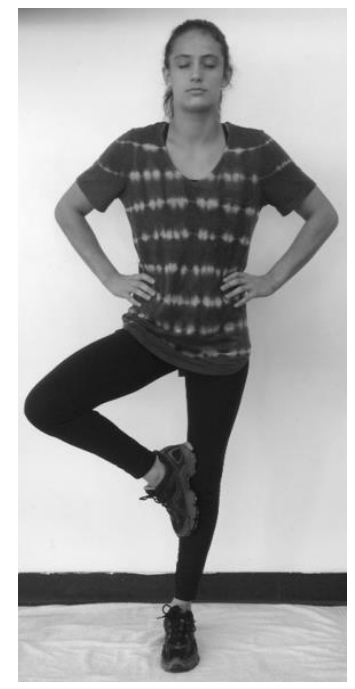

b.

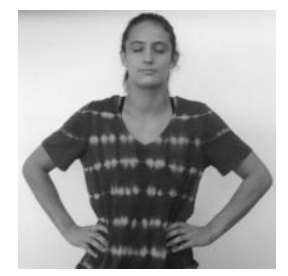

c.

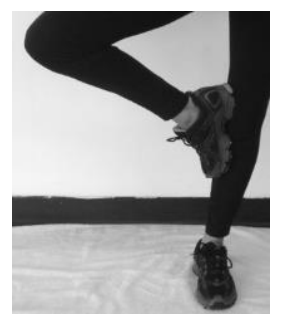

Figure 3.1. Modified Stork Standing Balance Test pose. (a) Stork pose. (b) Eyes closed and hands positioned on hips. (c) Base foot flat on floor and other foot positioned on the inside of the knee of the base leg.

Static balance. Modified Stork Standing Balance Test (Hammami et al., 2016) is a timed test to measure static balance. With shoes on, participants placed their hands on their hips and placed the non-supporting foot against the inside of the supporting leg's knee. Holding that position, the participant closed their eyes and the evaluator started the time on a stopwatch. The test ended when any of the following occurred: when the supporting foots heel raised off the floor, supporting foot moved or hopped in any direction, hand(s) came off the hips, eyes opened, or the non-supporting foot moved from the supporting leg. The evaluator demonstrated the procedure, but no other instruction was given to the participant. Subjects had one practice attempt and two timed attempts with a short rest of approximately two minutes between each 
attempt. The longest attempt time recorded to the nearest one hundredth of a second between the two attempts was recorded on the scoring sheet in Appendix E. Figure 3.1 illustrates the Modified Stork Standing Balance Test pose.

Explosive power. Explosive power was measured by the vertical jump (Cheah, Cheong, Razman, Zainal Abidin, \& 3rd International Conference on Movement Health and Exercise [MoHE], 2017; Leard, 2007). To perform this task, the evaluator measured a standing reach. With shoes on, the participant stood in a natural position with their side against the wall and their dominant arm reaching overhead without overreaching. A measurement of the highest reaching point was measured to the nearest half-inch to establish the standing height (Chu, 1998). After the standing height was established, a Vertec jumping apparatus measured the jumping height. With their dominate side facing the apparatus, the participant stood under the apparatus with their feet shoulder width apart. The participant then performed a counter movement that allowed he or she to swing their arms down and back as they bent their knees then performed a jump and swung their arms up to touch the highest possible moveable vane with their dominate hand (Wood, 2008a). The evaluator demonstrated the procedure, but no other instruction was given to the participant. The vertical jump is determined by subtracting the highest vane touched minus standing reach and recorded to the nearest half-inch. Participants were given one practice jump and two attempts with the best jump recorded to the nearest half-inch on a scoring sheet provided in Appendix E. Figure 3.2 illustrates the vertical jump technique. 
a.

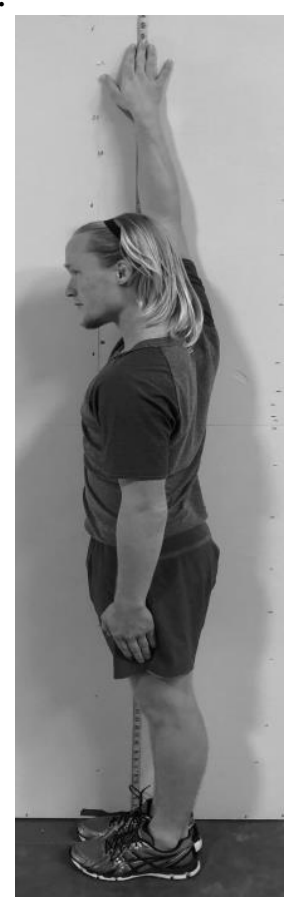

b.

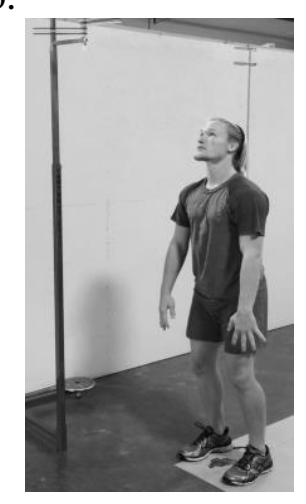

c.

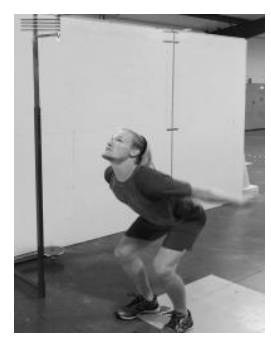

d.

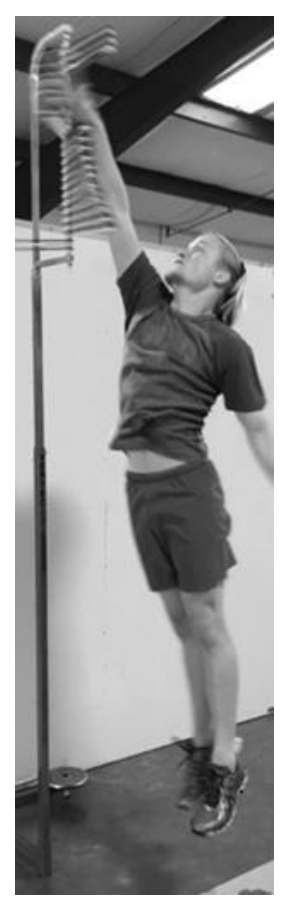

Figure 3.2. Vertical jump. (a) Standing reach measured. (b) Start positon. (c) Countermovement: body drops to a squat and arms swing back in one continuous motion. (d) Jump and reach for the highest vain.

Agility run. The Illinois Agility Test (Dawes, 2012; Raya et al., 2013) was administered to measure the subjects running agility. The length of the course was 10 meters long with a width of 5 meters. Four cones were used to mark the perimeter of the box and designate the start, finish and turning points of the test. In addition, four cones ran the length of the 10 meters in the middle (5 meters from the edge) of the box spaced 3.3 meters apart. Subjects assumed the start position by lying face down with head facing the start line and hands by their shoulders. The timer said 'Go' and the stopwatch was started. The subjects quickly rose from the floor and ran the course without knocking over any cones to the finish line where time was stopped. The evaluator demonstrated the procedure, but no other instruction was given to the participant. Participants performed two attempts with a short rest of approximately two minutes between each attempt. The fastest time of the two attempts was recorded to the nearest one hundredth of 
a second on the scoring sheet provided in Appendix E. Taped arrows were placed on the floor to aid participants in performing the task. Figure 3.3 illustrates the Illinois Agility Run layout.

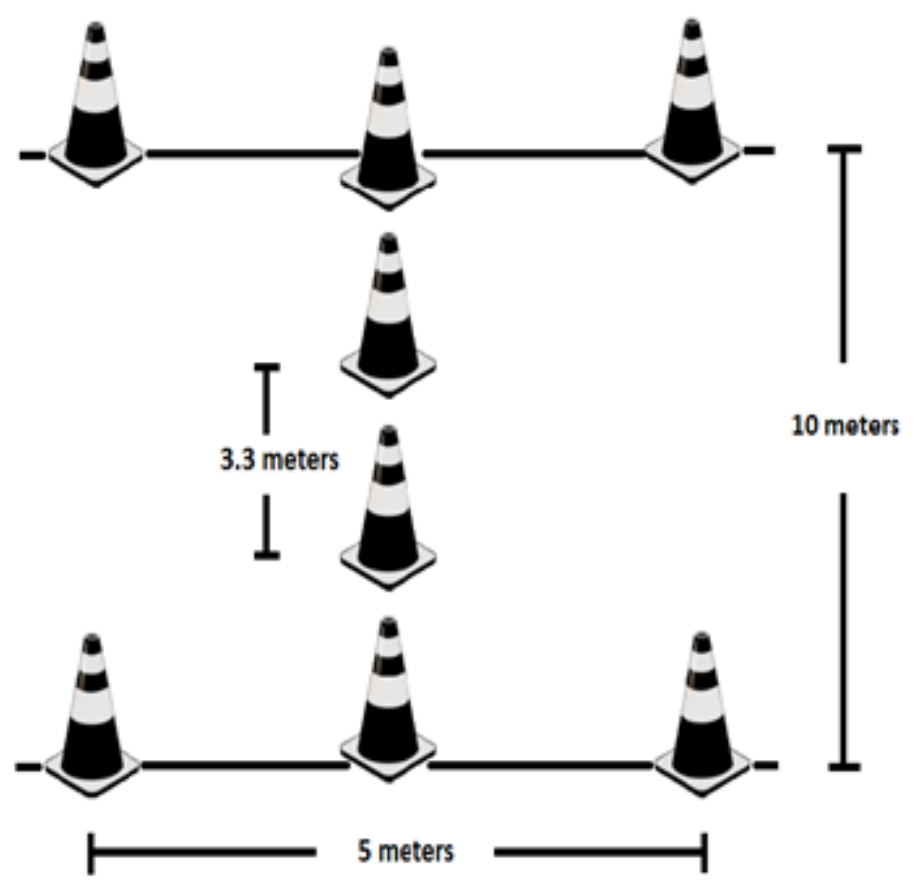

Figure 3.3. Illinois Agility Run Layout (Raffael, 2011).

Teacher exit questionnaire. Upon completion of the skating unit, the physical

education teacher was asked to participate in a short questionnaire designed to solicit impressions and observations of a skating unit and to share feelings expressed by students. Topics of the questionnaire included; overall impression of the skating unit, fears and concerns, student impressions, successes, and future considerations. The questionnaire is detailed in Appendix G.

Data was collected and transferred to an Excel spreadsheet and Statistical Package for Social Sciences (SPSS) version 23 software. All research data was backed up on an external thumb drive. All electronic information, fitness testing, and consent forms will be locked in a 
safe for five years. After the five year period, student fitness and consent forms will be shredded and thumb drive erased.

\section{Procedure}

After IRB approval was granted, letters of Consent for a Minor form (see Appendices C and D for English and Spanish versions) were sent explaining the details of the intent of the study and research design. Consent forms were sent home with students during the beginning of the fall 2017 school year. All signed documentation was required to be returned to the teacher and gathered by the researcher prior to the start of the intervention. A copy of the documentation was made for the participants and parents to keep for their records and reference. The teacher also received a copy of the documentation which was returned to the researcher upon completion of the study. The researcher and fifth grade physical education teacher worked together to assign which class periods would serve as the control and two experimental groups (roller skating and inline skating) with consideration to the least disruption to a student's normal daily routine. To assist the reader with the research schedule, Table 3.1 provides a general overview of the time line for this study. This study followed a pretest posttest design where the pretest and posttest will bookend a skating curriculum adapted with permission from Skatetime (see Appendix $\mathrm{H}$ ) and Skate in School (see Appendix I) for both the roller skating and inline skating experimental groups (see Appendix $\mathrm{J}$ for lesson plans and Appendix $\mathrm{K}$ for enrichment activities). 
Table 3.1

Research Schedule

\begin{tabular}{ll}
\hline Time Line & General Overview \\
\hline Week 1 & Pretesting for Control and Experimental Groups \\
Weeks 2-7 & $\begin{array}{r}\text { Intervention Period } \\
\text { - Control Group: Regularly scheduled curriculum } \\
\text { - Experimental Groups: lessons 1-12* }\end{array}$ \\
& Posttesting for Control and Experimental Groups \\
Week 8 & Note. $*$ See Appendix J for lesson plans and Appendix K for enrichment activities.
\end{tabular}

Week 1 pretests. Before students started the skating unit, students in the control and experimental groups participated in a series of fitness evaluations. Each class was evaluated over a two day period by a team of evaluators to ensure reliability and validity of the results. On day 1 , the following three tasks set up to measure the following: the modified Stork to test static balance, the vertical jump to measure lower body explosive power, and the Illinois Agility run to test agility. The Standing Stork was the first test conducted to evaluate participants. Students formed a line in front of one of the team evaluators and performed the task. After the first attempt, students then went to the back of each line to wait their turn to perform the second attempt. After completing both attempts, the student then went back to their assigned seating location. When all the students completed the task, the class was divided into two groups, one to the vertical jump station and the other to the agility courses. After all the students completed the second station, they would switch to the third and final station of the day. On day 2, the PACER test was conducted to measure cardiovascular fitness. The class was divided into several groups that consisted of about five to seven participants to perform the task. Students had one attempt with the number of laps completed recorded for analysis. After completing the task, students walked around the tennis court to cooldown and recover from the run. 
Table 3.2

\section{Control Curriculum Overview}

\begin{tabular}{ll}
\hline Lesson & Overview \\
\hline 1 & Softball Unit continued. \\
& Activities included throwing, catching with running integrated. \\
& Softball Unit continued. \\
& Activities included throwing, catching with running integrated. \\
& Softball Unit continued. \\
& "Softball Grab Bag Game" Activities included throwing, \\
& catching with running and balance integrated. \\
4 & Dance Unit \\
& Dances included: Cha Cha Slide, Cupid Shuffle, Macarena, \\
& Electric Slide, Cotton-Eyed Joe \\
& Dance Unit continued \\
& Dances included: Electric Slide, Cotton-Eyed Joe, Ju Ju on that \\
& Beat, \& Watch Me \\
& Dance Unit continued \\
& Dance Unit continued \\
& Cultural Dance from other countries like Tarantella, Mexican \\
& Hat Dance, Virginia Reel, \& Australian Bush Dance \\
& Exercise Stations \\
& Jump Rope, Just Dance, free throw shooting, jump bands, \\
& throwing, \& soccer pass \\
& Dance Review \\
11 & Soccer Unit \\
& Ball control \& dribbling drills, pass \& shooting drills \\
& Soccer Unit continued \\
& Review skills and integrated games to reinforce learned skills \\
& Station Activities \\
& Hula hoops, basketball skills, jump roping, soccer ball skills \\
\hline &
\end{tabular}

Week's 2-7 intervention period. During the intervention period, the control and experimental groups met during regularly scheduled 45 minute, twice weekly fifth grade physical education classes. This protocol required no change to their daily routine. During this time, the control group participated in regularly scheduled curriculum. The control group was not permitted to participate in any roller skating or inline skating activities during class periods through the course of the eight week study. The curriculum included activities such as the 
completion of a softball unit, dance unit, exercise stations, and the beginning of a soccer unit.

Table 3.2 provides an overview of the curriculum for the control group during this study.

The experimental skating groups participated in a modified skating curriculum adapted and/or reprinted with permission from Skatetime (2013a, 2013b, 2017) and Skate in School (2016a, 2016b) that ensured commonality between the roller skating and inline skating groups for purposes of this study. Each lesson provided a warm-up, an activity of the day, and closure. Table 3.3 provides an overview of the curriculum and Appendix $\mathrm{J}$ and Appendix $\mathrm{K}$ details each lesson and supplemental enrichment activity administered during this study. Additionally, all skating activities were held indoors through the course of this study. During the study, the students in the inline class had a scheduled Friday holiday that required the students to make up that day. The teacher and students agreed to make up the time for that missed Friday during their recess that followed the classes normally scheduled class time.

Table 3.3

Skating Curriculum Overview

\begin{tabular}{ll}
\hline Lesson & Overview \\
\hline 1 & Introduction to skating \\
2 & Skating basics: falls, standing, and basic stops \\
3 & Skating basics: V-walk, stroke, and basic stops \\
4 & Skating basics: stride lengthening \\
5 & Extending stances, gliding, stride, and stops \\
6 & Basic turns \\
7 & Put it together: Skills progress check \\
8 & Fitness Stations \\
9 & Backwards skating basics \\
10 & Put it together: Skills practice and refinement \\
11 & Put it together: Skills practice and refinement \\
12 & Skating Unit skills test \\
\hline Note. See Appendix J for lesson plans and Appendix K for enrichment activities.
\end{tabular}


Week 8 posttests. At the end of the intervention period, a series of posttests were performed to re-measure students' fitness. The posttests were conducted by the assessment team and followed the two day protocol established during the pretesting. Students followed the same rotation of stations and evaluators managed the same stations established in the pretests for consistency of data collection.

\section{Statistical Analysis}

The Statistical Package for Social Sciences (SPSS) version 23 was utilized to analyze the descriptive statistics for this study. Data is displayed as group means and standard deviations. A one-way analysis of variance (ANOVA) was conducted separately to evaluate the mean differences for each of the four factors: cardiovascular fitness, static balance, explosive power, and agility. Each factor consisted of three levels to include a control group, roller skating group, and inline skating group. The dependent variable for this study was the difference in posttest minus pretest fitness testing scores. Post hoc tests were conducted when appropriate. An alpha set at the .05 level defined the significance for all tests. 


\section{CHAPTER 4}

\section{RESULTS}

This chapter details the results for each of the four hypotheses to determine the effect of a skating unit on cardiovascular fitness, balance, explosive power, and agility in fifth grade students. Additionally, this chapter provides a sample analysis on the participants to determine their viability for final analysis and an exploratory analysis that examines the impact of gender on each of the four hypotheses.

\section{Sample Analysis}

Prior to final analysis, several evaluations were performed on the samples to determine their viability to be used for analysis. Participants were evaluated based on attendance, improper physical education attire during the pre and posttest evaluations, and the removal of extreme outliers. Daily attendance was recorded by the teacher during the intervention period of this study. Participants, who did not meet the 8 out of 11 lessons (72\%) attendance, would have had their data removed from final analysis. After a review of the attendance records, all $(n=71)$ students met the attendance requirement. The attendance rate by class was: control $95.65 \%$, roller skating experimental 96.5\%, and inline skating experimental 93\%. Next, participants were removed from the analysis due to measurement error and/or improper physical education attire (i.e. boots) during testing periods. In total, nine Stork, five vertical jump, and three agility data points were removed from analysis and treated as missing data. Finally, extreme outliers were identified and removed prior to final analysis. Prior to and during this study, a few participants were identified to have high athletic prowess that could positively or negatively skew the analysis. For purposes of analysis, an extreme outliner was defined by a value which lies more 
than 3.0 times the interquartile range (IQR) below the first quartile (Q1) or above the third quartile (Q3) and is represented mathematically where the score (x) is: $\mathrm{x}<\mathrm{Q} 1-3 * \mathrm{IQR}$ or $\mathrm{x}>$ Q3 + 3* IQR (Jones, n.d.). In total, four participants (Illinois Agility, $n=1$; Stork Standing, $n=3$ ) were removed from the samplings (see Figure 4.1 and 4.2).

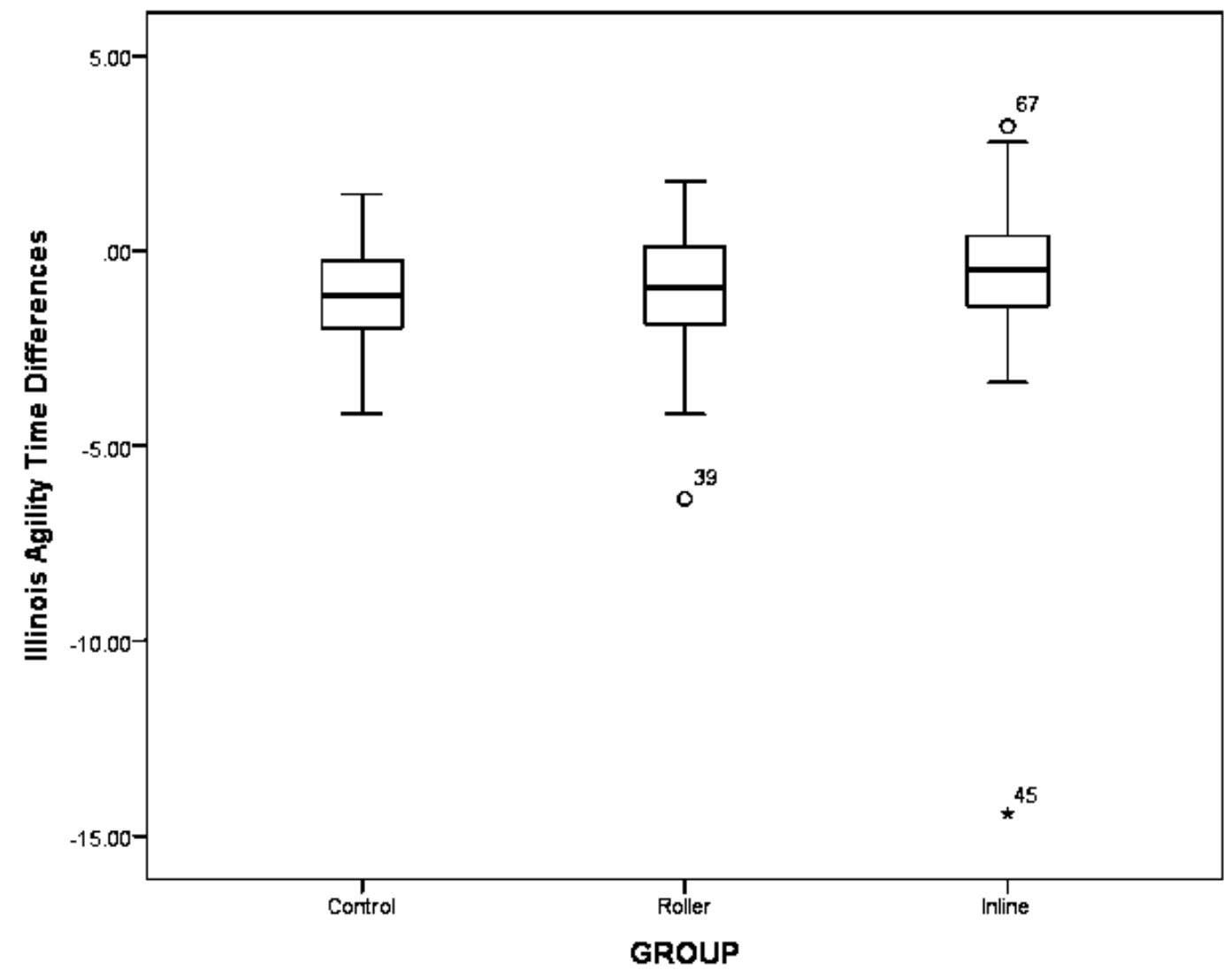

Figure 4.1. Illinois Agility Outliers. The extreme outlier is defined by a star. 


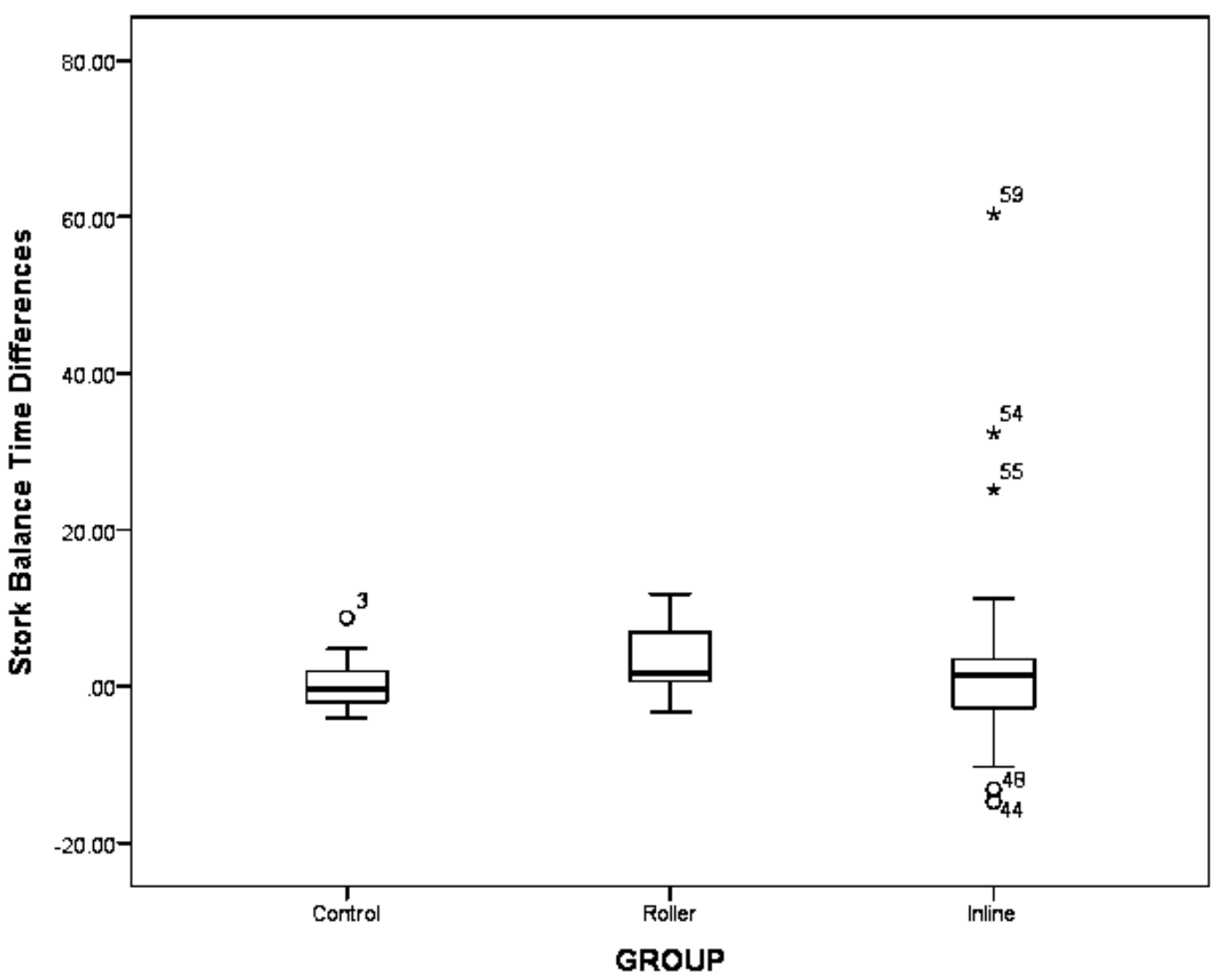

Figure 4.2. Stork Balance Outliers. The extreme outliers are defined by a star.

\section{Hypotheses Results}

This section will report the results for each of the hypotheses to investigate the effects of the skating unit. The four hypotheses $\left(H_{1}\right)$ are as follows: (1) Does the mean change in the PACER scores differ among the three experimental populations: those in the control, those who roller skate, and those who inline skate? (2) Does the mean change in the static balance scores differ among the three experimental populations: those in the control, those who roller skate, and those who inline skate? (3) Does the mean change in the vertical jump scores differ among the three experimental populations: those in the control, those who roller skate, and those who inline skate? (4) Does the mean change in the agility scores differ among the 
three experimental populations: those in the control, those who roller skate, and those who inline skate?

Hypothesis 1 cardiovascular fitness. A one-way analysis of variance (ANOVA) was conducted to evaluate the mean change in the population for cardiovascular fitness between the skating groups and the change in PACER testing scores. The independent variable, group cardiovascular fitness factor, included three levels: control, roller skating, and inline skating. The dependent variable was the difference (posttest minus pretest) in PACER scores. The ANOVA was non-significant at the .05 level, $F(2,67)=1.49, p=.23$. The strength of the relationship between the group cardiovascular fitness factor and difference in PACER scores, as assessed by $\eta^{2}$, was a small to medium association, with the cardiovascular factor accounting for $4.2 \%$ of the variance of the dependent variable.

The results of the findings do not support hypotheses one. Figure 4.3 shows the distribution of the three group levels for cardiovascular fitness and the means and standard deviations are reported in Table 4.1. 


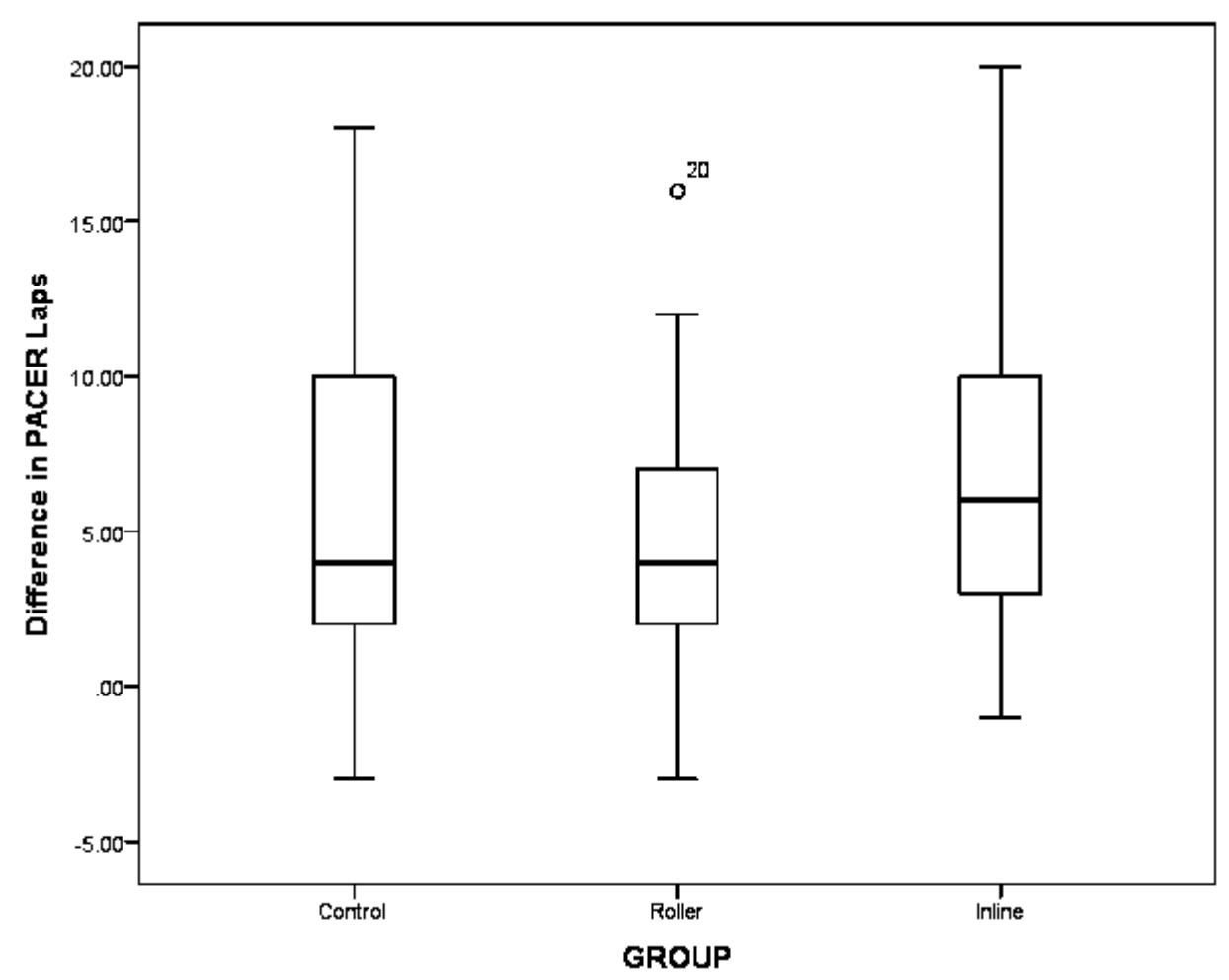

Figure 4.3. Changes in PACER laps completed for control, roller skating, and inline skating groups.

Table 4.1

Means and Standard Deviations for PACER laps completed

\begin{tabular}{llll}
\hline Group & $n$ & $M$ & $S D$ \\
\hline Control & 19 & 6.21 & 5.85 \\
Roller Skating & 25 & 4.60 & 4.26 \\
Inline Skating & 26 & 7.12 & 5.66 \\
\hline
\end{tabular}

Hypothesis 2 static balance. A one-way ANOVA was conducted to evaluate static balance between the skating groups. The dependent variable was the difference in Standing Stork Balance time. The ANOVA was significant at the .05 level, $F(2,56)=4.90, p=.011$. The strength of the relationship between the group static balance factor and difference in Standing Stork Balance time, as assessed by $\eta^{2}$, was a strong association, with the group static balance 
factor accounting for $14.9 \%$ of the variance of the dependent variable. Figure 4.4 shows the distribution of the three group levels for balance.

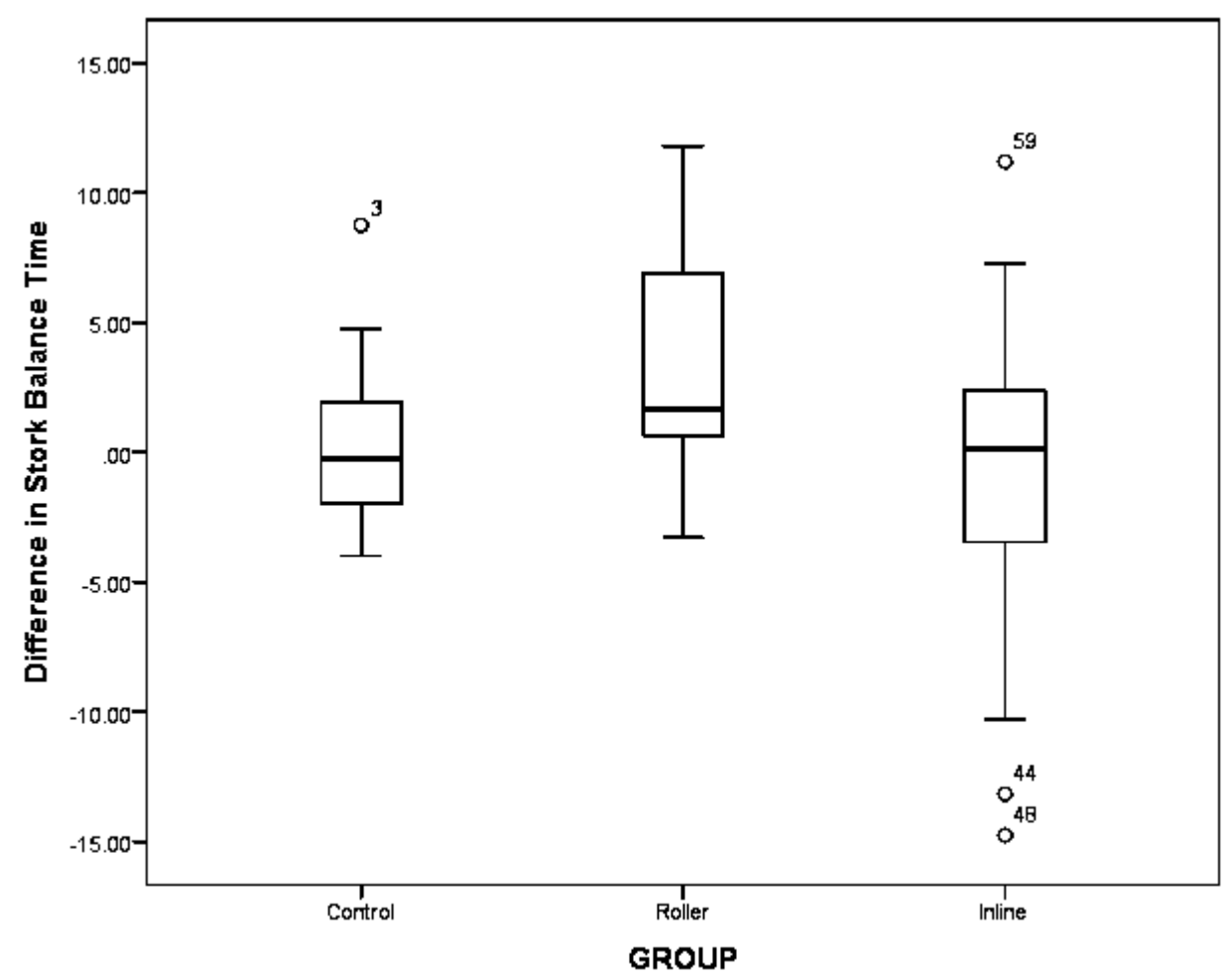

Figure 4.4. Changes in Stork balance time for control, roller skating, and inline skating groups. Follow-up tests were conducted to evaluate pairwise differences among the means.

Because Levene's test was non-significant, $F(2,56)=2.57, p=.090$, we assume the variances were homogenous and conducted post hoc comparisons using the Tukey-Kramer test. An alpha at the .05 level determined the significance. There was a significant difference in the means between the groups that received the inline skating $(M=-0.98)$ and roller skating $(M=3.57)$ treatment. The group that participated in roller skating showed on average a greater increase in balance time compared to inline skating. No significant differences reported between the roller skating $(M=3.57)$ and control $(M=0.29)$ groups and the inline skating $(M=-0.98)$ and control $(M=0.29)$ groups. The $95 \%$ confidence intervals for the pairwise differences, as well as the means and standard deviations for the three balance groups, are reported in Table 4.2. 
Table 4.2

95\% Confidence Intervals of Pairwise Differences in Mean Changes and Standard Deviations for Modified Stork Standing Balance Test in seconds

\begin{tabular}{lccccc}
\hline Group & $n$ & $M$ & $S D$ & Control & Roller Skating \\
\hline Control & 17 & 0.29 & 3.38 & & \\
Roller Skating & 22 & 3.57 & 4.13 & {$[-0.50,7.05]$} & \\
Inline Skating & 20 & -0.98 & 6.42 & {$[-5.14,2.59]$} & {$[-8.17,-0.93]^{*}$}
\end{tabular}

Note: An asterisk indicates that the $95 \%$ confidence interval does not contain zero, and therefore the differences in the means is significant at the .05 significance using Tukey-Kramer procedure.

The results of the findings support hypotheses two in that there are differences between those who roller skate compared to those who inline skate.

Hypothesis 3 explosive power. A one-way ANOVA was conducted to evaluate explosive power between the skating groups. The dependent variable was the difference in the vertical jump inches. The ANOVA was non-significant at the .05 level, $F(2,63)=1.34, p=.27$. The strength of the relationship between the group explosive power factor and difference in vertical jump inches, as assessed by $\eta^{2}$, was a small to medium association, with the group explosive power factor accounting for $4.1 \%$ of the variance of the dependent variable.

The results of the findings do not support hypotheses three. Figure 4.5 shows the distribution of the three group levels for explosive power and the means and standard deviations are reported in Table 4.3 . 


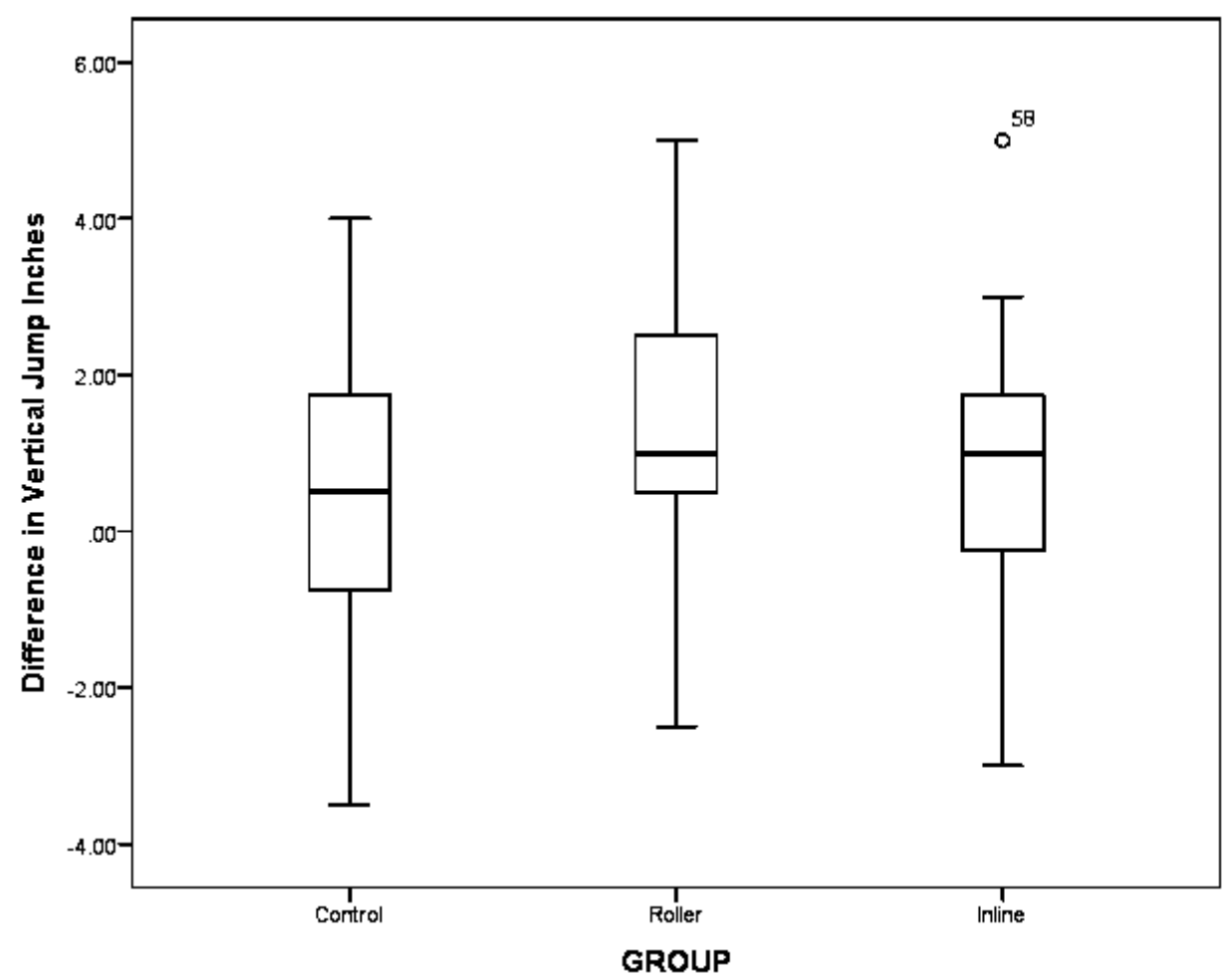

Figure 4.5. Changes in vertical jump inches for control, roller skating, and inline skating groups.

Table 4.3

Means and Standard Deviations for Vertical Jump in inches

\begin{tabular}{lccc}
\hline Group & $n$ & $M$ & $S D$ \\
\hline Control & 19 & 0.39 & 1.93 \\
Roller Skating & 24 & 1.27 & 1.84 \\
Inline Skating & 23 & 0.67 & 1.69 \\
\hline
\end{tabular}

Hypothesis 4 agility. A one-way ANOVA was conducted to evaluate agility between the skating groups. The dependent variable was the difference in Illinois Agility time. The ANOVA was non-significant at the .05 level, $F(2,63)=1.60, p=.21$. The strength of the relationship between the group agility factor and difference in Illinois Agility time, as assessed by $\eta^{2}$, was a small to medium association, with the group agility factor accounting for $4.8 \%$ of the variance of the dependent variable. 
The results of the findings do not support hypotheses four. Figure 4.6 shows the distribution of the three group levels for agility and the means and standard deviations are reported in Table 4.4 .

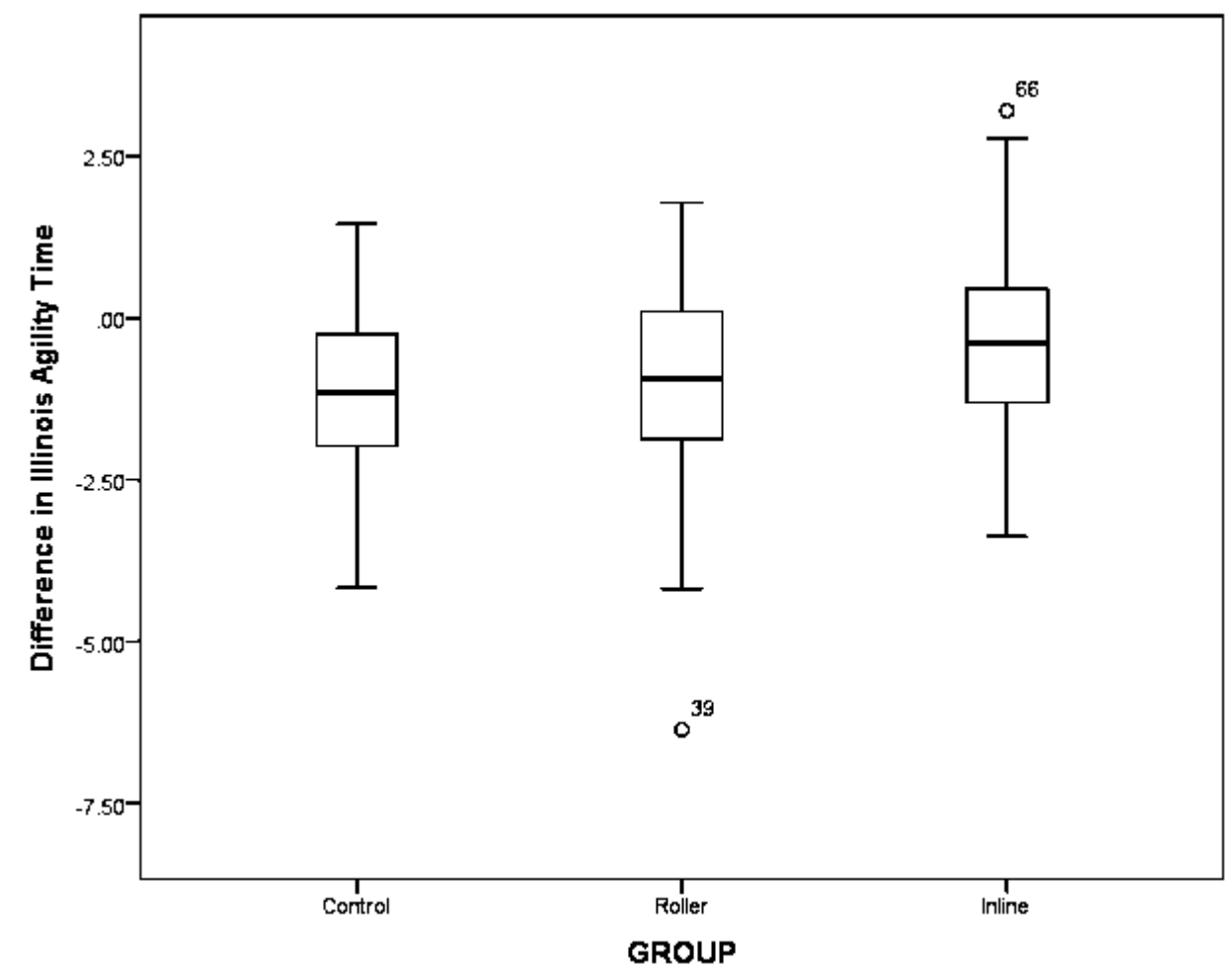

Figure 4. 6. Changes in Illinois Agility time for control, roller skating, and inline skating groups.

Table 4.4

Means and Standard Deviations for Illinois Agility Test in seconds

\begin{tabular}{lccc}
\hline Group & $n$ & $M$ & $S D$ \\
\hline Control & 19 & -1.28 & 1.60 \\
Roller Skating & 25 & -1.12 & 1.86 \\
Inline Skating & 22 & -0.40 & 1.62 \\
\hline
\end{tabular}




\section{Teacher Exit Questionnaire}

This section will detail the results of the Teacher Exit Questionnaire. The physical education teacher was asked to participate in a short questionnaire designed to solicit impressions and observations of the skating unit and to share the feelings expressed by students. Below are those responses to the questionnaire (see Appendix $\mathrm{K}$ for question set).

Question 1: "What was your overall impression of the skating unit?" The teacher spoke highly of the skate study. Prior to the study, the teacher and researcher met often where the teacher expressed her excitement about what kind of an opportunity this was going to be for the fifth grade class. This excitement continued through the course of the study. That enthusiasm was expressed in phone conversations, text messaging, and email. In response to this question, the Teacher stated, "I thought it was great! The kids really loved it and it was something new and exciting for most of them. It made them use muscles many of them were not used to using on a regular basis."

Question 1a: "Fears or concerns prior to the study?" As with any study, there are some concerns that may arise on behalf of those who will be conducting the intervention during the study and the participants of the uncertainty of what may transpire. This study was no different. One of the main concerns expressed by the teacher was space. A structural obstacle was located in one of the corners of the gym that would require the teacher to plan accordingly to ensure student safety and that the structure did not negatively influence the study. This concern was reflected in our first meeting and was a concern throughout the life of the study. After reviewing the structure, it would pose some challenges, but the researcher and teacher felt that there would be ample space to proceed. During the intervention period, on a few occasions, the teacher had to make some adjustments to the activities. It is important to note, the wheels on the roller skates 
and inline skates were specifically designed for indoor use only. If the teacher would have been able to conduct some of the activities outside, spacing would not have been a challenge. In response to this question, the Teacher stated, "Space was a concern because of the new storage unit. I was also worried about whether or not the kids would have as much excitement as I did about the unit."

Question 2: "What were the students' impressions during this unit?" The purpose of this question was to share the students' perspective of the skating unit. In response to this question, the Teacher stated, "They LOVED it!! Most of them were really sad when it was over. They all said it went by really fast."

Question 2a: "Fears or concerns prior to the study?" Student fears or concerns were short lived. Most of the fears were from those students who never had an opportunity to skate before, which is an understandable feeling by anyone. The teacher was empathetic to those individuals and was overheard by the researcher spinning the potential negative thoughts into positive excitement. In response to this question, the Teacher stated, "There were a few students who were very nervous about skating for the first time. Other than those first time jitters there really weren't any concerns that were shared with me."

Question 2b: "Was there visual improvement on those who participated in the roller skating and inline skating classes? Please explain." The purpose of this question was to see how students were progressing through the curriculum. The curriculum was specifically designed to allow for flexibility depending on the success rate of the students as they progressed through each lesson. Enrichment activities were added to supplement the daily lessons to allow those more advanced to not be held back when special attention was needed.

In response to this question, the Teacher stated, 
Oh yes! There were only a handful of students who already had a decent skill set in skating. With more room I think they could have improved further but it was still very good exercise for them and they really enjoyed it. The other students significantly improved throughout the study. Some had to start on the entry rug but soon made it out onto the gym floor with everyone else. I saw balance go up significantly in all of the students while they were skating. It was also really great to watch the students get more and more comfortable and less wobbly on the skates as we went along. The looks on their faces when they accomplished something new was so rewarding!

Question 3: "What do you feel was successful about the skating unit?" The question was an opportunity for the teacher to share both the hard and soft skills learned during the skate unit. The curriculum was adapted from Skate in School that followed the SHAPE American National PE Standards and the researcher wanted to know what impact the skating unit had beyond the classroom.

In response to this question, the Teacher stated, For most of the students it gave them the chance to try something out of their comfort zone and daily norm. There were so many students who told me they were asking their parents to get them their own pair of skates they loved it so much. It was great knowing that a study turned into something that the kids were wanting to take the next step further outside of class!

Question 4: "What do you feel was unsuccessful about the skating unit?" As with any curriculum, there is always room for improvement. Curriculum is dynamic and needs to adapt to given situations. This was an opportunity for the researcher to address changes to the curriculum to improve/strengthen student learning. 
In response to this question, the Teacher stated,

I wish that our schedule would have worked out in a way so that there could have been 2 of us instructing in class. That way one of us could have focused on the students needing extra help and one of us could have focused on improving the skill set of those who were at a higher level. Those just starting out in skating needed a lot of assistance and I found it hard to spread myself evenly between the two groups. I also wish we could have had more space so the students could have spread out more.

Question 5: "What modifications might be made in the future for the skating unit?" One of the biggest challenges that physical education teachers have is trying to find the balance between those students who are excelling and those who may require some extra attention. This skating unit was not immune to this and the teacher would need to be able to adapt to those situations.

In response to this question, the Teacher stated,

With our students I found that their skill sets were either high or in the beginning stages. For some they transitioned from beginner to intermediate quickly, but some didn't ever transition. Possibly having two curriculums, one for the more advanced skaters and then one that really focused on just getting the kids up and working on balance at a more drawn out pace. The curriculum we used worked very well for those who picked up on the skating. The ones who were struggling on maintaining good balance however many times were not entirely ready to move on with the class. They were able to attempt all of the new skills but I would not say that many of them felt completely comfortable with them. 
Questions 6: "Would you consider doing a skating unit in the future?" When any time a new curriculum is utilized for the first time, it is important of a teacher to determine its merit. This is especially important when introducing non-traditional activities into one's classroom. This question was an opportunity for the teacher to share would they consider utilizing a skating unit in the future. In response to this question, the Teacher stated, "Yes, the students really enjoyed it and now that I have the experience from the first one I know what to expect."

Question 7: "Other comments." This was an open section for the teacher to add any additional comments that were not addressed in any of the above questions. In response to this question, the Teacher stated, "We are so happy that we got to participate in the study. Thank you so much for providing this opportunity for our students!"

The comments by the physical education teacher demonstrate that a non-traditional unit like skating can be a refreshing and fun activity for students.

\section{Exploratory Analysis Results}

An exploratory analysis was conducted beyond the scope of this study to investigate how males and females performed in four hypotheses in this study. Below are the results of that exploration.

A one-way ANOVA was conducted on each of the four fitness factors to investigate the findings if there were differences within the male populations and with the female populations. The dependent and independent variables at the .05 level were used similar to the hypothesis tested earlier to determine significance. Cardiovascular fitness based on gender were reported to be non-significant for males, $F(2,26)=.40, p=.675$ (see Figure $4.7 \&$ Table 4.5$)$ and females, $F(2,38)=1.71, p=.194$ (see Figure $4.8 \&$ Table 4.6). Static balance results reported non- 
significance for males, $F(2,22)=1.94, p=.167$ (see Figure $4.9 \&$ Table 4.7) and females, $F(2$, $31)=2.95, p=.067$ (see Figure $4.10 \&$ Table 4.8). Explosive power also reported nonsignificance in males, $F(2,25)=2.01, p=.155$ (see Figure $4.11 \&$ Table 4.9) and females, $F(2$, $35)=.42, p=.659$ (see Figure $4.12 \&$ Table 4.10$)$. Finally, agility also reported nonsignificance in both males, $F(2,24)=1.08, p=.357$ (see Figure $4.13 \&$ Table 4.11) and females, $F(2,36)=1.31, p=.283($ see Figure $4.14 \&$ Table 4.12$)$.

While the results for each gender were found to be non-significant in each of the four factors, further analysis of $\eta^{2}$ was conducted to determine the strength of their associations. The range for $\eta^{2}$ was between $3.0 \%$ and $15 \%$ for males and between $2.4 \%$ and $16 \%$ for females for each of the four factors. All but three of the associations were classified as low to medium; while male static balance (15\%), female static balance (16\%), and male explosive power (13.9\%) had demonstrated a strong or near strong association. While the $p$-value's did not indicate these two factors to be significant, an argument could be made that if there was either a larger sample size or the intervention period lasting longer than the 12 lessons, the exploratory analysis could induced significance in these two factors. 


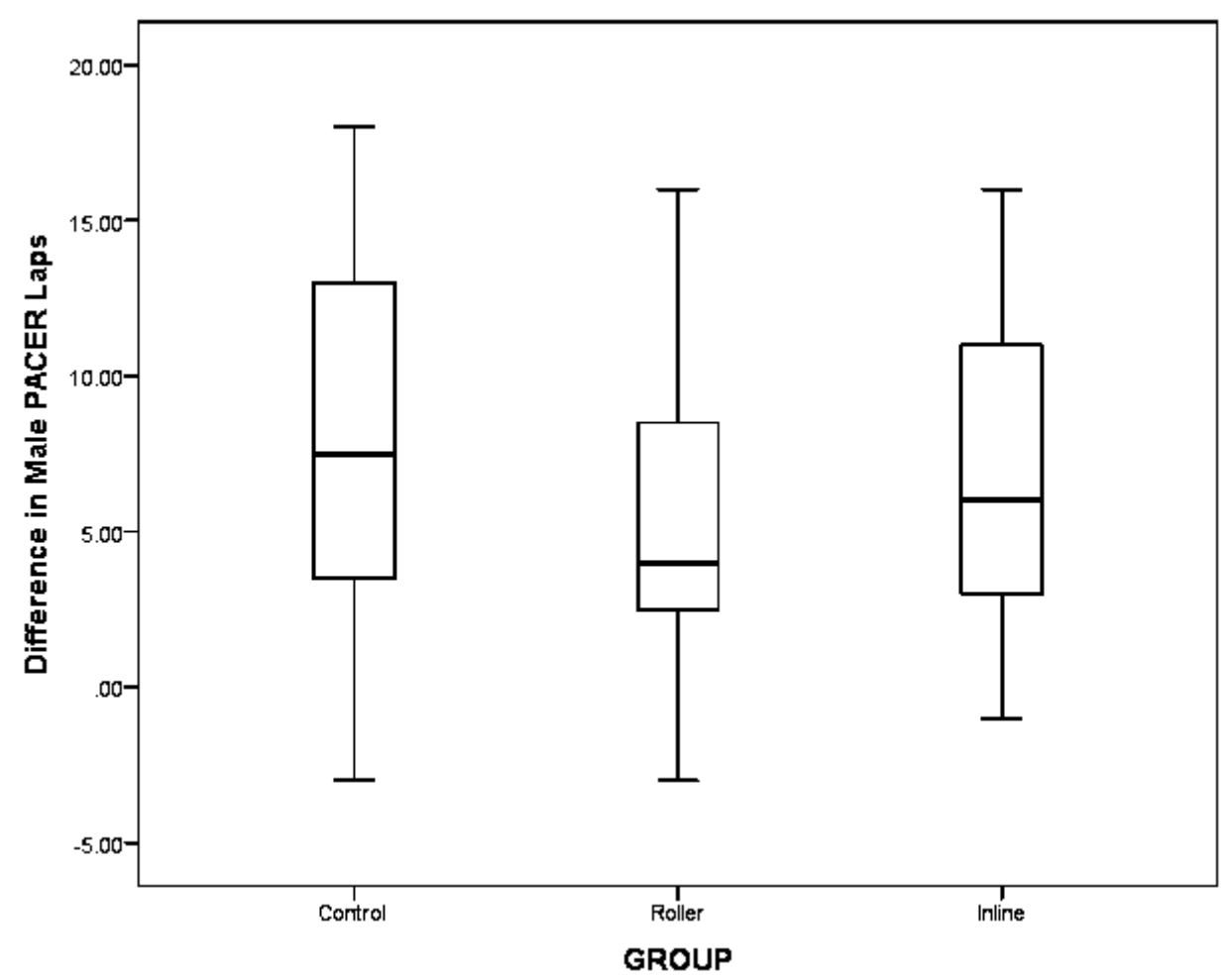

Figure 4. 7. Changes in male PACER laps completed for control, roller skating, and inline skating groups.

Table 4.5

Means and Standard Deviations for Male PACER in laps completed

\begin{tabular}{lccc}
\hline Group & $n$ & $M$ & $S D$ \\
\hline Control & 8 & 7.88 & 6.92 \\
Roller Skating & 11 & 5.55 & 5.32 \\
Inline Skating & 10 & 7.20 & 5.75
\end{tabular}




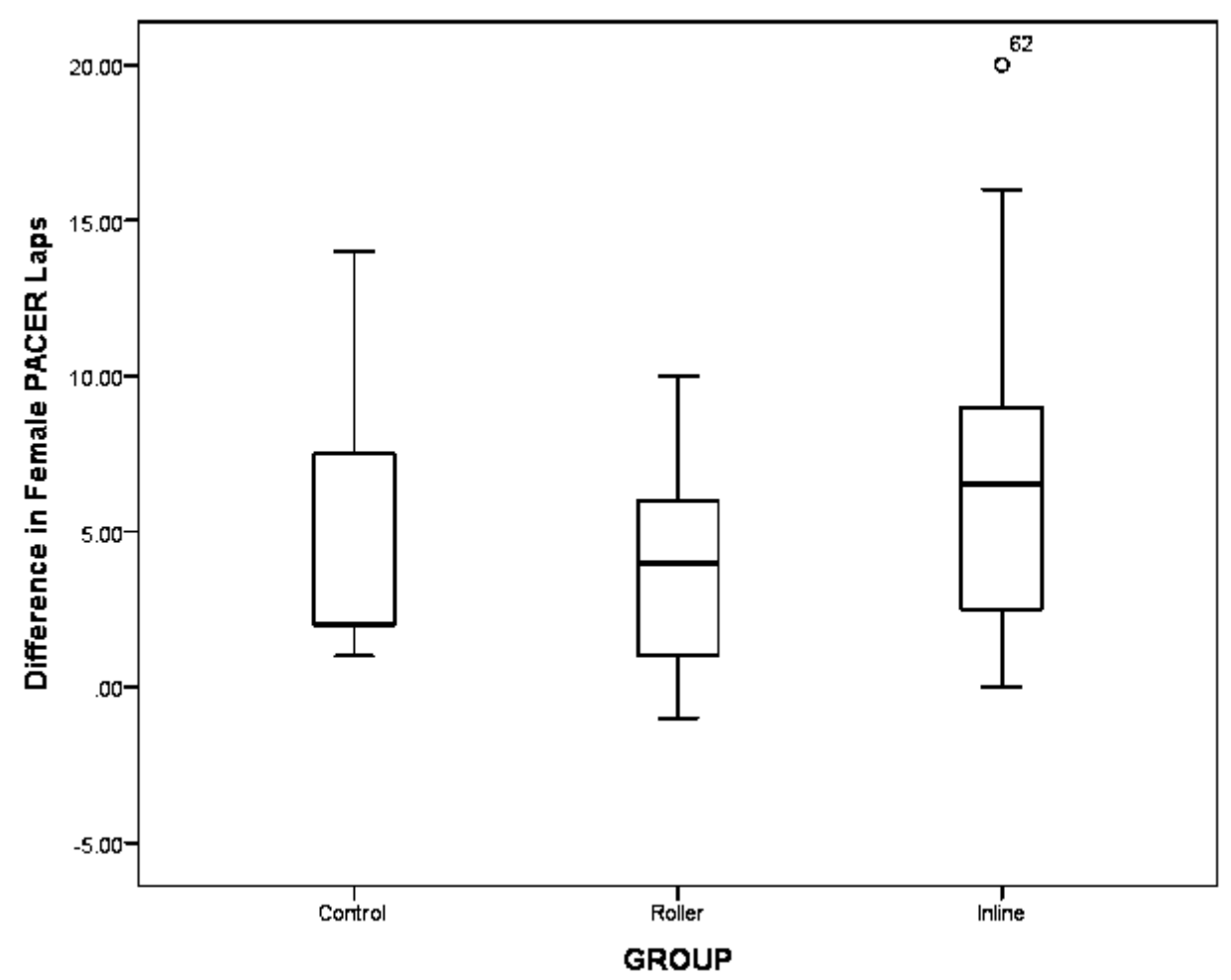

Figure 4.8. Changes in female PACER laps completed for control, roller skating, and inline skating groups.

Table 4.6

Means and Standard Deviations for Female PACER in laps completed

\begin{tabular}{lccc}
\hline Group & $n$ & $M$ & $S D$ \\
\hline Control & 11 & 5.00 & 4.92 \\
Roller Skating & 14 & 3.86 & 3.23 \\
Inline Skating & 16 & 7.06 & 5.79 \\
\hline
\end{tabular}




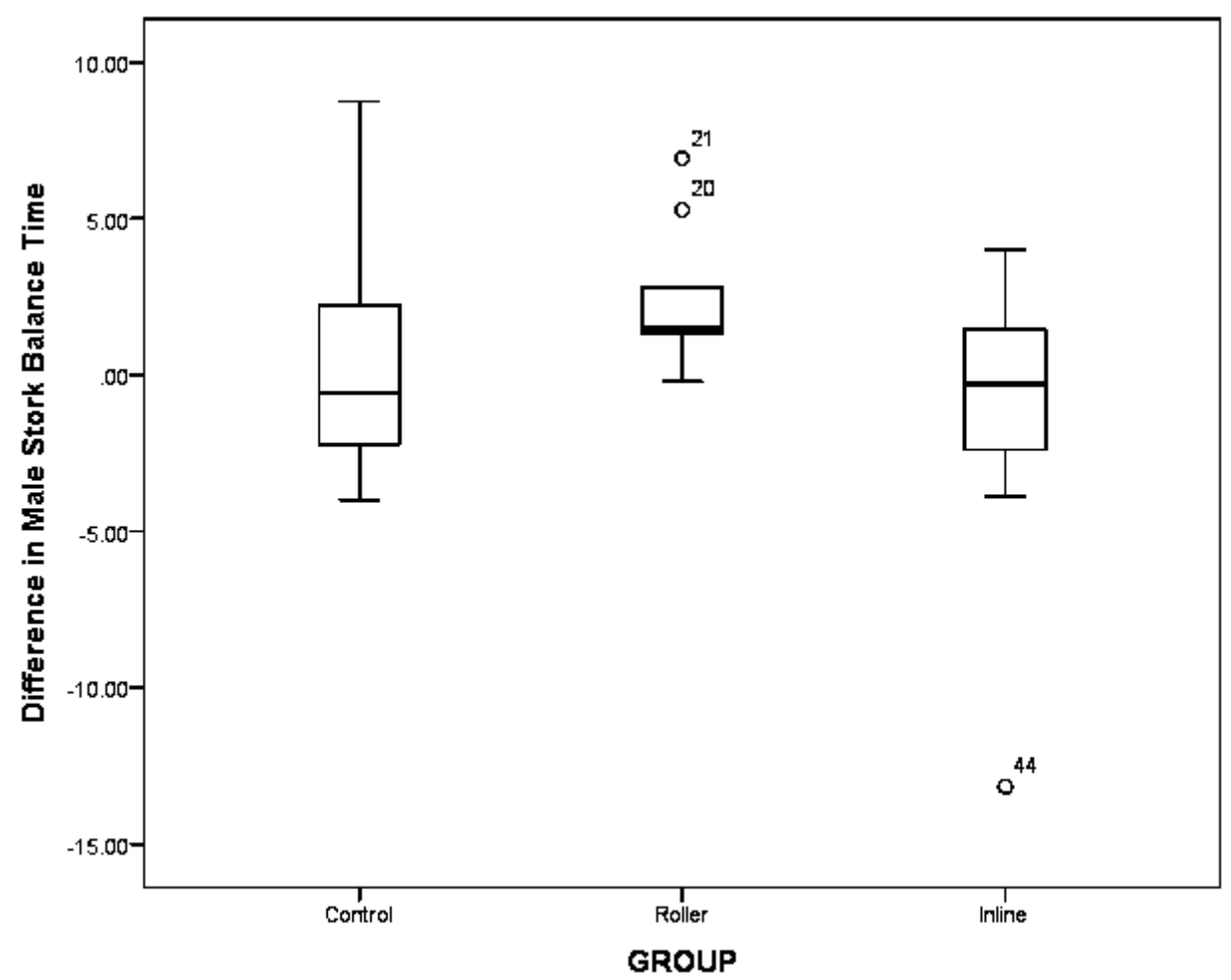

Figure 4.9. Changes in male Stork balance time for control, roller skating, and inline skating groups.

Table 4.7

Means and Standard Deviations for Male Modified Stork Standing Balance Test in seconds

\begin{tabular}{llcc}
\hline Group & $n$ & $M$ & $S D$ \\
\hline Control & 7 & 0.60 & 4.55 \\
Roller Skating & 9 & 2.46 & 2.31 \\
Inline Skating & 9 & -1.34 & 5.03 \\
\hline
\end{tabular}




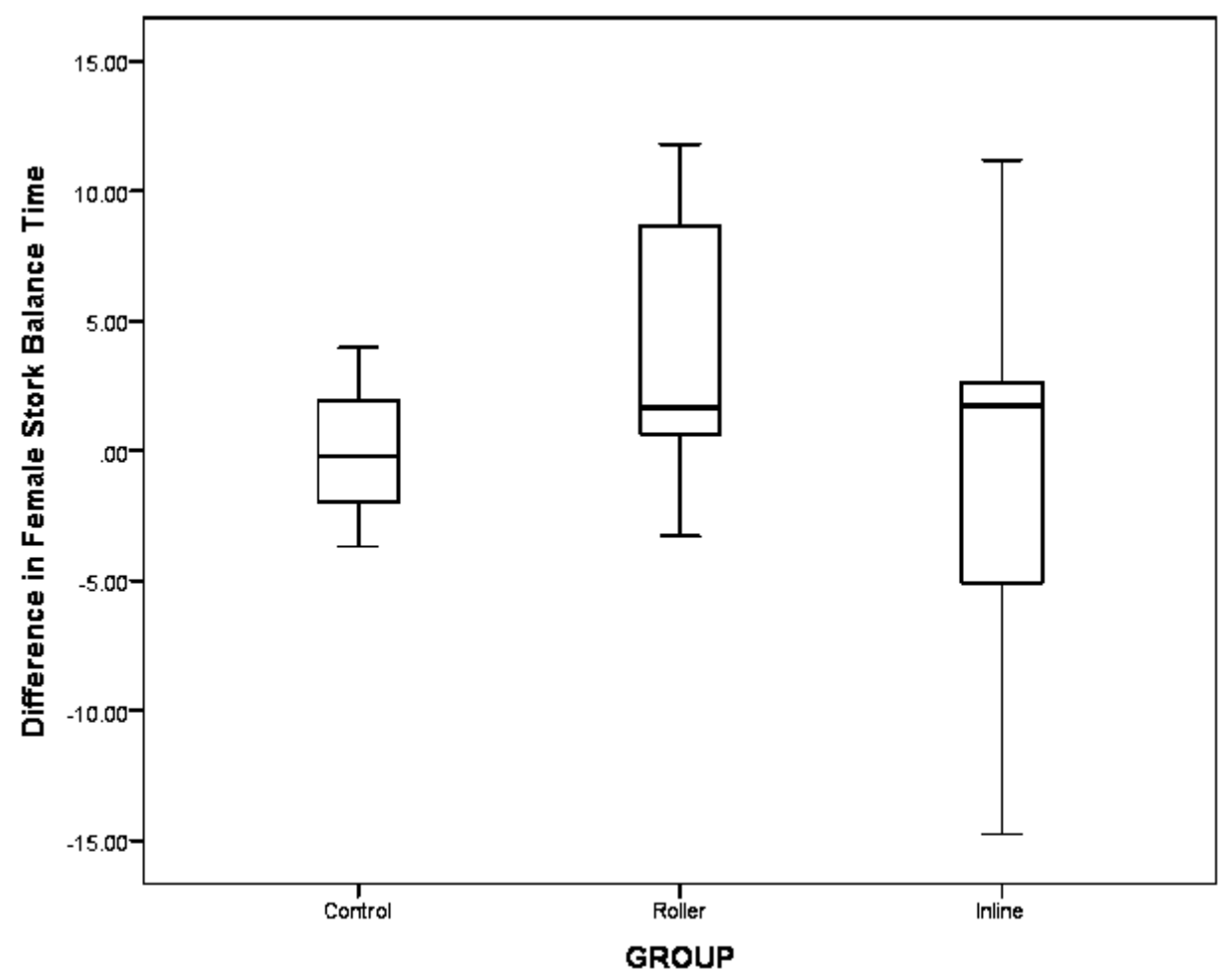

Figure 4.10. Changes in female Stork balance time for control, roller skating, and inline skating groups.

Table 4.8

Means and Standard Deviations for Female Modified Stork Standing Balance Test in seconds

\begin{tabular}{lccc}
\hline Group & $n$ & $M$ & $S D$ \\
\hline Control & 10 & 0.07 & 2.53 \\
Roller Skating & 13 & 4.33 & 4.97 \\
Inline Skating & 11 & -0.69 & 7.60
\end{tabular}




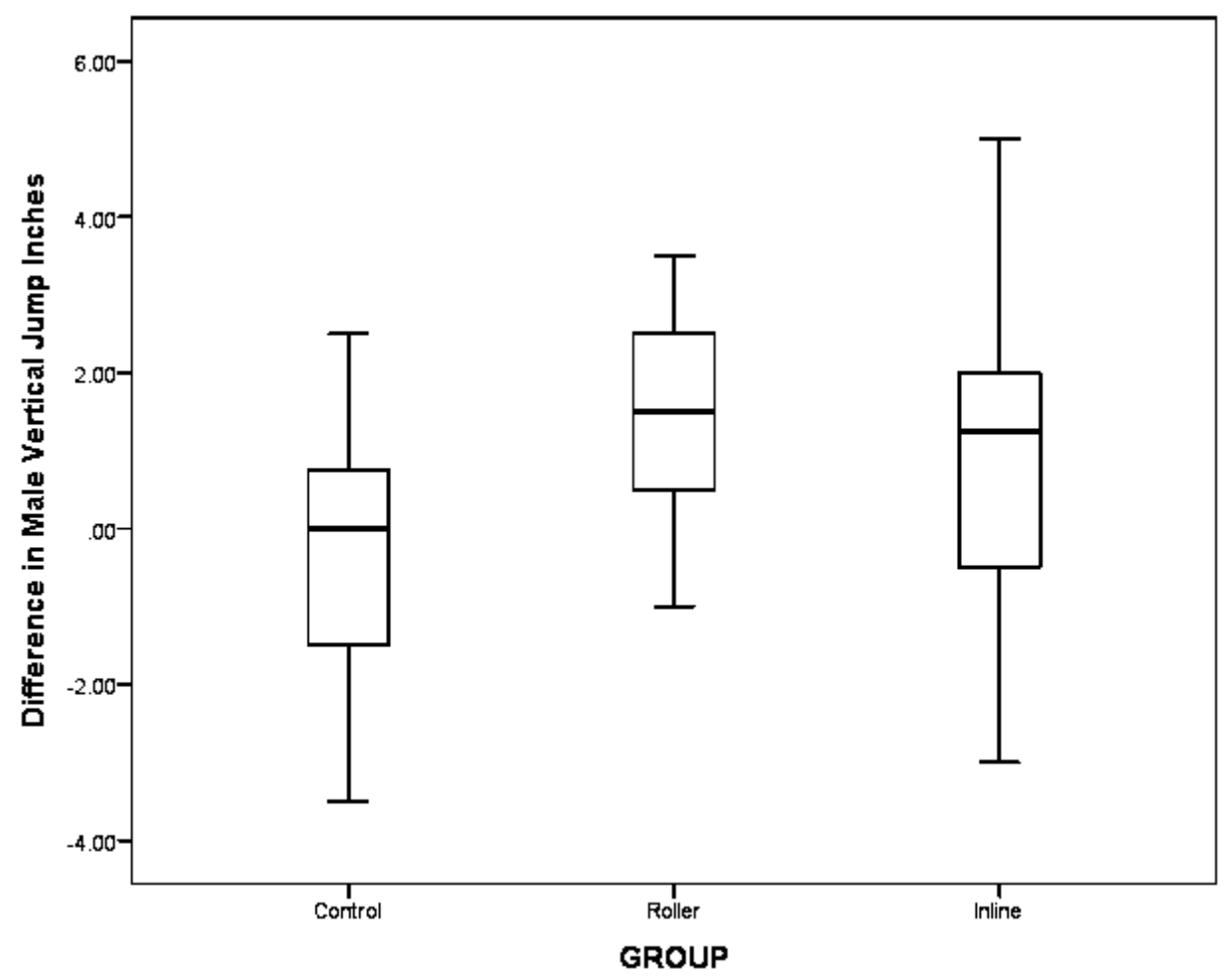

Figure 4.11. Changes in male vertical jump for control, roller skating, and inline skating groups.

Table 4.9

Means and Standard Deviations for Male Vertical Jump in inches

\begin{tabular}{lccc}
\hline Group & $n$ & $M$ & $S D$ \\
\hline Control & 8 & -0.31 & 1.85 \\
Roller Skating & 10 & 1.50 & 1.41 \\
Inline Skating & 10 & 0.90 & 2.37 \\
\hline
\end{tabular}




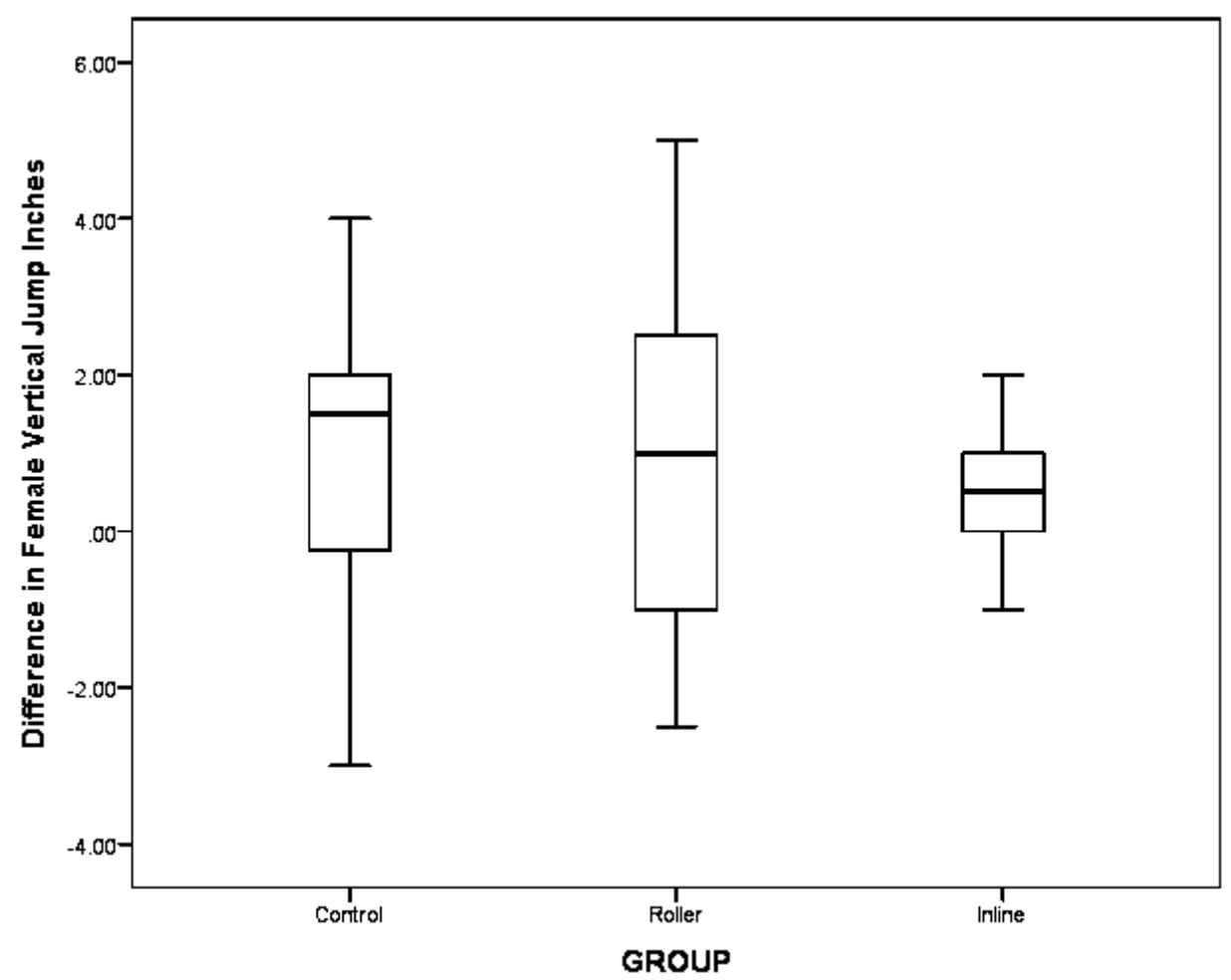

Figure 4.12. Changes in female vertical jump inches for control, roller skating, and inline skating groups.

Table 4.10

Means and Standard Deviations for Female Vertical Jump in inches

\begin{tabular}{lccc}
\hline Group & $n$ & $M$ & $S D$ \\
\hline Control & 11 & 0.91 & 1.89 \\
Roller Skating & 14 & 1.11 & 2.12 \\
Inline Skating & 13 & 0.50 & 0.98
\end{tabular}




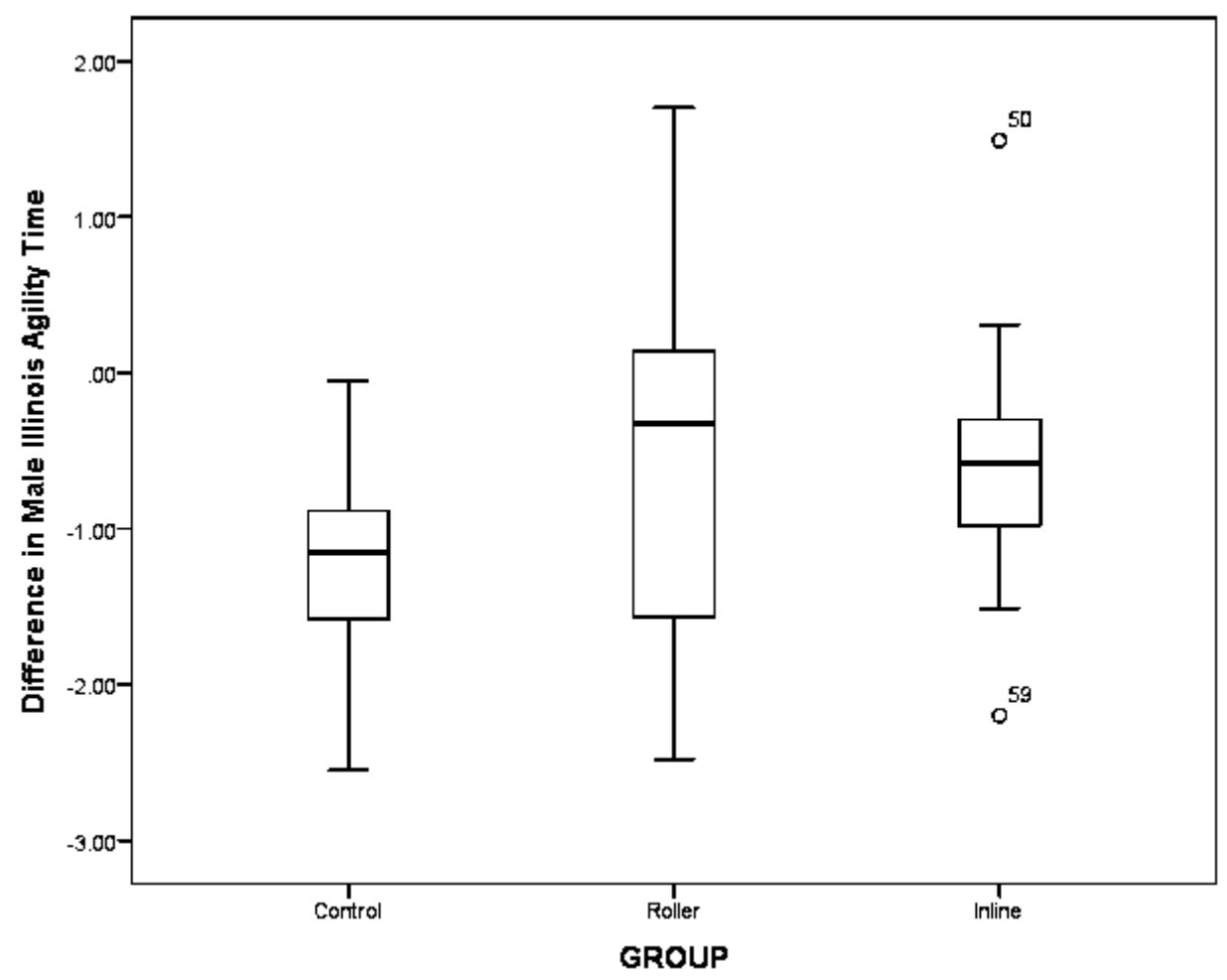

Figure 4.13. Changes in male Illinois Agility time for control, roller skating, and inline skating groups.

Table 4.11

Means and Standard Deviations for Male Illinois Agility Test in seconds

\begin{tabular}{lccc}
\hline Group & $n$ & $M$ & $S D$ \\
\hline Control & 8 & -1.23 & 0.73 \\
Roller Skating & 10 & -0.59 & 1.25 \\
Inline Skating & 9 & -0.56 & 1.05 \\
\hline
\end{tabular}




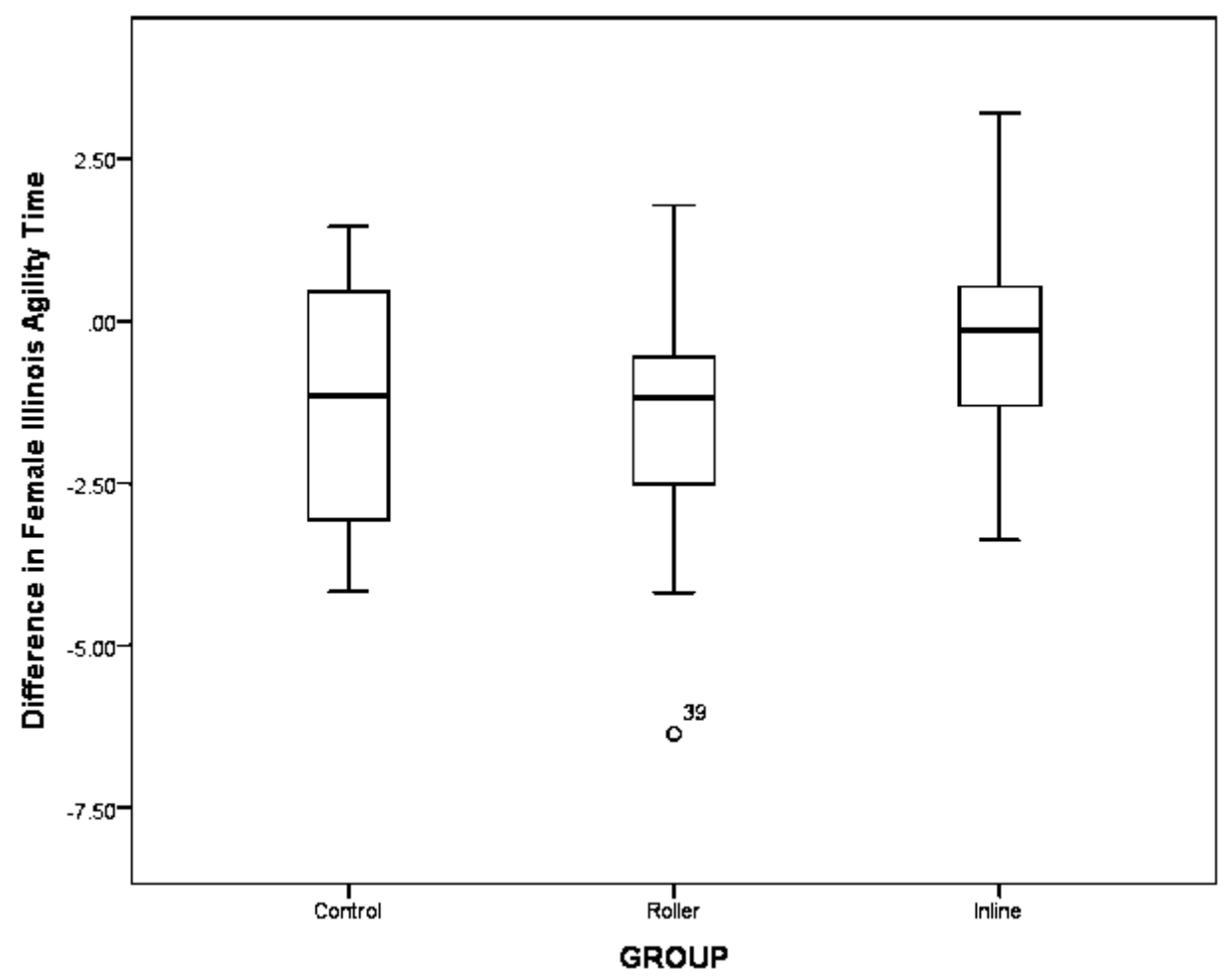

Figure 4.14. Changes in female Illinois Agility time for control, roller skating, and inline skating groups.

Table 4.12

Means and Standard Deviations for Female Illinois Agility Test in seconds

\begin{tabular}{lccc}
\hline Group & $n$ & $M$ & $S D$ \\
\hline Control & 11 & -1.31 & 2.06 \\
Roller Skating & 15 & -1.48 & 2.13 \\
Inline Skating & 13 & -0.29 & 1.96 \\
\hline
\end{tabular}




\section{CHAPTER 5}

\section{DISCUSSION}

The overarching purpose of this quantitative study was to investigate the effect of a skating unit on cardiovascular fitness, static balance, explosive power, and agility in fifth grade students in a northwestern Arkansas school district. To investigate the effects of the skating unit, four hypotheses were developed to test for significance. Those hypotheses are as follows: (1) Does the mean change in the PACER scores differ among the three experimental populations: those in the control, those who roller skate, and those who inline skate? (2) Does the mean change in the static balance scores differ among the three experimental populations: those in the control, those who roller skate, and those who inline skate? (3) Does the mean change in the vertical jump scores differ among the three experimental populations: those in the control, those who roller skate, and those who inline skate? (4) Does the mean change in the agility scores differ among the three experimental populations: those in the control, those who roller skate, and those who inline skate?

\section{Discussion}

To date, research on the effects of a skating unit in children is limited. An extensive review of the literature produced only one comparable study by Muehlbauer et al. (2013). However, while they found significance between their control group and inline skating experimental sample population, but they only investigated the impacts of a skating unit on children in balance and explosive power. This study is unique in that not only did it investigate the relationship between balance and explosive power, it further explored the factors of 
cardiovascular fitness and agility. As a result the factors of cardiovascular fitness and agility are unique and will be compared to other studies similar in nature like ice skating.

Students were invited to participate in this study during their normally scheduled class time with the intervention duration over a 6-week period (2x weekly, 12 lessons). The class schedule was as follows: control group met on Tuesdays and Fridays and the two experimental groups, roller skating on Mondays and Thursdays and the inline skating on Wednesdays and Fridays. During the intervention period, the control group (Table 3.2) participated in activities that the teacher normally schedules from year to year. The goal of this study, related to the control group, was to allow the teacher to not have to deviate from what was already scheduled for the students during the intervention. With the control group following their regularly scheduled curriculum this ensured that the researcher did not create a bias in the results. As a result, the control group continued with their scheduled activities that included (time spent) following; the completion of a softball unit (3 lessons, 25\%), dance unit (5 lessons, 41.7\%), exercise stations with activities such as dancing and soccer skills (1 lesson, 8.3\%), beginning of a soccer unit (2 lessons, 16.7\%), and finally a skills station that included activities like soccer and jump roping (1 lesson, $8.3 \%$ ) during the six week intervention period.

The skating groups followed a specifically designed curriculum. Prior to that design, an extensive review of literature was conducted to see if a curriculum already existed that could be utilized for this study. The review produced limited evidence of skating curriculums designed specifically for schools which leaves physical education teachers in a positon to have to develop their own curriculum. However, the search did produce two resources, Skatetime and Skate in School that provides a curriculum for skating as well as supplemental enrichment activities. As 
such, the curriculum designed for this study was an adaptation, with permission, from Skatetime and Skate in School (Appendix H and Appendix I). The creation of a single curriculum was used since roller skating and inline skating share many of the same commonalities (i.e. stride and crossover turns) and by having a single curriculum for both, ensured that their schedules would be consistent as participants progressed over the 6-week intervention. The curriculum was designed with course objectives that follow SHAPE's National Standards (2013), a vocabulary list, assessment example(s), teaching strategies, and an activity that consisted of a warm-up and cooldown. In addition, depending on the pace of the course, the teacher had a list of enrichment activities/games to use at their discretion to ensure a full days' worth of activity during each lesson.

Cardiovascular fitness. While the finding reported to be non-significant for cardiovascular fitness, further investigation of the results found that the two skating groups demonstrated an improvement in their PACER scores illustrated by the means of the pretest and posttest scores. A review of literature was conducted to find comparable research on a skating unit's effect on cardiovascular fitness. While the review produced no comparable research related to child populations, the review did produce several studies on the effects of skating on adult's cardiovascular fitness. While adults and children are not comparable physiologically, the studies conducted on adults demonstrated that skating could induce significance in those adult populations tested. The most recent study by Orepic et al. (2013) concluded that inline skating could induce physiological changes improving the cardiovascular fitness in healthy adults. Additionally, studies conducted in the 1990's concluded that skating induced significant changes in cardiovascular fitness in adult populations ( Melanson, Freedson, and Jungbluth, 1996; Melanson, Freedson, Webb, Jungbluth, and Kozlowski, 1996; Wallick et al., 1995). 
The curriculum incorporated the research on cardiovascular fitness to allow for improvements. Participants in the skating groups were able to meet a portion of their daily requirement of 60 minutes of moderate to vigorous activity (SHAPE, 2014, 2016; AHA, 2014) during physical education class. This is attributed to several activities during the intervention like a long and continuous skating session to music, the change of pace (slow, medium, and fast) intermittently during activities, introduction of exercise stations, interval training based on laps or time, relay races, and prolonged continuous pace at various intensities. Additionally, the use of perceived breathing and the use heart rate (HR) monitors could be incorporated by physical education teachers to demonstrate the physiological demands of the heart to skate at various intensities or to target an intensity for a given period of time.

While this study found that a skating unit did not induce significance in cardiovascular fitness, the comparable studies on adults contradict the finding of this research. Additionally, since the means of the PACER scores (posttest minus pretest) were found to improve cardiovascular fitness, further investigation into the control groups activities was warranted to potentially explain why not significant. A review of the literature into soccer might have explained the non-significance. The distance a soccer player runs during a soccer game places physiological demands on the body. Research indicates that soccer does indeed have a significant effect on physiological health markers, like blood pressure and body composition, in children (Ørntoft et al., 2016), adolescents (Vasconcellos et al., 2016;2015), and men (Milanović, Pantelić, Kostić, Trajković, \& Sporiš, 2015; Milanovic, Pantelic, Sporis, Mohr, \& Krustrup, 2015). The current research into soccer suggests that the control groups' cardiovascular fitness might have been influenced by participating in this activity during the intervention period, thus contributing to the non-significance of the hypothesis. 
Static Balance. The results suggest that those who participate in roller skating showed significance compared to those who inline skate. Since there is no research to compare these findings, these unique results suggest that roller skating is a better activity to improve static balance than inline skating. There are a few speculative theories as to why this phenomenon may have occurred. First, the finding suggests that differences in the material used in the construction of the skate, leather for the roller skates and molded plastic for inline skates may have influenced the ankle strength needed to maintain balance when using the leather booted roller skates. The leather boot is more pliable and which may require the ankle to "work harder" to maintain balance. Another theory is that there may be an increase in the frictional force required to roller skate then compared to inline skating where an increase in frictional forces require participants to work "harder" thus increasing ones lower body strength (McGinnis, 2013). The increase in friction could be attributed to two factors; the design of the skate and wheels in contact with the surface. The design of the roller skate places the wheels in a side by side (two in front and two in back) where the roller blade place the wheels in an inline pattern. This design may require participants to lift their legs higher so the wheels to not coming into contact during the recovery phase in the gait while skating. This could place an increased work load on the weight bearing leg thus increasing proprioception and strength to maintain balance in the biomechanics between roller skating and inline skating. Additionally, the differences in wheel size may be a factor related to friction. Inline skate wheels are taller and thinner compared to the smaller and wider roller skate wheel. These two design differences could have an influencing factor on the potential for an increase in friction. However, to date, there is no research to back these theories and future research would need to conducted to investigate as to why roller skating was found to be significant compared to inline skating. Finally, one last 
reason as to why the roller skating group was found to be significant compared to the inline skating group could be attributed to the athletic prowess of the inline skating group which meant that the inline skating group "hit the ceiling" on the posttest scores. This could be one explanation as to why Standing Stork time decreased on the posttests.

While no studies were found in the review of literature related to roller skating, a comparable study by Muehlbauer et al. (2013) concluded that inline skating did induce a significance in a child's balance when measured with the Star Excursion Balance Test (measures both static and dynamic balance) when compared to a non-skating control group. However, since a review of literature was limited in scope for roller and inline skating, a broadened search to include ice skating revealed that children who participated in various ice skating programs (Fragala-Pinkham et al., 2009; Keller et al., 2014; Walsh \&Scharf , 2014) were found to induce a significant improvement in balance. Additionally, Lamoth and Heuvelen, (2012) concluded that ice skating improved postural control in the elderly reducing the risk of falls. While ice skating was not one of the treatment groups for this study, the similarities that are shared with roller skating, inline skating and research demonstrates that skating in various populations can induce improvement in balance for those who participate in these activities. Additionally, research has demonstrated that those who participate in activities that improve balance could indirectly influence other factors like explosive power and agility (Granacher, et al. 2010; Hrysomallis, 2011; Yaggie \& Campbell, 2006).

The intervention of a skating unit allowed for participants to improve their balance. The findings by Muehlbauer et al. (2013) suggest that skating improves postural control. Activities that introduce standing on two legs to more advanced maneuvers that incorporate weight transfer 
from one leg to the other (like starts and stops, gliding, striding, twisting and turning on one or two legs) foster balance. While balance was not reported statistically in this study, the teacher stated several participants at the beginning of the unit who needed assistance (carpet pads, use of the wall, partners, or ball cages with wheels) finding a sense of balance where observed at the end of the intervention period no longer needed assistance. Furthermore, students were required to push their balance comfort zones by participating in activities like the obstacle course and slalom by weaving in and out of cones or other barriers. Additionally, activities like Limbo and Shoot the Duck required students to change their center of gravity and/or balance on one leg for a given period of time. All of these biomechanical changes, like the turning, twisting, and spinning actions in skating places a high demand on the vestibular organs. Through the use of proprioception of joints and muscle groups, proper foot placement is needed to maintain balance. Additionally, the change in the center of gravity during tag game activities (Noodle Tag, Sideby-Side Tag, \& High-5 Tag) reinforced the development of balance in participants when having to duck, dodge, jump to avoid being tagged or trying to tag other participants.

Finally, a further investigation was conducted into the impacts of the control group's activities during the intervention to determine if the activities of soccer and dance could explain why the control groups means in balance improved during the study as compared to the roller skating and inline skating groups. In soccer, it is not uncommon for soccer players to find the need to balance on one and two legs while jumping or in the change of direction. Research into the effects of postural control in soccer players suggests that participates could induce an improvement in balance (Barone, 2010; Biec \& Kuczyski, 2010; Jakobsen, Sundstrup, Krustrup, \& Aagaard, 2011) while playing in soccer activities. Those who participate in dance activities incorporate many different types of foot positions from standing with both feet closely together 
to the extreme of standing on the toes with one leg. Research conducted on children (Aldemir, Ramazanoglu, Camliguney, \& Kaya, 2011; Srhoj, 2002) and special populations (Cerebral Palsy and elderly) (López-Ortiz, Egan, \& Gaebler-Spira, 2016; Mavrovouniotis et al., 2013; Shigematsu, 2002; Stribling, K., \& Christy, 2017) illustrate that dance can induce an improvement in balance. Since the control group spent a combined eight out of twelve $(66.7 \%)$ lessons during the intervention participating in soccer and dance suggests that their mean differences were influenced by these activities which may have been an influencer in the nonsignificant results for the skating unit.

Explosive power. Explosive power was reported as non-significant in the three populations. However, a comparable study by Muehlbauer et al. (2013) contradicts these findings. Muehlbauer et al. (2013) concluded that explosive power, measured electronically, induced significance in children who participated in an inline skating unit. Additionally, the different types devices used to measure vertical jump could also explain the differences in the findings for this study. Since the findings of research were limited for roller and inline skating, the findings of studies conducting for ice skating found an increase in leg strength (Lamoth \& van Heuvelen 2012; Walsh \& Scharf 2014) that suggests a skating unit could increase a participant's vertical jump. Additionally, further examination of the mean scores (posttest minus pretest) in this study reported an increase (positive), suggesting that in vertical jump inches increased (see Table 4.3), while not significant, suggests that skating could explosive power. The research parallels the physical education teacher's observations during the skating unit. In the beginning of the skating unit, students pointed out how muscles in their lower body were sore suggesting participants could have an under development in muscular strength or are sore from the muscle demands of skating. This is attributed to the engagement of core muscles in the 
abdomen and legs that are engaged to not only maintain balance, but are also utilized to start movement (forward or backwards) requiring the recruitment of muscle fiber (slow and fast twitch) to maintain or increase pace. The posture of skating is unlike walking where the legs are bent to not only lower one's center of gravity to maintain balance, but allow for a greater amount of biomechanical force to create motion of the roller or inline skate. This position requires a greater demand physically on the muscles of the legs and abdomen thus increasing the potential of an increase in one's strength. Activities like Red Light Green Light and the change in directions required to perform the slalom and obstacle courses place a high demand on strength in the lower body. Additionally, literature suggests that those who incorporate balance training have demonstrated to have an increase in one's explosive power (Granacher, et al. 2010) and skating places a higher degree of balance innately.

Further investigation into the mean differences of the control was warranted to determine if the activities of the control group influenced the non-significant results. Since soccer players must leap above opponents to head soccer balls and dancers performance jumps, twists, and pliés, illustrates the importance of explosive power for those who participate in these activities. A review of literature found that soccer (Milanovic et al., 2015) and dance (Aldemir et al., 2011; Pereira, Schettino, \& Machado, 2010; Ross \& Butterfield, 1989) in fact induced significant improvements in explosive power. The findings suggest that the control groups' explosive power may have been influenced by these activities producing the non-significant results.

Agility. While the results for agility were reported to be non-significant, the means in the Illinois Agility Run scores illustrated improvement during the intervention. This suggests that a skating unit could be a viable activity for fifth graders to increase one's agility prowess. Skating 
could place an increased demand on agility through the footwork required to perform starts, stops, and directional change similar to what is required to perform tasks that require agility. Additionally, research into balance training activities has been linked to improving agility (Yaggie \& Campbell, 2006). The skating curriculum incorporated both balance activities (Human Bowling, Limbo, and Shoot the Duck) and footwork activities (Red Light Green Light, tag games, and Slalom courses) to increase agility.

Since the mean difference for the control group also improved, further investigation into the effects of the control groups' activities during the intervention could illustrate as to why the data did not report any significance. As with the other three factors (cardiovascular fitness, balance, and explosive power), the activities of soccer and dance were investigated further to determine their influence on agility. The review of soccer's effect on agility produced no results, but a review of literature for dance did. The literature indicates that those who participate in a dance unit or some form of dance training, agility could improve (Aldemir et al., 2011; Alricsson, Harms-Ringdahl, Eriksson, \& Werner, 2003). The findings suggest that dance could have influenced the control groups' agility, thus adding to the possibility as to why a skating unit was not found to be significant.

Before generalizations are made by the researcher on the findings of this study, it is important to review the limitations discussed in Chapter 1 and provide additional observed limitations that presented during the life of this study. In Chapter 1, the researcher identified one limitation related to pretest posttest designs that require participants to perform at their "best" during the testing time periods which could negatively impact the results when a participant under performs when not feeling well or has low performing day. During the posttest evaluation 
it was observed by the researcher and evaluation team and confirmed by the teacher observed that the students did not perform at their best that day which negatively impacted the students' scores on the Standing Stork Balance, vertical jump, and the Illinois Agility run tests.

Additionally, during the intervention of the study, three other limitations were observed. The first had to do with the gym floor surface friction. It was observed by the researcher and evaluation team that surface friction on the gym floor decreased during the semester causing students to slip and slide more frequently on the posttest evaluations than compared to the pretest. While the participants' did show an overall improvement on the agility run, those results may not have represented their full potential because of the adjustments required to maintain balance as the participants weaved in and out of the cones on the gym floor. A second limitation observed was that this study was incorporated during a typical school day which required modifications to be made to the pre and posttest environment and physical education schedule. During the pretest evaluations, the last Friday of that week was a holiday for students. As a result, that Friday session was moved to the Friday before the holiday. Additionally, during the intervention period of the study, the students from the control and inline groups had to make up a lesson due to a scheduled holiday. The lesson time was made up during the students recess time (over a two day period) to maintain consistency in the total amount of time between all three groups during the skating unit. The final limitation identified was the size of the gym the participants skated in. The researcher and physical education teacher (expressed in the exit questionnaire) discussed that space could be problematic and may negatively impact the four fitness factors being evaluated in this study. The space limited the participants' the freedom to "push their physical boundaries'." While skating outdoors would have given the students the 
space needed, the wheels on the skates were not designed for outdoor usage forcing students to adapt to the indoor environment.

\section{Conclusions}

The purpose of this study was to determine the effects of a skating unit in fifth grade students. Overall, the data suggests that only static balance would benefit a participant who roller skated compared to someone who inline skated. The finding suggests that the biomechanics required to roller skate is inheritably different compared to an inline skater as it relates weight transfer to maintain an upright position while skating. Additionally, a potential increase in friction could influence strength and proprioception that could contribute to an increase in balance. Lastly, the material used to build the skate could have influenced balance. However, at this time, there is a lack of evidence in the literature to confirm this and future research would need to be conducted to investigate this phenomenon. Additionally, the data suggests that statistically, a skating unit would not induce improvements in a participant's cardiovascular fitness, explosive power, and agility.

While the data suggests that a skating unit would not benefit a participant's cardiovascular fitness, explosive power, and agility, there is evidence to contradict the statistical findings. First, in investigating the means in the testing scores (posttest minus pretest), there is clearly an indication that improvements were taking place in the roller and inline skating groups PACER ends run, vertical inches jumped, agility time, and in balance with the control and roller skating groups. While these factors were found to be non-significant, it suggests that these fitness factors can be positively influenced during a skating unit. Furthermore, studies concluded that activities that require balance (Hrysomallis, 2011), like skating, can indirectly impact other factors such as agility and the vertical jump. Additionally, studies by Granacher et al. (2010) and 
Yaggie and Campbell (2006) reported similar results that training in one factor (i.e. balance) could impact that of another (i.e. explosive power and agility). Secondly, the control group activities during the intervention period need to be taken into account. A review of the literature on both dance and soccer suggests that those activities can induce significant improvement in a participants' fitness to suggest as to why the skating findings reported non-significance. Thirdly, the opinions made from the physical education teacher on the Teacher Exit Questionnaire where she stated the kids "loved it" and that she observed balance and strength, discussed with her students, did improve from the beginning of the curriculum to the end. All of these points, taken in their totality illustrate that a skating unit is not only a fun activity, but could improve cardiovascular fitness, balance, explosive power, and agility in participants. Finally, during the exploratory analysis, male explosive power and male and female balance, as indicated by $\eta 2$, suggests that if the study had either a larger sample size and/or continued beyond the 6-week intervention, the analysis could illustrate significance.

\section{Implications and Recommendations}

The implications and recommendations that presented themselves from this skate study are discussed in the follows sections: implications for practice, implications for theory, and recommendations for future research.

Implications for practice. With no conclusive proof that a skating unit induces significant change in the fitness of fifth grade students, except for balance between those who roller skated compared to inline skated, there are no direct implications for practice with the utilization of a skating unit in schools. While the direct implications were not present by the statistical analysis, there is much indirect evidence of the benefit of a skating unit. First, was a 
review of the mean (posttest minus pretest) that suggests improvements occurred the four factors in skating unit. Finally, were the opinions expressed (see Teacher Exist Questionnaire) by the physical education teacher on the questionnaire (Question 1-3, 6, and other comments section) where they (teacher and students) discussed how much they enjoyed the activity, the desire to want to continue with the unit, and opportunities the activity provided beyond the classroom with students. Taking these two points in their totality, suggests that a skating unit could be a viable activity for professionals to consider implementing into their classrooms.

Implications for theory. Improving the health and wellbeing of our students is one of the largest initiatives by physical education teachers and health professionals and organizations like the AHA (2014) and SHAPE America. The report by Global Burden of Disease (GBD) 2015 Obesity Collaborators (2017) points out the drastic rise in obesity (over 33\%) and the significant cost of health care related to obesity (Finkelstein et al., 2009; Kim \& Basu, 2016). There becomes a need for schools to not only incorporate classroom activities to reduce the obesity epidemic in our youth, but to teach lifetime skills that last long beyond childhood (Skatetime, 2018). Previous studies demonstrate how skating benefits students (Melanson, Freedson, and Jungbluth, 1996; Melanson, Freedson, Webb, Jungbluth, and Kozlowski, 1996; Orepic et al., 2013; Wallick et al., 1995) and by schools incorporating a skating unit, could provide students the tools needed to help curb the obesity epidemic.

Recommendations for future research. It is recommended that future studies be conducted to investigate potential biomechanical differences and the influence of friction on participants between roller skating and inline skating as well as investigate the length of a class session to see how it impacts the cardiovascular fitness, balance, explosive power, and agility in 
fifth grade students. First, since this study found there to be a significance between roller skating and inline skating, the biomechanical differences and potential influence of friction would need to be explored since, at this time, there appears to be a lack of research into these phenomenon. Finally, the results from this study indicate that a class that only meets two times weekly for a length of 45 minutes did not produce the overall significant results desired when compared to a study by Muehlbauer et al. (2013). The total length of time for this study was 540 minutes (12 lessons multiplied by 45 minutes); while a comparable study concluded that their participants who skated for 720 minutes ( 8 lessons multiplied by 90 minutes) induced significant results (Muehlbauer, et al., 2013). Future research needs to investigate what would be an "ideal" length of time for students to demonstrate significant improvements in the four factors evaluated in this study. The study would be to evaluate the time length of a skating session at 15 minute increments starting with the first time point at 45 minutes in duration and ending at 90 minute over a given 4 week period to see where the significant and non-significant cross emerges.

\section{Summary}

In summary, the purpose of this study was to investigate the effect of a skating unit on fitness in fifth graders. To review, this study examined the factors of cardiovascular fitness, balance, explosive power, and agility in three sample populations that consisted of a control group and two experimental groups who participated in roller skating and inline skating activities. While the data only supported the findings that those who participated in a roller skating activity compared to a inline skating activity to be statistically significant in improving static balance, the findings do suggest that skating, in any form, could improve the fitness of those who participant in such an activity. This study illustrates that non-traditional activities, 
like skating, could be an effective teaching tools utilized by physical education teachers.

Physical education teachers need to start to consider:

Moving beyond the ball sport into lifelong leisure pursuits, venturing beyond the brick and mortar of a school's physical plant into nature, and offering youth opportunities for exploration, wonder, questioning, problem solving, decision making, and team building can do much more for the whole child than sport skill instruction of physical conditioning alone. (Schwab \& Dustin, 2014, p. 31) 


\section{REFERENCES}

Aldemir, G., Ramazanoglu, N., Camliguney, A., \& Kaya, F. (2011). The effects of dance education on motor performance of children. Educational Research and Reviews, 16(19), 979-982.

Alricsson, M., Harms-Ringdahl, K., Eriksson, K., \& Werner, S. (2003). The effect of dance training on joint mobility, muscle flexibility, speed and agility in young cross-country skiers - a prospective controlled intervention study. Scandinavian Journal Of Medicine \& Science In Sports, 13(4), 237-243.

American Heart Association. (2014). American Heart Association Recommendations for Physical Activity in Adults. Retrieved from http://www.heart.org/HEARTORG/HealthyLiving/PhysicalActivity/FitnessBasics/Ameri can-Heart-Association-Recommendations-for-Physical-Activity-inAdults_UCM_307976_Article.jsp\#.WUAvb9y1vIV

American Heart Association. (2016). American Heart Association Recommendations for Physical Activity in Children. Retrieved from http://www.heart.org/HEARTORG/HealthyLiving/HealthyKids/ActivitiesforKids/TheAHAs-Recommendations-for-Physical-Activity-inChildren_UCM_304053_Article.jsp\#.WUCGEty1vIW

American Heart Association. (2017). Our Mission. Retrieved from http://www.heart.org/HEARTORG/General/About-Us---American-HeartAssociation_UCM_305422_SubHomePage.jsp

Barone, R. (2010). Soccer players have a better standing balance in nondominant one-legged stance. Open Access Journal of Sports Medicine, 2011, 1-6. 10.2147/OAJSM.S12593

Bicycle Coalition of the Ozarks (n.d.). Bike ED Curriculum Grade Levels 3-5 . Retrieved from: https://arkansashighways.com/Trans_Plan_Policy/bikeped/files/BICYCLE\%20CURRIC ULUM.pdf

Biec, E., \& Kuczyski, M. (2010). Postural control in 13-year-old soccer players. European Journal of Applied Physiology, 110(4), 703-8. http://dx.doi.org/10.1007/s00421-010$1551-2$

Bravo, M. M., Cummins, K. M., Nessler, J. A., \& Newcomer, S. C. (2016). Heart rate responses of high school students participating in surfing physical education. Journal of Strength and Conditioning Research, 30(6), 1721-1726. doi:10.1519/JSC.0000000000001263

Brokaw, I., d. 1939. (1910). The art of skating, its history and development, with practical directions. United States 
Burgeson, C. (2004). Physical education's critical role in educating the whole child \& reducing childhood obesity. Retrieved from

http://www.shapeamerica.org/publications/resources/teachingtools/qualitype/loader.cfm? csModule=security/getfile $\&$ pageid $=5330$

Burns, R. D., Hannon, J. C., Allen, B. M., \& Brusseau, T. A. (2014). Convergent validity of the one-mile run and PACER VO2MAX prediction models in middle school students. SAGE Open, 4(1) doi:10.1177/2158244014525420

Castellano, J., Puente, A., Echeazarra, I., Usabiaga, O., \& Casamichana, D. (2016). Number of players and relative pitch area per player: Comparing their influence on heart rate and physical demands in under-12 and under-13 football players. PLoS One, 11(1)http://dx.doi.org/10.1371/journal.pone.0127505

Chaouachi, A., Othman, A., Hammami, R., Drinkwater, E., \& Behm, D. (2014). The combination of plyometric and balance training improves sprint and shuttle run performances more often than plyometric-Only training with children. Journal of Strength and Conditioning Research, 28(2), 401-401.

Cheah, P., Cheong, J., Razman, R., Zainal Abidin, N., \& 3rd International Conference on Movement Health and Exercise, MoHE 2016 3rd International Conference on Movement, Health and Exercise, MoHE 2016 3rd 20160928 - 201609 30. (2017). Comparison of vertical jump height using the force platform and the vertec. Ifmbe Proceedings, 58, 155158. doi:10.1007/978-981-10-3737-5_33

Chu, D. (1998). Jumping into plyometrics (2nd ed.). Champaign, IL: Human Kinetics.

Cureton, K., Plowman, S., \& Mahar, M. (2013). Aerobic Capacity Assessment. In S. A. Plowman \& M.D. Meredith (Eds.), Fitnessgram/Activitygram Reference Guide (4th Edition) (pp. Internet Resource). Dallas, TX: The Cooper Institute, 6-1 - 6-22.

Dawes, J., Roozen, M., \& National Strength \& Conditioning Association (U.S.). (2012). Developing agility and quickness (Sport performance series). Champaign, IL: Human Kinetics.

Farlinger, C. M., Kruisselbrink, L. D., \& Fowles, J. R. (2007). Relationships to skating performance in competitive hockey players: 1. Journal of Strength and Conditioning Research, 21(3), 915.

Finkelstein, E., Trogdon, J., Cohen, J., \& Dietz, W. (2009). Annual medical spending attributable to obesity: Payer-And service-Specific estimates. Health Affairs, $28(5), 831$.

Formenti, F., \& Minetti, A. (2007). Human locomotion on ice: The evolution of ice-skating energetics through history. The Journal of Experimental Biology, 210, 1825-33. 
Forseth, A., \& Sigmundsson, H. (2003). Static balance in children with hand-eye co-ordination problems. Child: Care, Health and Development, 29(6), 569-579. doi:10.1046/j.13652214.2003.00378.x

Fragala-Pinkham, M. A., Dumas, H. M., Boyce, M., Peters, C. Y., \& Haley, S. M. (2009). Evaluation of an adaptive ice skating programme for children with disabilities. Developmental Neurorehabilitation, 12(4), 215-223. doi:10.1080/17518420902980100

Franklin, B. (2016). Cardiopulmonary Exercise Testing: Adjunctive and Practical Applications. American Heart Association. Retrieved from http://professional.heart.org/professional/ScienceNews/UCM_485725_CardiopulmonaryExercise-Testing-Adjunctive-and-Practical-Applications.jsp

Fromel, K., Kudlacek, M., Groffik, D., Svozil, Z., Simunek, A., \& Garbaciak, W. (2017). Promoting healthy lifestyle and well-Being in adolescents through outdoor physical activity. International Journal of Environmental Research and Public Health, 14(5), 533533. doi:10.3390/ijerph14050533

Global Burden of Disease (GBD) 2015 Obesity Collaborators. (2017). Health effects of overweight and obesity in 195 countries over 25 years. The New England Journal of Medicine, 2017 Jun 12. doi:10.1056/NEJMoa1614362

Geithner, C., Lee, A., \& Bracko, M. (2006). Physical and performance differences among forwards, defensemen, and goalies in elite women's ice hockey. Journal of Strength and Conditioning Research, 20(3), 500-5.

Gold, N. (2006). Rolling with the flow.(skating as physical fitness method). Sherman Oaks: Aerobics and Fitness Association of America.

Goto, H., Morris, J. G., \& Nevill, M. E. (2015). Match analysis of U9 and U10 english premier league academy soccer players using a global positioning system: Relevance for talent identification and development. Journal of Strength and Conditioning Research, 29(4), 954. Retrieved from http://libraryproxy.tulsacc.edu:2069//ogin?url=https://libraryproxy.tulsacc.edu:2781/doc view/1679730439? accountid=58

Granacher, U., Gollhofer, A., \& Kriemler, S. (2010). Effects of balance training on postural sway, leg extensor strength, and jumping height in adolescents. Research Quarterly for Exercise and Sport, 81(3), 245-251. doi:10.1080/02701367.2010.10599672

Guion, W. (2002). The reliability and validity of the pacer for $3^{\text {rd }}$ and $4^{\text {th }}$ grade males. Medicine \& Science in Sports \& Exercise, 34(5), 278. doi:10.1097/00005768-200205001-01561 
Hachana, Y., Chaabène, H., Nabli, M. A., Attia, A., Moualhi, J., Farhat, N., \& Elloumi, M. (2013). Test-retest reliability, criterion-related validity, and minimal detectable change of the illinois agility test in male team sport athletes. Journal of Strength and Conditioning Research, 27(10), 2752-2759. doi:10.1519/JSC.0b013e3182890ac3

Hammami, R., Granacher, U., Makhlouf, I., Behm, D., \& Chaouachi, A. (2016). Sequencing effects of balance and plyometric training on physical performance in youth soccer athletes. Journal of Strength and Conditioning Research, 30(12), 3278-3289.

Howard-Shaughnessy, C., \& Sluder, J. B. (2015). Roller skating and interdisciplinary physical education. Strategies, 28(4), 26-32. Retrieved from http://0search.proquest.com.library.uark.edu/docview/1698102870?accountid=8361

Hrysomallis, C. (2011). Balance ability and athletic performance. Sports Medicine, 41(3), 22132. doi:http://0-dx.doi.org.library.uark.edu/10.2165/11538560-000000000-00000

Inline Skating Resource Center (ISRC). (n.d.a). Health benefits of inline skating. Retrieved from http:// http://www.iisa.org/resources/health.htm

Inline Skating Resource Center (ISRC). (n.d.b). History of inline skating. Retrieved from http://www.iisa.org/resources/history.htm

Jakobsen, M. D., Sundstrup, E., Krustrup, P., \& Aagaard, P. (2011). The effect of recreational soccer training and running on postural balance in untrained men. European Journal of Applied Physiology, 111(3), 521-30. http://dx.doi.org/10.1007/s00421-010-1669-2

Janot, J. M., Beltz, N. M., \& Dalleck, L. D. (2015). Multiple Off-Ice Performance Variables Predict On-Ice Skating Performance in Male and Female Division III Ice Hockey Players. Journal of Sports Science \& Medicine, 14(3), 522-529.

Jones, J. (n.d.). Stats: Measures of Position. Retrieved from https://people.richland.edu/james/lecture/m170/ch03-pos.html

Keller, M., Röttger, K., \& Taube, W. (2014). Ice skating promotes postural control in children. Scandinavian Journal Of Medicine \& Science In Sports, 24(6), E456-461. doi:10.1111/sms.12230

Kim, D., \& Basu, A. (2016). Estimating the medical care costs of obesity in the united states: Systematic review, meta-Analysis, and empirical analysis. Value in Health, 19(5), 602613. doi:10.1016/j.jval.2016.02.008

Klavora, P. (2000). Vertical-jump tests: A critical review. Strength and Conditioning Journal, 22(5), 70. doi:10.1519/00126548-200010000-00020 
Kozina, Z., Repko, O., Kozin, S., Kostyrko, A., Yermakova, T., \& Goncharenko, V. (2016). Motor skills formation technique in 6 to 7-year-old children based on their psychological and physical features (rock climbing as an example). Journal of Physical Education and Sport, 16(3), 866-874. doi:http://0-dx.doi.org.library.uark.edu/10.7752/jpes.2016.03137

Lamoth CJ, \& van Heuvelen MJ. (2012). Sports activities are reflected in the local stability and regularity of body sway: older ice-skaters have better postural control than inactive elderly. Gait \& Posture, 35(3), 489-93. doi:10.1016/j.gaitpost.2011.11.014

Leard, J. S., Cirillo, M. A., Katsnelson, E., Kimiatek, D. A., Miller, T. W., Trebincevic, K., \& Garbalosa, J. C. (2007). Validity of two alternative systems for measuring vertical jump height. Journal of Strength and Conditioning Research, 21(4), 1296-1299.

doi:10.1519/00124278-200711000-00055

Léger, L. A., \& Lambert, J. (1982). A maximal multistage 20-m shuttle run test to predict VO2 max. European Journal of Applied Physiology and Occupational Physiology, 49(1), 1.

Léger, L. A., Mercier, D., Gadoury, C., \& Lambert, J. (1988). The multistage 20 metre shuttle run test for aerobic fitness. Journal of Sports Sciences, 6(2), 93.

Lirgg, C. D., Gorman, D. R., Merrie, M. D., \& Hadadi, A. M. (in press, 2018). Effect of a bicycling unit on the fitness of middle school students. The Physical Educator.

López-Ortiz, C., Egan, T., \& Gaebler-Spira, D. J. (2016). Pilot study of a targeted dance class for physical rehabilitation in children with cerebral palsy. SAGE Open Medicine, $410.1177 / 2050312116670926$

Mackenzie, B. (2000). Standing Stork Test [WWW] Available from https://www.brianmac.co.uk/storktst.htm [Accessed 17/5/2017]

Mahar, M. T., Rowe, D. A., Parker, C. R., Mahar, F. J., Dawson, D. M., \& Holt, J. E. (1997). Criterion-referenced and norm-referenced agreement between the mile Run/Walk and PACER. Measurement in Physical Education and Exercise Science, 1(4), 245-258. doi:10.1207/s15327841mpee0104_4

Mahar, M.T., Welk, G.J., Rowe, D.A., Crotts, D.J., \& McIver, K.L. (2006). Development and validation of a regression model to estimate VO2peak from PACER 20-m shuttle run performance. Journal of Physical Activity and Health, VOL 3; SUPP/2, pages S34-S46

Mark, S. C., Jensen, T., Voigt, C. B., Nielsen, J. B., \& Lorentzen, J. (2017). To be active through indoor-climbing: An exploratory feasibility study in a group of children with cerebral palsy and typically developing children. BMC Neurology, 17 doi:http://0dx.doi.org.library.uark.edu/10.1186/s12883-017-0889-z 
Markovic, G., Dizdar, D., Jukic, I., \& Cardinale, M. (2004). Reliability and factorial validity of squat and countermovement jump tests. Journal of Strength and Conditioning Research, 18(3), 551-5.

Mavrovouniotis, F. I., Papaioannou, C. S., Argiriadou, E. A., Mountakis, C. M., Konstantinakos, P. D., Pikoula, I. T., \& Mavrovounioti, C. F. (2013). The effect of a combined training program with greek dances and pilates on the balance of blind children. Journal of Physical Education and Sport, 13(1), 91-100. Retrieved from http://0search.proquest.com.library.uark.edu/docview/1438042331 ?accountid=8361

McGinnis, P. (2013). Biomechanics of sport and exercise (3rd ed. ed.). Champaign, IL: Human Kinetics.

McManama, J. (2014). Physical education activity handbook (13 ${ }^{\text {th }}$ ed.). Boston: Pearson.

Melanson, E. L., Freedson, P. S., \& Jungbluth, S. (1996). Changes in VO2max and maximal treadmill time after $9 \mathrm{wk}$ of running or inline skate training. Medicine and Science in Sports and Exercise, 28(11), 1422-1426. doi:10.1097/00005768-199611000-00012

Melanson, E. L., Freedson, P. S., Webb, R., Jungbluth, S., \& Kozlowski, N. (1996). Exercise responses to running and inline skating at self-selected paces. Medicine \&amp Science In Sports \&amp Exercise, 28(2), 247-250. doi:10.1097/00005768-199602000-00014

Menschik, D., Ahmed, S., Alexander, M.,, \& Blum, R. (2008). Adolescent Physical Activities as Predictors of Young Adult Weight. Arch Pediatr Adolesc Med., 162(1):29-33. doi:10.1001/archpediatrics.2007.14

Milanović, Z., Pantelić, S., Kostić, R., Trajković, N., \& Sporiš, G. (2015). Soccer vs. running training effects in young adult men: Which programme is more effective in improvement of body composition? randomized controlled trial. Biology of Sport, 32(4), 301-305. $10.5604 / 20831862.1163693$

Milanovic, Z., Pantelic, S., Sporis, G., Mohr, M., \& Krustrup, P. (2015). Health-related physical fitness in healthy untrained men: Effects on VO2max, jump performance and flexibility of soccer and moderate-intensity continuous running. PLoS One, 10(8)http://0dx.doi.org.library.uark.edu/10.1371/journal.pone.0135319

Miller, L. (2003). Get rolling : The beginner's guide to inline skating (3rd ed. ed.). Danville, Calif.: Get Rolling Books.

Muehlbauer, T., Kuehnen, M., \& Granacher, U. (2013). Inline skating for balance and strength promotion in children during physical education. Perceptual And Motor Skills, 117(3), 665. 
National Museum of Roller Skating. (2016). Education Homework. Retrieved from http://www.rollerskatingmuseum.com/homework.html

Nguyen, N. (2015). Incorporation outdoor education into the physical education curriculum. Strategies, 28(1), 34-40. Retrieved from http://0search.proquest.com.library.uark.edu/docview/1650644525 ?accountid=8361

Nottingham, S. (1997). Fitness inline skating (Fitness spectrum series). Champaign, IL: Human Kinetics.

Ørntoft, C., Fuller, C. W., Larsen, M. N., Bangsbo, J., Dvorak, J., \& Krustrup, P. (2016). 'FIFA 11 for health' for europe. II: Effect on health markers and physical fitness in danish schoolchildren aged 10-12 years. British Journal of Sports Medicine, 50(22), 1394-1399. 10.1136/bjsports-2016-096124

Orepic, P., Mikulic, P., Sorice, M., Ruzic, L., \& Markovic, G. (2014). Acute physiological responses to recreational inline skating in young adults. European Journal of Sport Science, 14(Sup1), 31. doi:10.1080/17461391.2011.638936

Panta, K., Arulsingh. W., Oliver Raj, J., Sinha, M., \& Rahman, M. (2015, September 30). A study to associate the Flamingo Test and the Stork Test in measuring static balance on healthy adults. The Foot and Ankle Online Journal. Retrieved from https://faoj.org/2015/09/30/a-study-to-associate-the-flamingo-test-and-the-stork-test-inmeasuring-static-balance-on-healthy-adults/

Paradisis, G. P., Zacharogiannis, E., Mandila, D., Smirtiotou, A., Argeitaki, P., \& Cooke, C. B. (2014). Multi-Stage 20-m Shuttle Run Fitness Test, Maximal Oxygen Uptake and Velocity at Maximal Oxygen Uptake. Journal of Human Kinetics, 41, 81-87. http://doi.org/10.2478/hukin-2014-0035

Pereira, R., Schettino, L., \& Machado, M. (2010). Development of muscular explosive force in older women: Influence of a dance-based exercise routine. Medicina Sportiva, 14(4), 209-213.

Play and Playground Encyclopedia. (2017a). National Association for Sport and Physical Education . Retrieved from https://pgpedia.com/n/national-association-sport-andphysical-education

Play and Playground Encyclopedia. (2017b). Shape American. Retrieved from https://pgpedia.com/s/shape-america

Powell, M. (1998). Inline skating (2nd ed.). Champaign, Ill.: Human Kinetics.

Raffael. (2011). Cone Clip Art [PNG file]. Retrieved from http://www.clker.com/clipart-cone4.html 
Raya, M., Gailey, R., Gaunaurd, I., Jayne, D., Campbell, S., Gagne, E., ...Tucker, C. (2013). Comparison of three agility tests with male servicemembers: Edgren side step test, T-test, and illinois agility test. Journal of Rehabilitation Research and Development, 50(7), 95160. Retrieved from http://0search.proquest.com.library.uark.edu/docview/1467683788?accountid=8361

Rinne, M., Miilunpalo, S., \& Heinonen, A. (2007). Evaluation of required motor abilities in commonly practiced exercise modes and potential training effects among adults. Journal of Physical Activity and Health, 4(2), 203-214. doi:10.1123/jpah.4.2.203

Rodríguez-Rosell, D., Mora-Custodio, R., Franco-Márquez, F., Yáñez-García, J. M., \& González-Badillo, J. J. (2017). Traditional vs. sport-specific vertical jump tests: Reliability, validity, and relationship with the legs strength and sprint performance in adult and teen soccer and basketball players. Journal of Strength and Conditioning Research, 31(1), 196-206. doi:10.1519/JSC.0000000000001476

Roller Skating Association International. (2015a). About us. Retrieved from: http://www.rollerskating.com/pages/about/2

Roller Skating Association International. (2015b). Exercise benefits of roller skating. Retrieved from: http://www.rollerskating.com/pages/all+about+roller+skating/51

Ross, A., \& Butterfield, S. (1989). The effects of a dance movement education curriculum on selected psychomotor skills of children in grades k-8. Research in Rural Education, 6(1), 51-56.

Scott, S. N., Thompson, D. L., \& Coe, D. P. (2013). The ability of the PACER to elicit peak exercise response in the youth. Medicine \& Science in Sports \& Exercise, 45(6), 11391143. doi:10.1249/MSS.0b013e318281e4a8

Schwab, K., \& Dustin, D. (2014). Engaging youth in lifelong outdoor adventure activities through a nontraditional public school physical education program. Journal of Physical Education, Recreation and Dance, 85(8), 27-31. doi:10.1080/07303084.2014.9461

Shigematsu, R., Chang, M., Yabushita, N., Sakai, T., Nakagaichi, M., Nho, H., \& Tanaka, K. (2002). Dance-based aerobic exercise may improve indices of falling risk in older women. Age and Ageing, 31(4), 261.

Skatetime. (2013a). Teacher Resources. All new full games packet. Retrieved from http://www.skatetime.com/SkateGames2013.pdf

Skatetime. (2013b). Teacher Resources. Full games packet. Retrieved from http://www.skatetime.com/skategames.pdf 
Skatetime. (2017). Teacher Resources. Instruction Manual. Retrieved from http://www.skatetime.com/teacher.htm

Skatetime. (2018). Welcome to Skatetime. Retrieved from http://www.skatetime.com/

Skate in School. (2016a). Get your student's inline. Minneapolis, MN: Rollerblade Inc.

Skate in School (2016b). Inline skating lesson plans intermediate \& enrichment activities. Minneapolis, MN: Rollerblade Inc.

Skinner, A., Perrin, E., \& Skelton, J. (2016). Prevalence of obesity and severe obesity in us children, 1999-2014. Obesity, 24(5), 1116-1123. doi:10.1002/oby.21497

Society of Health and Physical Educators. (2013). National Standards for K-12 Physical Education. Retrieved from http://www.shapeamerica.org/standards/pe/

Society of Health and Physical Educators. (2014). Guide for Physical Education Policy. Retrieved from http://www.shapeamerica.org

Society of Health and Physical Educators. (2016). 2016 shape of the nation: Status of physical education in the USA. Retrieved from http://www.shapeamerica.org/advocacy/son/2016/upload/Shape-of-the-Nation2016_web.pdf

Srhoj L. (2002). Effect of motor abilities on performing the hvar folk dance cicilion in 11-yearold girls. Collegium Antropologicum, 26(2), 539-43.

Stewart, P. F., Turner, A. N., \& Miller, S. C. (2014). Reliability, factorial validity, and interrelationships of five commonly used change of direction speed tests. Scandinavian Journal of Medicine \& Science in Sports, 24(3), 500-506. doi:10.1111/sms.12019

Stribling, K., \& Christy, J. (2017). Creative dance practice improves postural control in a child with cerebral palsy. Pediatric Physical Therapy: The Official Publication of the Section on Pediatrics of the American Physical Therapy Association, 29(4), 365-369. doi:10.1097/PEP.0000000000000450

Taube, W., Kullmann, N., Leukel, C., Kurz, O., Amtage, F., \& Gollhoter, A. (2007). Differential reflex adaptations following sensorimotor and strength training in young elite athletes. International Journal of Sports Medicine, 28(12), 999-1005.

Teramoto, M., Cross, C., \& Willick, S. (2016). Predictive value of national football league scouting combine on future performance of running backs and wide receivers. Journal of Strength and Conditioning Research, 30(5), 1379-90. doi:10.1519/JSC.0000000000001202 
Todd, T., \& Medina, J. (2013). PADDLING with individuals with developmental disabilities. Strategies, 26(1), 14-19. Retrieved from http://0search.proquest.com.library.uark.edu/docview/1319493430?accountid=8361

United States Department of Education. (2017). Science, Technology, Engineering and Math: Education for Global Leadership. Retrieved from https://www.ed.gov/Stem

Vasconcellos, F., Seabra, A., Cunha, F., Montenegro, R., Penha, J., Bouskela, E., . . Farinatti, P. (2016;2015). Health markers in obese adolescents improved by a 12-week recreational soccer program: A randomised controlled trial. Journal of Sports Sciences, 34(6), 564-12. $10.1080 / 02640414.2015 .1064150$

Vincent, S. D., Barker, R., Clarke, M., \& Harrison, J. (1999). A comparison of peak heart rates elicited by the 1-mile run/walk and the progressive aerobic cardiovascular endurance run. Research Quarterly for Exercise and Sport, 70(1), 75-8. Retrieved from http://0search.proquest.com.library.uark.edu/docview/218555488?accountid=8361

Wallick, M., Porcari, J., Wallick, S., Berg, K., Brice, G., \& Arimond, G. (1995). Physiological responses to inline skating compared to treadmill running. Medicine \& Science in Sports \& Exercise, 27(2), 242-248.

Walsh, S.F., \& Scharf, M.G. (2014). Effects of a recreational ice skating program on the functional mobility of a child with cerebral palsy. Physiotherapy Theory And Practice, 30(3), 189-95. doi:10.3109/09593985.2013.863414

Watts, P. B., \& Ostrowski, M. L. (2014). Oxygen uptake and energy expenditure for children during rock climbing activity. Pediatric Exercise Science, 26(1), 49-55. doi:10.1123/pes.2013-0035

Whitney, E., \& Rolfes, S. (2016). Understanding nutrition (14 ${ }^{\text {th }}$ ed.). Stamford, CT: Cengage Learning.

Wilson, D., Williams, J., Evans, A., Mixon, G., \& Rheaume, C. (2005). Brief report: A qualitative study of gender preferences and motivational factors for physical activity in underserved adolescents. Journal of Pediatric Psychology, 30(3), 293-7.

Wood, R. (2008a). Vertec: vertical jump equipment. Topend Sports, Access Date (6/11/2017). Retrieved from http://www.topendsports.com/testing/equipment-vertec.htm

Wood, R. (2008b). Vertical jump test. Topend Sports, Access Date (6/18/2017). Retrieved from http://www.topendsports.com/testing/tests/vertjump.htm

Yaggie, J., \& Campbell, B. (2006). Effect of balance training on selected skills. Journal of Strength and Conditioning Research, 20(2), 422-8. 


\section{APPENDICES}

Appendix A: Institutional Review Board Approval Letter

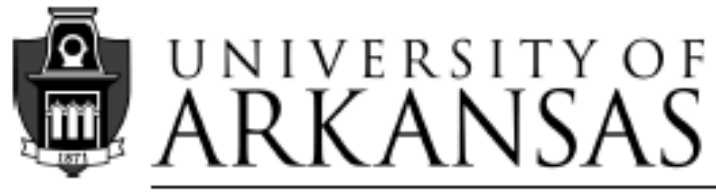

August 28, 2017

Office of Research Compliance

Institutional Review Board

MEMORANDUM

TO:

Eric Lange

Dean Gorman

FROM: $\quad$ Ro Windwalker

IRB Coordinator

RE:

New Protocol Approval

IRB Protocol \#:

1708006734

Protocol Title:

Effect of a Skating Unit on Fithess in Fifth Grade Students

Review Type:

$\square$ EXEMPT $\triangle E X P E D I T E D ~ \square$ FULL IRB

Approved Project Period: $\quad$ Start Date:08/23/2017 Expiration Date: 08/17/2018

Your protocol has been approved by the IRB. Protocols are approved for a maximum period of one year. If you wish to continue the project past the approved project period (see above), you must submit a request, using the form Continuing Review for IRB Approved Projects, prior to the expiration date. This form is available from the IRB Coordinator or on the Research Compliance website (https://vpred.uark.edu/units/rscp/index.php). As a courtesy, you will be sent a reminder two months in advance of that date. However, failure to receive a reminder does not negate your obligation to make the request in sufficient time for review and approval. Federal regulations prohibit retroactive approval of continuation. Failure to receive approval to continue the project prior to the expiration date will result in Termination of the protocol approval. The IRB Coordinator can give you guidance on submission times.

This protocol has been approved for 90 participants. If you wish to make any modifications in the approved protocol, including enrolling more than this number, you must seek approval prior to implementing those changes. All modifications should be requested in writing (email is acceptable) and must provide sufficient detail to assess the impact of the change.

If you have questions or need any assistance from the IRB, please contact me at 109 MLKG Building, 5-2208, or irb@uark.edu.

109 MLKG * 1 University of Arkansas • Fayetteville, AR 72701-1201 • (479) 575-2208 • Fax (479) 575-6527 • Email

irb@uark.edu

The Unveraty of Arkansas is an equar acportunityatmmative action instrution. 
Appendix B: Institutional Review Board Approval Modification

UNIVERSITYOF

III. ARKANSAS

To:

From:

Date:

Action:

Action Date:

Protocol \#.

Study Title:

Expiration Date:

Last Approval Date:

\section{Eric James Lange}

Douglas James Adams, Chair IRB Committee

03/02/2018

\section{Expedited Approval}

03/02/2018

1708006734A001

Effect of a Skating Unit on Fitness in Fifth Grade Students

$08 / 17 / 2018$

03/02/2018

The above-referenced protocol has been approved following expedited review by the IRB Committee that oversees research with human subjects.

If the research involves collaboration with another institution then the research cannot commence until the Committee receives written notification of approval from the collaborating institution's IRB.

It is the Principal Investigator's responsibility to obtain review and continued approval before the expiration date.

Protocols are approved for a maximum period of one year. You may not continue any research activity beyond the expiration date without Committee approval. Please submit continuation requests early enough to allow sufficient time for review. Failure to receive approval for continuation before the expiration date will result in the automatic suspension of the approval of this protocol. Information collected following suspension is unapproved research and cannot be reported or published as research data. If you do not wish continued approval, please notify the Committee of the study closure.

Adverse Events: Any serious or unexpected adverse event must be reported to the IRB Committee within 48 hours. Al other adverse events should be reported within 10 working days.

Amendments: If you wish to change any aspect of this study, such as the procedures, the consent forms, study personnel, or number of participants, please submit an amendment to the IRB. All changes must be approved by the IRB Committee before they can be initiated.

You must maintain a research file for at least 3 years after completion of the study. This file should include all correspondence with the IRB Committee, original signed consent forms, and study data.

$\propto$ Dean Richard Gorman, Investigator 
Appendix C: Consent for a Minor to Participate in a Research Study

\section{EFFECT OF A SKATING UNIT ON FITNESS IN FIFTH GRADE STUDENTS Consent for a Minor to Participate in a Research Study \\ Principal Researcher: Eric Lange \\ Faculty Advisor: Dr. Dean Gorman}

This is a parental permission form for research participation. It contains important information about this study and what to expect if you permit your child to participate.

\section{Your child's participation is voluntary.}

Please consider the information carefully. Feel free to discuss the study with your friends and family and to ask questions before making your decision whether or not to permit your child to participate. If you permit your child to participate, you will be asked to sign this form and will receive a copy of the form. We must also have your child's assent to participate in this study.

\section{INVITATION TO PARTICIPATE}

Your child is being invited to participate in a research study about the effects of a skating unit on fitness. Your child is being asked to participate in this study because the fifth graders in your child's school have been selected to participate in this study.

\section{WHAT YOU SHOULD KNOW ABOUT THE RESEARCH STUDY}

Who is the Principal Researcher?

Eric Lange

ejlange@uark.edu

(918)230-9442

Who is the Faculty Advisor?

Dr. Dean Gorman

dgorman@uark.edu

(479) $575-2890$

What is the purpose of this research study?

The purpose of this study is to investigate the effect of a skating unit on cardiovascular fitness, static balance, explosive power, and agility on fifth grade students in a northwestern Arkansas school district. To measure cardiovascular fitness, the district uses the PACER that is a timed test where students run from end to end 20 meters apart. The number of laps recorded is the score for the student and they are to see how many laps they can run. Static balance will be measured using the Stork Standing Balance Test. Students will stand stationary in the Stork position and are timed to see how long they can hold that position. Explosive power will be measured by students jumping vertically to see how high they jump. Finally, student's agility will be measured by the Illinois Agility Run where students will weave in and out of cones to see how fast they can complete the course. 
Who will participate in this study?

The fifth grade classes in your school have been selected to serve as participants in this study. During normal physical education classes, three separate class periods will serve as the control group $(n=30)$ and two intervention groups: experimental roller skating $(n=30)$, and experimental inline skating $(n=30)$.

For purposes of this study, students in the control group will not have access to the roller skates or inline skates during physical education classes. However, upon completion of this study, those students who did not get an opportunity to skate will have an opportunity to participate in a skating curriculum led by their physical education teacher after the study.

What will your child be asked to do?

Your child's participation will require the following:

Your child will take part in an 8-week study. Week 1, a team of evaluators will come to your child's school and measure cardiovascular fitness, balance, explosive leg power, and agility. Week 2-7, your teacher will lead a physical education unit designed specifically for the class they meet. Week 8 , similar to week 1 , a team of evaluators will come to the child's school and measure cardiovascular fitness, balance, explosive leg power, and agility.

Again, I would like to stress that after the study is completed, those students who did not have an opportunity to skate will be able to participate in a skating unit led by their physical education teacher. Those students, who participated in skating, will return to their "regularly" scheduled curriculum.

What are the possible risks or discomforts?

As with any physical education class, there are some risks associated. These risks could include things like sore muscles, fatigue, cramping, and injuries sustained from falls. To reduce these risks, all children will be supplied and required to wear protective equipment to include a helmet, elbow pads, and elbow pads.

What are the possible benefits to your child if he/she participates in this study?

By participating in a skating unit, your child may potentially increase their cardiovascular fitness, balance, explosive power, and agility.

How long will the study last?

Students will meet during normally scheduled physical education class for an 8-week period. Students typically meet two times per week with a class session that lasts approximately 45-50 minutes in length.

Will your child receive compensation for time and inconvenience if you choose to allow him/her to participate in this study?

Your child will not receive any compensation for participating in this study. However, those students who did not have an opportunity to skate during the study will be able to skate during class after the study is completed so they have an opportunity to enjoy this activity. 
Will you or your child have to pay for anything?

No, there will be no cost for participation in this study. This study will be supported by

Skatetime and the school district in suppling all the necessary equipment at no cost to the participant.

What are the options if I do not want my child to be in the study?

Participation in the study is completely voluntary. If you do not want your child to be in this study, you may refuse to allow him/her to participate. Your child may refuse to participate even if you give permission. If your child decides to participate and then changes his/her mind, your child may quit participating at any time. You may end your participation at any time by telling your teacher or the principle researcher. Participation, non-participation, or ending your participation will not affect your grade in any way. Your child will not be punished or discriminated against in any way if you refuse to allow participation or if your child chooses not to participate in this study.

How will my child's confidentiality be protected?

All information will be kept confidential to the extent allowed by applicable State and Federal law and University policy.

Each student will be assigned a unique identification number for coding purposes and data analysis with all personal information removed. The physical education teacher(s) and fitness evaluation team will assist in data collection (pretest and posttest fitness tests) and the physical education teacher will conduct daily course curriculum. But, they will not have access to the data once the data is being prepared for analysis. However, since the school district uses the PACER test as part of the FITNESSGRAM (The Cooper Institute, Dallas, TX) fitness testing, the participants pretest scores will be used for the districts fitness testing during the fall semester. A student's posttest score will not be used by the school for testing purposes.

Data collected will be transferred to an Excel spreadsheet and Statistical Package for Social Sciences (SPSS) software. All research data will be backed up on an external thumb drive. All electronic information, fitness testing, and consent forms will be locked in a safe for five years. After the five year period, student fitness and consent forms will be shredded and thumb drive erased.

Will my child and/or I know the results of the study?

At the conclusion of the study you will have the right to request feedback about the results. You may contact the faculty advisor, Dr. Dean Gorman dgorman@uark.edu (479) 575-2890

or Principal Researcher, Eric Lange ejlange @uark.edu (918)230-9442. You will receive a copy of this form for your files.

What do I do if I have questions about the research study?

You have the right to contact the Principal Researcher or Faculty Advisor as listed below for any concerns that you may have.

Principal Researcher's name and contact information:

Eric Lange 
ejlange@uark.edu

(918)230-9442

Faculty Advisor's name and contact information:

Dr. Dean Gorman

dgorman@uark.edu

(479) 575-2890

You may also contact the University of Arkansas Research Compliance office listed below if you have questions about your rights as a participant, or to discuss any concerns about, or problems with the research.

Ro Windwalker, CIP

Institutional Review Board Coordinator

Research Compliance

University of Arkansas

109 MLKG Building

Fayetteville, AR 72701-1201

479-575-2208

irb@uark.edu

I have read the above statement and have been able to ask questions and express concerns, which have been satisfactorily responded to by the investigator. I understand the purpose of the study as well as the potential benefits and risks that are involved. I understand that participation is voluntary. I understand that significant new findings developed during this research will be shared with me and, as appropriate, my child. I understand that no rights have been waived by signing the consent form. I have been given a copy of the consent form.

Printed Name of Parent or

Guardian
Signature of Parent or Guardian
Date

"I have discussed this with my parent or guardian and I agree to participate."

Printed Name of Participant

Signature of Participant

Date

IRB \#1708006734 
Appendix D: Consent for a Minor to Participate in a Research Study Translated in Spanish

\section{EFECTO DE UNA UNIDAD DE PATINAJE PARA ACONDICIONAMIENTO FÍSICO EN ESTUDIANTES DE QUINTO GRADO}

\section{Consentimiento para que un Menor Participe en un Estudio de Investigación}

Investigador Principal: Eric Lange

Asesor de la Facultad: Dr. Dean Gorman

Este es un formulario de permiso de los padres para participar en la investigación. Contiene información importante sobre este estudio y qué esperar si usted permite que su hijo participe.

\section{La participación de su hijo es voluntaria.}

Por favor considere la información cuidadosamente. Tómese la libertad de conversar sobre el estudio con sus amigos y familiares y haga preguntas antes de tomar la decisión de permitir o no que su hijo participe. Si permite que su hijo participe, se le pedirá que firme este formulario y recibirá una copia. También debemos tener el consentimiento del niño para participar en este estudio.

\section{INVITACIÓN PARA PARTICIPAR}

Su hijo ha sido invitado a participar en un estudio de investigación sobre los efectos de una unidad de patinaje en acondicionamiento físico. A su hijo se le ha pedido que participe en este estudio porque los estudiantes de quinto grado en la escuela de su hijo han sido seleccionados para participar en este estudio.

\section{QUÉ DEBE USTED DE SABER SOBRE EL ESTUDIO DE INVESTIGACIÓN}

¿Quién es el Investigador Principal?

Eric Lange ejlange@uark.edu

(918)230-9442

¿Quién es el Asesor de la Facultad?

Dr. Dean Gorman dgorman@uark.edu

(479) $575-2890$

¿Cuál es el propósito de este estudio de investigación?

El propósito de este estudio es investigar los efectos de una unidad de patinaje en acondicionamiento cardiovascular, balance estático, fuerza explosiva y agilidad en estudiantes de quinto grado en una escuela del Noroeste de Arkansas. 


\section{¿Quién participará en este estudio?}

Las clases de quinto grado en su escuela han sido seleccionadas para servir como participantes en este estudio. Durante las clases regulares de educación física, tres periodos de clase separados servirán como el grupo de control $(n=30)$ y dos grupos de intervención: patinaje experimental $(n=30)$ y patinaje experimental en línea $(n=30)$.

Para propósitos de este estudio, los estudiantes en el grupo de control no tendrán acceso a los patines de ruedas ni a los patines en línea durante las clases de educación física. Sin embargo, al terminar este estudio, aquellos estudiantes que no tuvieron la oportunidad de patinar tendrán la oportunidad de participar en un programa de patinaje dirigido por su maestro de educación física después del estudio.

¿Qué se le pedirá a su hijo que haga?

La participación de su hijo requerirá lo siguiente:

Su hijo formará parte de un estudio de 8 semanas. Semana 1, un equipo de evaluadores vendrá a la escuela de su hijo a medir el acondicionamiento cardiovascular, balance, fuerza explosiva de pierna y agilidad. Semana 2-7, su maestro dirigirá una unidad de educación física diseñada específicamente para la clase que se reúne. Semana 8 , similar a la semana 1 , un equipo de evaluadores vendrá a la escuela de su hijo a medir el acondicionamiento cardiovascular, balance, fuerza explosiva de pierna y agilidad.

Para medir el acondicionamiento cardiovascular, el distrito utiliza el PACER que es un examen cronometrado donde los estudiantes corren de extremo a extremo a 20 metros de distancia. El número de vueltas registradas es el resultado para el estudiante y ellos pueden ver cuantas vueltas pueden correr. El balance estático se medirá usando el Stork Standing Balance Test. Los estudiantes estarán sin moverse en la posición de cigüeña y se les toma el tiempo para ver cuánto tiempo pueden mantener esa posición. La fuerza explosiva se medirá al brincar los estudiantes verticalmente para ver qué tan alto brincan. Finalmente, la habilidad del estudiante se medirá con el Illinois Agility Run donde los estudiantes pasarán entre los conos para ver qué tan rápido pueden terminar el curso.

Nuevamente, me gustaría enfatizar que después de terminado el estudio, aquellos estudiantes que no tuvieron la oportunidad de patinar podrán participar en una unidad de patinaje dirigida por su maestro de educación física. Aquellos estudiantes que participaron en patinaje, regresarán a su programa "regularmente" programado.

¿Cuáles son los posibles riesgos o incomodidades?

Como en cualquier clase de educación física, hay algunos riesgos asociados. Estos riesgos pueden incluir cosas como dolor de músculos, fatiga, calambres y lesiones sufridas por caídas. Para reducir estos riesgos, a todos los niños de les proporcionará y requerirá que usen su equipo protector que incluye, casco y coderas. 
¿Cuáles son los posibles beneficios para su hijo si participa en este estudio?

Al participar en una unidad de patinaje, su hijo puede potencialmente incrementar su bienestar cardiovascular, balance, fuerza explosiva y agilidad.

¿Cuánto durará el estudio?

Los estudiantes se reunirán durante la clase de educación física programada normalmente por un periodo de 8 semanas. Los estudiantes típicamente se reúnen dos veces a la semana en una clase que tiene aproximadamente 45-50 minutos de duración.

¿Recibirá su hijo compensación por el tiempo e inconveniencia si elige permitirle participar en este estudio?

Su hijo no recibirá ninguna compensación por participar en este estudio. Sin embargo, aquellos estudiantes que no tuvieron la oportunidad de patinar durante el estudio podrán patinar durante la clase después de que el estudio haya terminado para que tengan la oportunidad de disfrutar esta actividad.

¿Usted o su hijo tienen que pagar por algo?

No habrá ningún costo por participar en este estudio. Este estudio estará apoyado por Skatetime y el distrito escolar para suplir el equipo necesario sin costo para el participante.

¿Cuáles son las opciones si no deseo que mi hijo participe en este estudio?

La participación en el estudio es completamente voluntaria. Si no desea que su hijo participe en este estudio, usted puede negar que participe. Su hijo puede negarse a participar aunque usted le haya dado permiso. Si su hijo decide participar y después cambia de idea, puede dejar de participar en cualquier momento. Usted puede terminar su participación en cualquier momento diciéndole al maestro o al investigador principal. Participar, no participar o terminar su participación no afectará la calificación de ninguna manera. Su hijo no será castigado ni discriminado en ninguna forma si usted se rehúsa a permitir su participación o si su hijo elige no participar en este estudio.

¿De qué manera será protegida la confidencialidad de mi hijo?

Toda la información se mantendrá confidencial en la medida permitida por la ley Estatal y Federal y por la política de la universidad.

A cada estudiante se le asignará un número único de identificación para codificación y análisis de datos con toda la información personal removida. El maestro(s) de educación física y el equipo de evaluación de bienestar físico asistirán con la recopilación de información (exámenes de acondicionamiento previos y posteriores) y el maestro de educación física conducirá el plan 
de estudios del curso diariamente. Pero, no tendrán acceso a la información una vez que está siendo preparada para análisis. Sin embargo, debido a que el distrito escolar usa el examen de acondicionamiento físico PACER como parte del FITNESSGRAM (The Cooper Institute, Dallas, TX), los resultados previos al examen serán usados para los exámenes de acondicionamiento físico de los distritos durante el semestre de otoño. Los resultados posteriores del examen de un estudiante no serán usados por la escuela para exámenes.

La recolección de información será transferida a una hoja de cálculo de Excel y al software Statistical Package for Social Sciences (SPSS). Todos los datos de la investigación serán respaldados en una memoria USB externa. Toda la información electrónica, exámenes de acondicionamiento y formularios de consentimientos estarán guardados en una caja fuerte por cinco años. Después de los cinco años, los formularios de acondicionamiento físico de los estudiantes y los formularios de consentimiento serán triturados y borrados del USB.

¿Sabremos mi hijo y/o yo los resultados del estudio?

Al concluir el estudio, usted tendrá el derecho de solicitar información sobre los resultados. Usted puede contactar al asesor de la facultad, Dr. Dean Gorman dgorman@uark.edu (479) 5752890 o al Investigador Principal, Eric Lange ejlange@uark.edu (918)230-9442. Usted recibirá una copia de este formulario para sus registros.

¿Que hago si tengo preguntas sobre este estudio de investigación?

Usted tiene el derecho de contactar al Investigador Principal o al Asesor de la Facultad mencionados abajo para cualquier preocupación que pueda tener.

Investigador Principal:

Eric Lange

ejlange@uark.edu

(918)230-9442

Asesor de la Facultad:

Dr. Dean Gorman

dgorman@uark.edu

(479) $575-2890$

También puede contactar a la oficina de Cumplimiento de la Investigación de la Universidad de Arkansas mencionada abajo si tiene preguntas sobre sus derechos como participante o para conversar sobre cualquier preocupación o problema con la investigación.

Ro Windwalker, CIP

Coordinador del Consejo de Revisión Institucional

Cumplimiento de la Investigación 
Universidad de Arkansas Edificio 109 MLKG

Fayetteville, AR 72701-1201

479-575-2208

irb@uark.edu

He leído la declaración de arriba y he podido hacer preguntas y expresar preocupaciones, las cuales han sido satisfactoriamente respondidas por el investigador. Entiendo el propósito del estudio así como los beneficios y riesgos potenciales que implica. Entiendo que la participación es voluntaria. Entiendo que los nuevos hallazgos desarrollados durante esta investigación serán compartidos conmigo y si es apropiado, con mi hijo. Entiendo que no se ha renunciado a ningún derecho al firmar este formulario. Se me ha dado una copia de este formulario.

Nombre del Padre o Tutor Firma del Padre o Tutor Fecha

"He hablado sobre esto con mi padre o tutor y estoy de acuerdo en participar." 
Appendix E: Fitness Evaluation Form

\section{Fitness Evaluation Form}

Student ID:

Students Name:

Date of Birth:

Age

Gender (circle): Male Female

Dominate Hand:

Foot:

Group (check which applies): 1 Control

2 Roller Skating

3 Inline Skating

\begin{tabular}{|l|l|l|l|l|}
\hline \multicolumn{1}{|c|}{ Fitness Test } & \multicolumn{2}{|c|}{ Pretest } & \multicolumn{2}{c|}{ Posttest } \\
\cline { 2 - 5 } & \multicolumn{1}{|c|}{ Trial 1 } & \multicolumn{1}{c|}{ Trial 2 } & Trial 1 & Trial 2 \\
\hline $\begin{array}{l}\text { Vertical Jump } \\
\text { (in 1/2 inches) }\end{array}$ & Standing Reach: & & Standing Reach: & \\
\hline $\begin{array}{l}\text { Stork Balance } \\
\text { (time in seconds } \\
\text { to the nearest } \\
\text { 100 }\end{array}$ & Jump: & Jump: & Jump: & \\
\hline $\begin{array}{l}\text { Illinois Agility } \\
\text { Run } \\
\text { (time in seconds } \\
\text { to the nearest } \\
\text { 100 }\end{array}$ & & & & \\
\hline $\begin{array}{l}\text { PACER } \\
\text { (transfer from } \\
\text { score sheet) }\end{array}$ & & & & \\
\hline
\end{tabular}

\section{Additional Notes:}


Appendix F: Progressive Aerobic Cardiovascular Endurance Run (PACER) Scoring Sheet

\section{PACER Scoring Sheet}

Student Name:

Pacer Length: 20-meter

Score-keeper:
Date:

Circle One: Pretest Posttest

Laps Completed:

\begin{tabular}{|c|c|c|c|c|c|c|c|c|c|c|c|c|c|}
\hline Min & \multicolumn{13}{|c|}{ Laps } \\
\hline 1 & 1 & 2 & 3 & 4 & 5 & 6 & 7 & & & & & & \\
\hline 2 & 8 & 9 & 10 & 11 & 12 & 13 & 14 & 15 & & & & & \\
\hline 3 & 16 & 17 & 18 & 19 & 20 & 21 & 22 & 23 & & & & & \\
\hline 4 & 24 & 25 & 26 & 27 & 28 & 29 & 30 & 31 & 32 & & & & \\
\hline 5 & 33 & 34 & 35 & 36 & 37 & 38 & 39 & 40 & 41 & & & & \\
\hline 6 & 42 & 43 & 44 & 45 & 46 & 47 & 48 & 49 & 50 & 51 & & & \\
\hline 7 & 52 & 53 & 54 & 55 & 56 & 57 & 58 & 59 & 60 & 61 & & & \\
\hline 8 & 62 & 63 & 64 & 65 & 66 & 67 & 68 & 69 & 70 & 71 & 72 & & \\
\hline 9 & 73 & 74 & 75 & 76 & 77 & 78 & 79 & 80 & 81 & 82 & 83 & & \\
\hline 10 & 84 & 85 & 86 & 87 & 88 & 89 & 90 & 91 & 92 & 93 & 94 & & \\
\hline 11 & 95 & 96 & 97 & 98 & 99 & 100 & 101 & 102 & 103 & 104 & 105 & 106 & \\
\hline 12 & 107 & 108 & 109 & 110 & 111 & 112 & 113 & 114 & 115 & 116 & 117 & 118 & \\
\hline 13 & 119 & 120 & 121 & 122 & 123 & 124 & 125 & 126 & 127 & 128 & 129 & 130 & 131 \\
\hline 14 & 132 & 133 & 134 & 135 & 136 & 137 & 138 & 139 & 140 & 141 & 142 & 143 & 144 \\
\hline 15 & 145 & 146 & 147 & 148 & 149 & 150 & 151 & 152 & 153 & 154 & 155 & 156 & 157 \\
\hline
\end{tabular}

***Note: (/) indicates successful lap (O) indicates misses. 2 misses allowed.

Additional Notes:

Adapted from FITNESSGRAM/ACIVITYGRAM Test Administration Manual, Fourth Edition by the Cooper Institute, 2005, Champaign, IL: Human Kinetics. 


\section{Appendix G: Teacher Exit Questionnaire}

1. What was your overall impression of the skating unit?

a. Fears or concerns prior to the study?

2. What were the students' impressions during this unit?

a. Fears or concerns prior to the study?

b. Was there visual improvement on those who participated in the roller skating and inline skating classes? Please explain.

3. What do you feel was successful about the skating unit?

4. What do you feel was unsuccessful about the skating unit?

5. What modifications might be made in the future for the skating unit?

6. Would you consider doing a skating unit in the future?

7. Other comments: 
Appendix H: Skatetime Copyright Approval Letter and Email

\section{Skatetime School Programs, Inc.}

February 2, 2018

Mr Eric Lange

Re: Skatetime School Programs Inc. Curriculum Use

Mr. Lange:

I would like to formally thank you your interest in our curriculum. We have no problem with you using us a source of information and hereby authorize such use. In the event sentences or paragraphs are used verbatim I would ask that Skatetime is referred to as the source and given due credit.

Once the study is complete, please ad the following language on the bottom of each page, that simply states, ${ }^{*}$ This study contains copyrighted material, including but not limited to, the World Wide Web, any Mac based desktop word processing or publishing software, as well as Windows or any PC based desktop word processing or publishing software. Any reproduction without expressed permission from either the Author and Skatetime is strictly prohibited."

I hope this helps. I would also like copy of the study once complete.

Thank You

Sincerely,

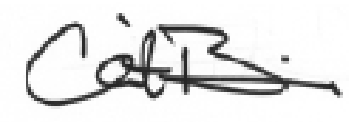

Clint Briggs, President

Skatetime School Programs, Inc.

Cc: file

$245020^{\text {th }}$ St. Rockford IL. 61104 :: 815.708 .7201 
$\therefore$ Clint Briggs <clintbriggs@skatetime.com>

to Lisa, me, Jeania $/$

Mr. Lange,

Thank you your interest in our curriculum. I have no problem with you using us a source of information. In the event sentences or paragraphs are used verbatim I would ask that Skatetime is referred to as the source and given due credit.

Once the study is complete, please ad the following language on the bottom of each page, that simply states "This study contains copyrighted material, including but not limited to, The world wide web, and Mac based desktop word processing or publishing software, as well as Windows or any PC based desktop word processing or publishing software. Any reproduction without expressed permission from either the Author and Skatetime is strictly prohibited ."

I hope this helps. I would also like copy of the study once complete.

Thank You

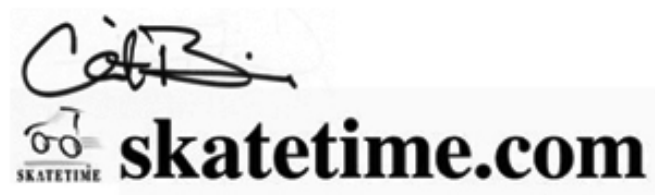

Clint Briggs :: Skatetime Companies :: $\underline{800.557 .5283}$ 
Appendix I: Skate in School Copyright Approval Letter and Email

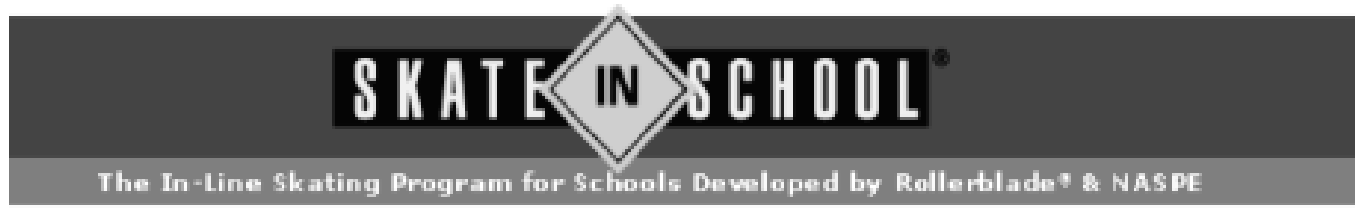

January 29, 2018

To Whom it May Concern:

Eric Lange, PhD student at the University of Arkansas, has total and full permission to use the Rollerblade Skate in School curriculums and other related materials for his in-line skating study and dissertation.

Sincerely,

Rave Bailey

Reade Bailey

Program Co-Director

11689 Thornhill Road • Eden Prairie • MN • 55344 
Reade Bailey sreade@deadlinecom.com>

to Bob, me

Eric:

Nice talking with you.

Will have beginner curriculum sent to you.

Attached are:

-Two lists of Arkansas schools that have purchased in-line skates from us in the past. Some overlap between lists.

-Intermediate/enrich curriculum for Skate in School.

$-U$ of Mass Amherst fitness study. Also available here.

http://www.skateinschool.com/benefits.htm

Thanks for sending German study. Do you also have a link to any website where it might have originally appeared?

Also, a thought: How many pairs of in-line skates do you need for the study you are doing? If you can't get them from a local school, I might be able to get you a really good deal.

Thanks,

Reade

Reade Bailey

Rollerblade Skate in School

5 Million Students. 1,500 Schools. One Great Program.

http://www.skateinschool.com

$\underline{952-941-2957}$

\section{From: Eric Lange <ejlange@email.uark.edu> \\ Date: Tuesday, May 23, 2017 at 12:23 PM \\ To: Reade Bailey<reade@deadlinecom.com> \\ Subject: Skating Study}

Mr. Bailey,

Thank your for taking the time to contact me back related to my questions for my study. Below are a few questions I need from you and then will attach my home address below. Also, the attached document is the skating study I pointed out to you related to balance and explosive power.

1. Do we have permission to use your cirriculum? YES

2. Can we modifiy it slightly to fit our study needs? YES

3. Citation (I want to properly cite your work):

YES

$\ldots$ 
Appendix J: Roller and Inline Skating Curriculum

\section{ROLLER AND INLINE SKATINIG CURRICULUM}

\section{Lesson Objectives Key}

Affective Domain (A). Domain that includes emotions, feelings, and values.

Cognitive Domain (C). Domain that includes knowledge and intellectual skills.

Psychomotor Domain (P). Domain that includes physical movement, coordination, and motorskill.

\section{LESSON \#1}

\begin{tabular}{|c|c|}
\hline $\begin{array}{l}\text { LESSON OBJECTIVES: } \\
\text { The student will... } \\
\text { 1. Discuss the goals, rules, and procedures } \\
\text { for the unit (C/A) (\#5). } \\
\text { 2. Discuss the purpose of protective gear } \\
\text { and identify each piece (C/A) (\#2). } \\
\text { 3. Select, fit, and retum equipment } \\
\text { correctly (C) (=5). } \\
\text { 4. Understand the positive opportunities } \\
\text { asaociated with skating (A) (\#5). }\end{array}$ & $\begin{array}{l}\text { ASSESSMENT EXAMPLE: } \\
\text { 1. With a partner, students discuss the } \\
\text { importance of protective gear, each } \\
\text { name two pieces of protective gear, and } \\
\text { check each other's equipment fit. } \\
\text { 2. Students name three components of the } \\
\text { skate when asked by teacher. }\end{array}$ \\
\hline $\begin{array}{l}\text { VOCABULARY: } \\
\text { in-line skating } \\
\text { protective gear: helmet, elbow pads, lnes } \\
\text { pads, wrist guards } \\
\text { American National Standards Institute (ANSI) } \\
\text { skate: shell, liner, frame, wheels, bearings, } \\
\text { spacers, brake }\end{array}$ & $\begin{array}{l}\text { EQUIPMINNT: } \\
\text { TV/VCR, video(s), extension cord } \\
\text { goals and rules chart }\end{array}$ \\
\hline $\begin{array}{l}\text { ACTIVTTIES: } \\
\text { INTRODUCTION } \\
\text { - Skating video or video clips } \\
\text { demonstrating in-line skating } \\
\text { - brief history of in-line skating } \\
\text { (optional) } \\
\text { - quick survey of students' in-line } \\
\text { skating experience } \\
\text { - overview/discusaion of goals, rules, } \\
\text { procedures }\end{array}$ & $\begin{array}{l}\text { STRATEGIES/TIPS: } \\
\text { - Pre-organize equipment as it will be for } \\
\text { the entire unit. } \\
\text { - Don't take short cuts in establishing } \\
\text { routine; back tracking will cost } \\
\text { valuable activity time. } \\
\text { - Reinforce that leaming and following } \\
\text { the equipment routine fully and } \\
\text { promptly will result in more skating } \\
\text { time. } \\
\text { - Emphasize control; no one should fall }\end{array}$ \\
\hline
\end{tabular}




\section{LESSON \#1 (Cont.)}

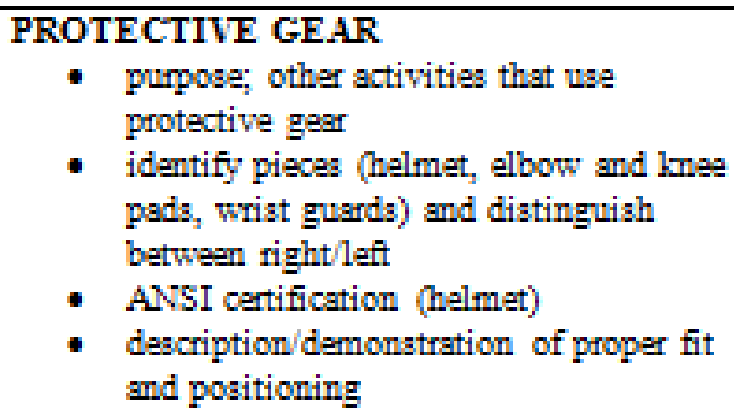

- purpose; other activities that use protective gear

- identify pieces (helmet, elbow and knee pads, wrist guards) and distinguish between right/left

- ANSI certification (helmet)

- description/demonstration of proper fit and positioning

\section{SKATES}

- basic components (ahell, liner, frame, wheels, bearings, spacers, brake)

- description/demonstration of proper fit (option of wearing extra pair of socks)

\section{SELECTING/FITTING EQUIPMENT}

- sizing students with smallest and largest feet first (try on only one skate; start with one size larger than shoe size)

- practice putting on/fitting/positioning all equipment reinforce position of wrist guards (shell on palm) and helmet (front edge touching eyebrows)

\section{ASSESSMENT \#1}

ASSESSMENT $\# 2$

\section{CLOSURE}

- practice retuming equipment (close skates correctly)

- summary of lesson (reminder about bringing shower caps and socks)

- preview of next lesson
TEACHER REFLECTIONS/NOTES:

,

TEACHER REFLCTIONS/OTES:




\section{LESSON \#2}

\section{LESSON OBJECTIVES:}

The student will...

1. Describe and perform standing up, falling, rolling, and basic stop on skates (C/P) $(=1,2)$.

2. Demonstrate the ready position $(\mathrm{P})(=1$, 2).

3. Work cooperatively with a partner to experience rolling (A) $(=4,5)$.

4. Appreciate the importance of wearing protective gear and being able to fall safely (A) (\#5).

VOCABULARY:

standing up, ready position

weight shift, support leg

roll/rolling, disinfect
ASSESSMENT EXAMPLE:

1. With a partner, students discuss falling progression and check each other's technique.

2. Teacher/partners check standing, rolling and stopping techniques.

3. Teacher acreens class for in-line skating skill levels (high, medium, low) (Use class list.)

\section{ACTIVITIES:}

\section{WARM-UP without skates}

\section{RETRIEVING/PUTTING ON EQUIPMINT}

- review proper procedures for getting/retuming equipment

- review proper fit

- reinforce promptness, efficiency

STANDING UP

DESCRIPTION/ DEMONSTRATION

PROGRESSION:

- start on both knees (fingers tucked into a fist)

- lift non-brake knee until foot is on ground; rest both hands on that knee

- extend knee to standing position

- position other foot (brake skate) so that both fest are in a "V" position
EQUIPMINT:

grass or carpet (beware of and, gravel, dirt) (be sure to use indoor or level areas)

STRATEGIES/TIPS:

- Always reinforce equipment procedures.

- Frequently remind students to kesp body weight low and slightly forward and lnees bent (click wrist guards on lnee pads).

- Emphasize importance of control and ability to stop.

- Emphasize that falling is and emergency akill and should not occur if control is maintained.

\section{TEACHER REFLECTIONS/NOTES:}

\section{PRACTICE}




\section{LESSON \#2 (Cont.)}

- on mats or carpeted ares first

- on floor or pavement when competent on mats/carpet

READY POSITION

DESCRIPTION/DEMONSTRATION

PROGRESSION

- feet "V" position and shoulder-width apart

- ankles, knees, and hips flexed, weight forward and low

beware: fully extended joints may canse loss of balance backwards

- shoulders slightly forward and relaxed

- ams forward and in front of knees

- "click" wrist guards on knee pad beware: put hands on knees to regain balance if "falling" backward; flinging arms is dangerous

\section{PRACTICE:}

- on mats or carpeted area first

- shift weight by raising and lowering one akate at a time ("marching")

Note: focus on putting majority of weight on support leg

- on floor

- shift weight by raising one skate at a time

- balance as long as possible on each skate

\section{FALLING}

\section{DESCRIPTION/DEMONSTRATION}

PROGRESSION:

- drop to knees

- drop to hands placing weight on plastic part of wrist guard

- slide forward onto elbow pads 


\section{LESSON \#2 (Cont.)}

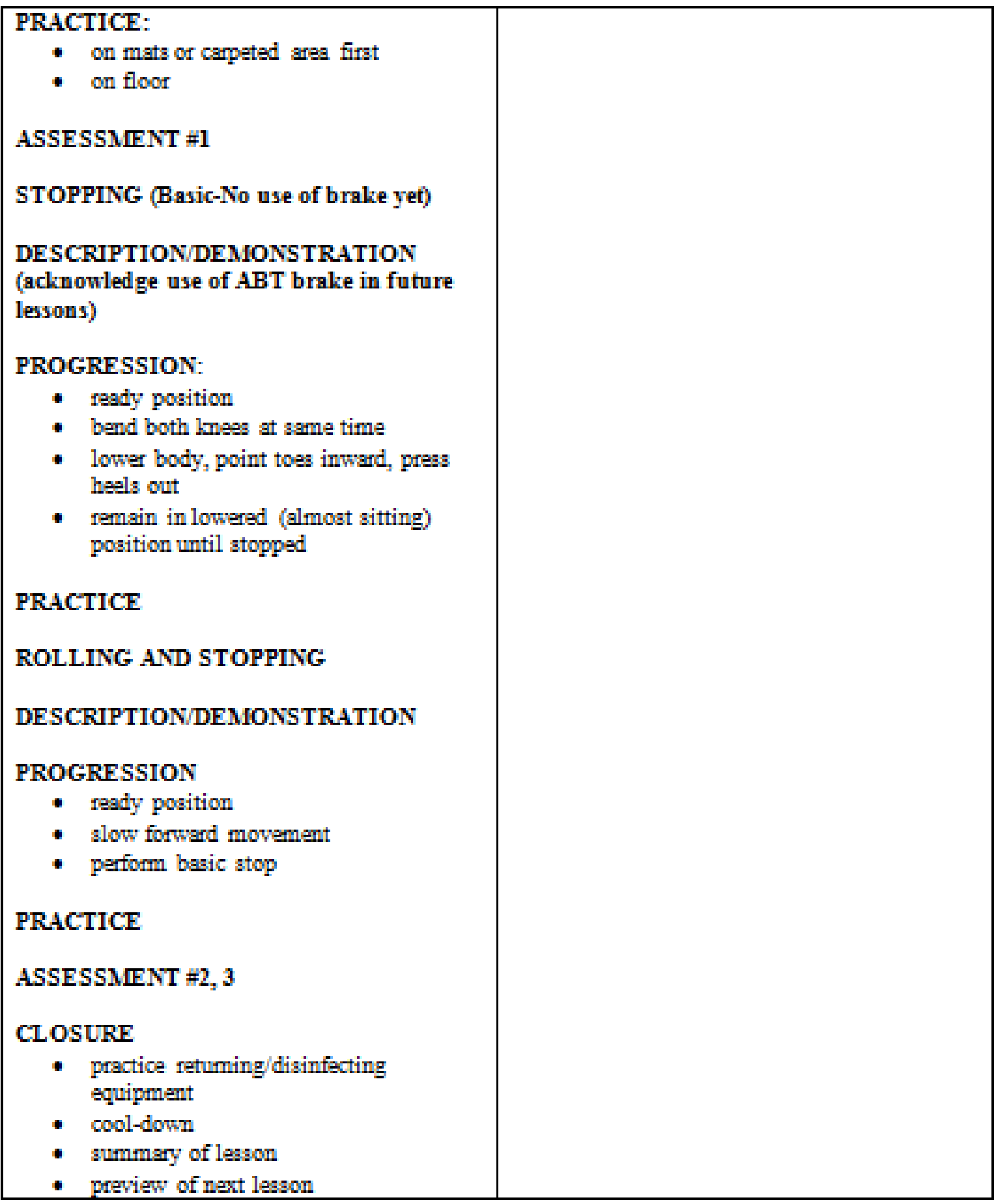

Adapted with permission from Get Your Students Inline (pp. 10-11), by Skate in School. Skate in School and Rollerblade, 2016, Skate in School Minneapolis, MN \& Rollerblade, West Lebanon, NH: Skate in School. Copyright 2016 by Skate in School and Rollerblade. 


\section{LESSON \#3}

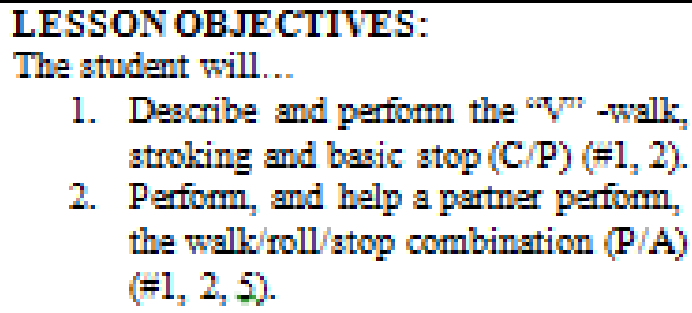

1. Describe and perform the "V" -walk, strolking and basic stop $(\mathrm{C} / \mathrm{P})(=1,2)$.

2. Perform, and help a partner perform, the wall/roll/stop combination (P/A) $(=1,2,5)$.

3. Demonstrate asfe technique and body control $(\mathrm{P})(=1,2)$.

\section{VOCABULARY:}

$V$-walk:

stroke/stroking

basic stop

ACTIVITIES:

WARM-UP with/without skates

REVIEW OF PREVIOUS LESSON

- standing up

- ready position

- falling

\section{ASSESSMENT \#1}

"V" -WALK/STROKING

DESCRIPTION/DEMONSTRATION

PROGRESSION ONMATS/CARPET:

- "V" stance (feet apart, toes tumed out, lnees bent)

- walk with feet in "V" (head and eyes up, arms out)

\section{PRACTICE ONMATS OR CARPET} FIRST

PROGRESSION ONFLOOR:

- ready position

- series of small weight shifts from one foot to the other
ASSESSMENT EXAMPLE:

1. Students self-assess their ability to stand up, perform ready position, and fall safely with a "thumbs up, thumbs down."

2. Teacher checks for mastery of "V" walk, strolking, and basic stop.

3. Peers coach each other during the wall/roll/stop combination practice

\section{EQUIPMINT:}

grass or carpet

level area for skating

STRATEGIES/TIPS:

- Set up practice to allow plenty of space for stopping.

- Frequently remind students of proper position for balance and control.

TEACHER REFLECTIONS/NOTES: 


\section{LESSON \#3 (Cont.)}

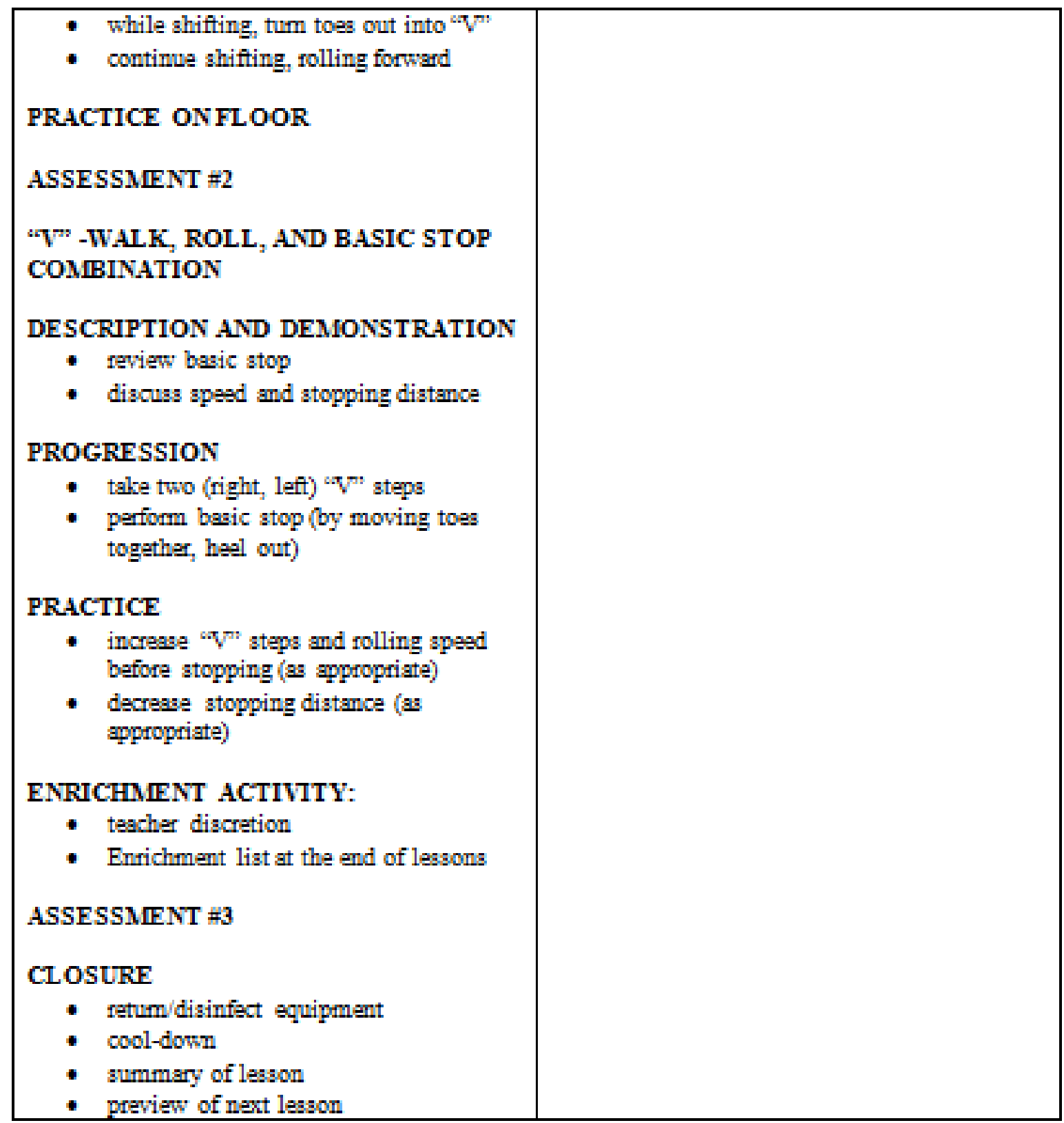

Adapted with permission from Get Your Students Inline (pp. 12-13), by Skate in School. Skate in School and Rollerblade, 2016, Skate in School Minneapolis, MN \& Rollerblade, West Lebanon, NH: Skate in School. Copyright 2016 by Skate in School and Rollerblade. 


\section{LESSON \#4}

\section{LESSON OBJECTIVES:}

The student will...

1. Describe and perform the stride (C/P) $(=1,2)$.

2. Use the stride and basic stop in an activity/game (P) ( $=1)$.

3. Exhibit good sportamanship and enjoyment during an activity/game (A) $(=4,5)$.
ASSESSMINT EXAMPLE:

1. Students give three helpful corrections about striding to partners.

2. Teacher asaesses skills and achievement of skills as students participate in games.

3. Students signal with thumbs up or down whether they enjoyed participating in the activity/game. (Describe in logs what they did or did not enjoy and why.)

4. Students identify characteristics of appropriate, considerate behavior during the in-line skating activities.

\section{EQUTPMENT:}

stereo and music, course markers, directional signs, bowling pins, gym tape (for lines on floor), boundary markers

glide/gliding, stride/striding, sportsmanship

\section{ACTIVITIES:}

WARM-UP WITHOUT SKATES

RETRIEVING/PUTTING ON EQUTPMENT

REVIEW OF PREVIOUS LESSON

- "V" -walk

- basic stop

- walk/roll/stop combination

TEACHER REFLECTIONS/NOTES:
STRATEGIES/TIPS:

- Use boundary markers to note asfe skating areas.

- Clearly mark and enforce traffic partems for circular or lane skating. Large arrows on walls and cones will help.

STRIDE (stroke and glide)

DESCRIPTION/DEMONSTRATION

PROGRESSION

Stroke-Glide-Stroke Exercise

- "ready position"

- bend knees and give steady push with one leg ('stroke") note: majority of weight should be on support leg 


\section{LESSON \#4 (Cont.)}

- feet back to ready position and glide

- repeat with other leg

Small Glides on One Leg

- stroke-glide-stroke exercise but glide with stroking foot slightly off ground

Gliding with One Leg Raised

- stroke-glide-stroke exercise but glide with stroking foot higher off ground

like a marching step

Stride

- right-foot stroke

- when right foot is being retumed to ground, left skate moves into "V" position almost simultaneously

- left-foot stroke

note: there is minimal time that both skates are in contact with the ground

\section{PRACTICE}

ASSESSMENT $\# 1$

ACTIVITY/GAME

DESCRIPTION/DEMONSTRATION

DISCUSSION ABOUT SPORTSMANSHIP

EXAMPLES:

"Musical Braking"

Students akate to music on a circular course.

Periodically the music is tumed off for a period of 3-5 aeconds. The gosl of the activity is for every student to come to a complete, controlled stop before the music is tumed on again.

Option: a point can be awarded to the entire class every time the goal is achieved.

"Skating Pins"

Students akate in lanes up and down the length of the floor. A "wall" of bowling pins is placed at each end and a line is taped to the floor approximately $2-3$ feet in front of the pins. The gosl of the activity is for students to perform 


\section{LESSON \#4 (Cont.)}

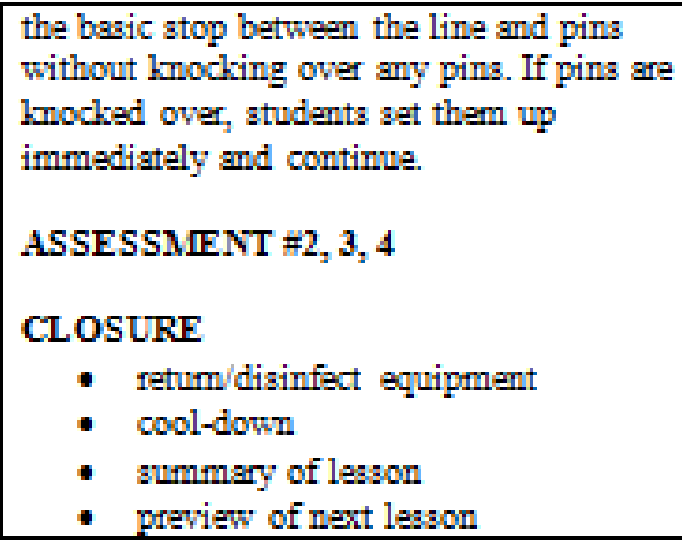

Adapted with permission from Get Your Students Inline (pp. 14-15), by Skate in School. Skate in School and Rollerblade, 2016, Skate in School Minneapolis, MN \& Rollerblade, West Lebanon, NH: Skate in School. Copyright 2016 by Skate in School and Rollerblade. 


\section{LESSON \#5}

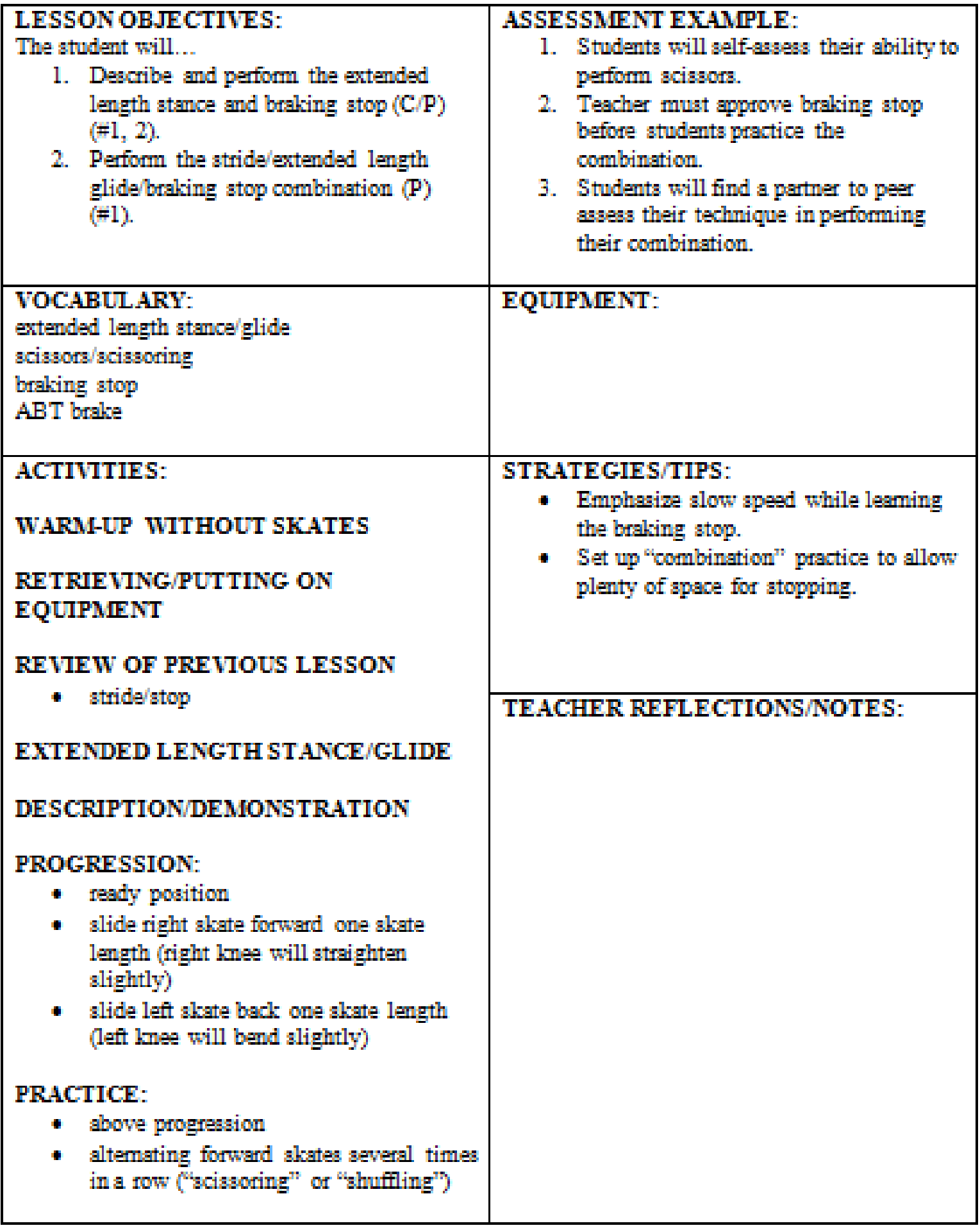




\section{LESSON \#5 (Cont.)}

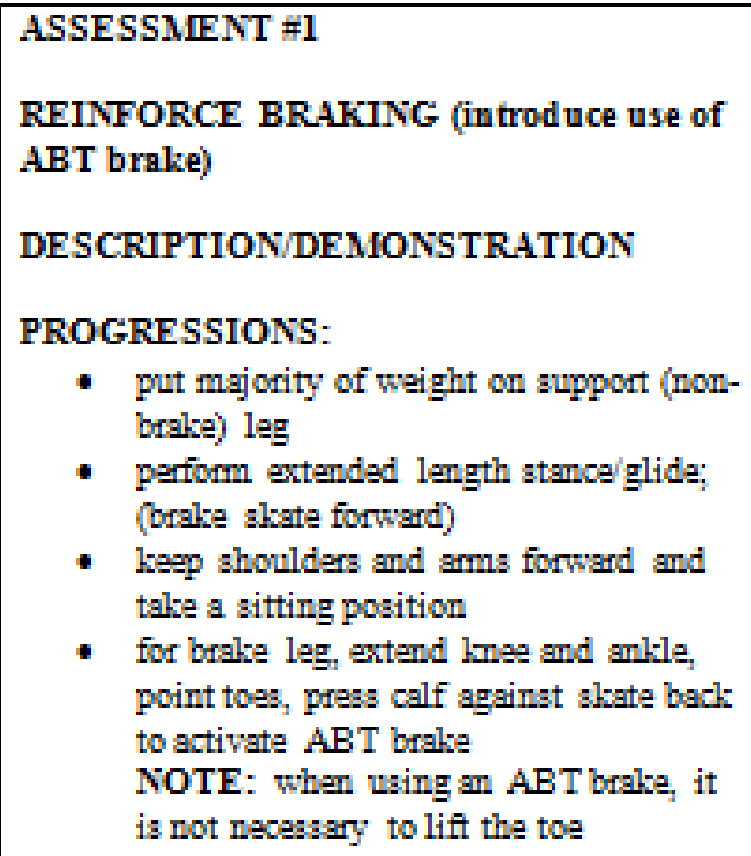

- put majority of weight on support (nonbrake) leg

- perform extended length stance/glide; (brake skate forward)

- kesp shoulders and ams forward and take a sitting position

- for brake leg, extend knee and ankle, point toes, press calf against skate back to activate $\mathrm{ABT}$ brake NOTE: when using an $A B T$ brake, it is not necessary to lift the toe

\section{PRACTICE}

ASSESSMENT $\# 2$

STRIDING/EXTENDED LENGTH GLIDE/BRAKING STOP COMBINATION DESCRIPTION/DEMONSTRATION

PROGRESSION:

- three or four strides

- extended length stance/glide

- braking stop

PRACTICE:

- above progression

- altemating striding and gliding multiple times before stopping

- increase spead (as appropriate)

- decrease stopping distance (as appropriate)

ENRICHMINT ACTIVTTY(IES):

- Red Light Green Light 


\section{LESSON \#5 (Cont.)}

\begin{tabular}{|l|l|}
\hline ASSESSMINT $\# 3$ & \\
CLOSURE & \\
- retum/disinfect equipment & \\
- cool-down & \\
- pummary of lesson & \\
\hline
\end{tabular}

Adapted with permission from Get Your Students Inline (pp. 16-17), by Skate in School. Skate in School and Rollerblade, 2016, Skate in School Minneapolis, MN \& Rollerblade, West Lebanon, NH: Skate in School. Copyright 2016 by Skate in School and Rollerblade. 


\section{LESSON \#6}

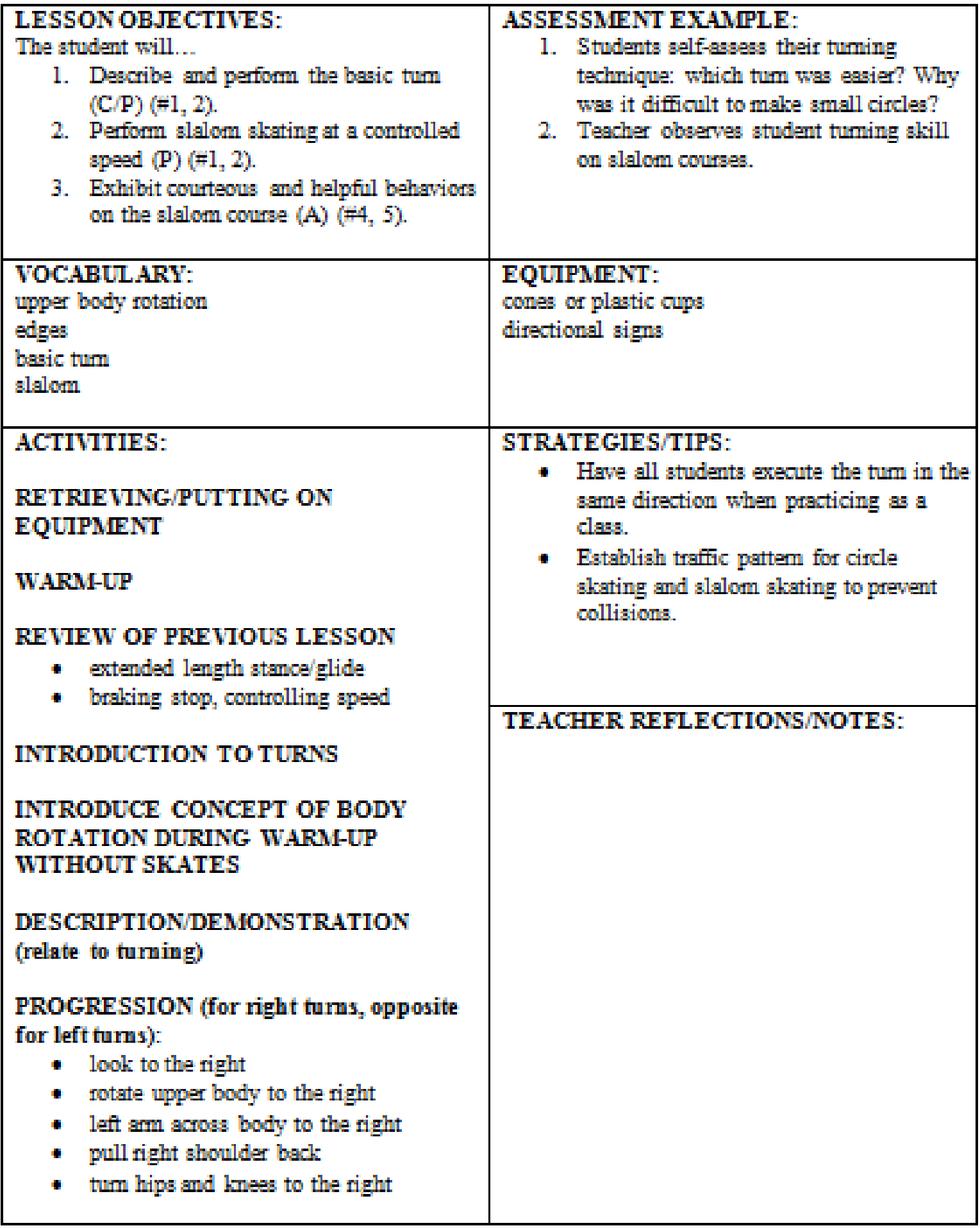




\section{LESSON \#6 (Cont.)}

PRACTICE WHILE STATIONARY

USE OF EDGES (inside and outside)

DESCRIPTION/DEMONSTRATION

(relate wheel edges to turning)

PROGRESSION:

- stand with feet 4-6 inches apart

- lean to each side so that wheels of skates are on altemate edges, i.e. one skate on outside edge and one on inside edge.

- roll forward by pressing on edges, moving feet apart and together, starting at "V" position

- continual outside-inside edge rolling, "swizzle," "ins and outs"

BASIC TURN (also called parallel turn or glide turn)

\section{DESCRIPTION/DEMONSTRATION}

\section{PROGRESSION:}

- extended length glide (forward leg same as tuming direction)

- upper body rotation

- lean into edges

PRACTICE:

- right tums

- left tums

\section{DESCRIPTION/DEMONSTRATION}

\section{PROGRESSION:}

- tuming in both directions

- tum continually to right (circle) and

- tum continually to left make altemating tums to right and left

- make tums with one foot stationary tuming by strolking with altemating foot 


\section{LESSON \#6 (Cont.)}

\section{PRACTICE:}

- skate in small (15-20' diameters) circles designated by cones; going counter clockwise and then clockwise; vary sizes of circles (larger = easier, smaller $=$ more difficult $)$

- practice tuming on slalom courses of varying difficulty (cones placed in straight line with lots of space = easiest; closer together = more difficult; staggered $=$ most difficult)

\section{ENRICHMINT ACTIVTTY(IES):}

\section{SLALOM SKATING}

- Description: vary slalom stations with distance between cones and staggering to challenge leamed skills.

\section{TEACHER DISCRETION}

- Enrichment list at the end of lessons

\section{ASSESSMENT $\# 1,2$}

\section{CLOSURE}

- retum/disinfect equipment

- cool-down

- summary of lesson

- preview of next lesson

Adapted with permission from Get Your Students Inline (pp. 18-19), by Skate in School. Skate in School and Rollerblade, 2016, Skate in School Minneapolis, MN \& Rollerblade, West Lebanon, NH: Skate in School. Copyright 2016 by Skate in School and Rollerblade. 


\section{LESSON \#7}

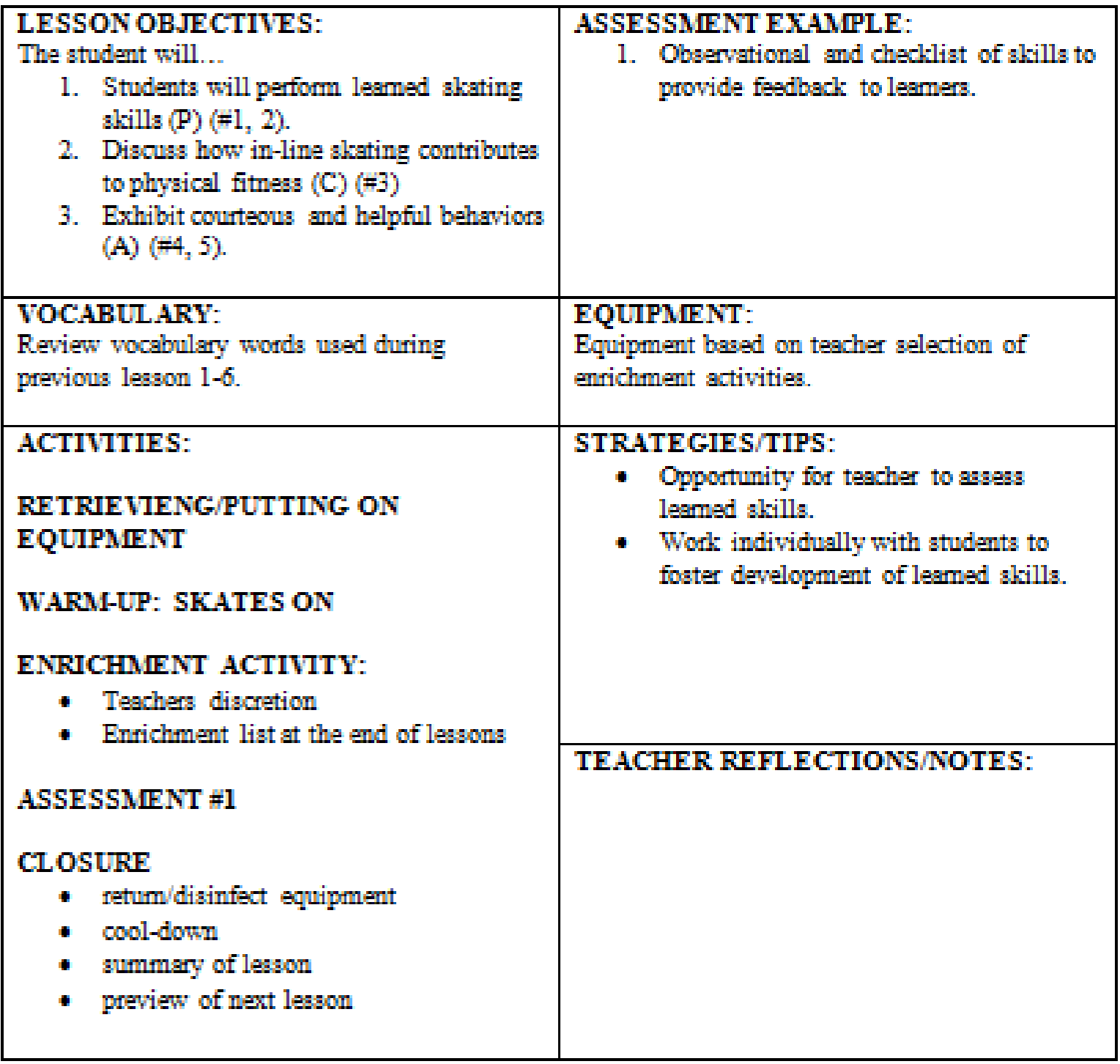

Adapted with permission from Get Your Students Inline, by Skate in School. Skate in School and Rollerblade, 2016, Skate in School Minneapolis, MN \& Rollerblade, West Lebanon, NH: Skate in School. Copyright 2016 by Skate in School and Rollerblade. 


\section{LESSON \#8}

\begin{tabular}{|c|c|}
\hline $\begin{array}{l}\text { LESSON OBJECTIVES: } \\
\text { The student will... } \\
\text { 1. Discuss how skating contributes to } \\
\text { physical fitness (C) (=3). } \\
\text { 2. Monitor heart rate during slesting (C) } \\
(=2,3) \text {. } \\
\text { 3. Choose and perform appropriate tasks } \\
\text { at fitness stations (P/A) }(=3,5) \text {. } \\
\text { 4. Work cooperatively at fitness stations } \\
\text { (A) }(=4,5) \text {. }\end{array}$ & $\begin{array}{l}\text { ASSESSMENT EXAMPLE: } \\
\text { 1. At the slalom station, students per- } \\
\text { assess technique and record number of } \\
\text { cones/cups that their partner misses or } \\
\text { touches. } \\
\text { 2. At the squats station, teacher assesses } \\
\text { students' skills and ability to work } \\
\text { safely and cooperatively. } \\
\text { 3. At striding station, students measure } \\
\text { and record their heart rate. }\end{array}$ \\
\hline $\begin{array}{l}\text { VOCABULARY: } \\
\text { Review physical fitness terminology (i.e. } \\
\text { cardiovascular endurance, muscular endurance, } \\
\text { muscular strength, flexibility, body } \\
\text { composition, heart rate) } \\
\text { squats, shoot the duck }\end{array}$ & $\begin{array}{l}\text { EQUIPMENT: } \\
\text { skill practice charts (for stations) } \\
\text { performance assessment checklists } \\
\text { clock with second hand, heart monitors } \\
\text { cones/cups, directional signs }\end{array}$ \\
\hline $\begin{array}{l}\text { ACTIVITIES: } \\
\text { RETRIEVING/PUTTING ON } \\
\text { EQUIPMENT } \\
\text { WARM-UP } \\
\text { IN-LINE SKATING AND PHYSICAL } \\
\text { FITNES } \\
\text { - discuss fitness components and in-line } \\
\text { skating's contributions to fitness } \\
\text { - review of heart rate monitoring }\end{array}$ & $\begin{array}{l}\text { STRATEGIES/TIPS: } \\
\text { - Clearly number and name each station } \\
\text { - Each skill station should have a chart } \\
\text { which lists practice options for all skill } \\
\text { levels and students should be allowed } \\
\text { to select the appropriate level(s). } \\
\text { - Have checklists and pencils available at } \\
\text { appropriate stations. Make sure that } \\
\text { students put their names on the } \\
\text { checklists and leave them at the } \\
\text { stations. }\end{array}$ \\
\hline $\begin{array}{l}\text { FITNESS/SKILL STATIONS } \\
\text { - description/demonstration of each } \\
\text { station } \\
\text { - procedures for selecting/changing } \\
\text { stations } \\
\text { - explanation of assessment checklists, } \\
\text { heart monitoring } \\
\text { - examples: } \\
\text { slalom course } \\
\text { squats: two-foot and one-foot ("shoot } \\
\text { the duck") } \\
\text { skating track (striding) }\end{array}$ & TEACHER REFLECTIONS/NOTES: \\
\hline
\end{tabular}




\section{LESSON \#8 (Cont.)}

\section{PRACTICE}

- all stations

ASSESSMENTS $\# 1,2,3$

CLOSURE

- retum/disinfect equipment

- cool-down

- summary of lesson

- preview of next lesson

Adapted with permission from Get Your Students Inline (p. 20), by Skate in School. Skate in School and Rollerblade, 2016, Skate in School Minneapolis, MN \& Rollerblade, West Lebanon, NH: Skate in School. Copyright 2016 by Skate in School and Rollerblade. 


\section{LESSON \#9}

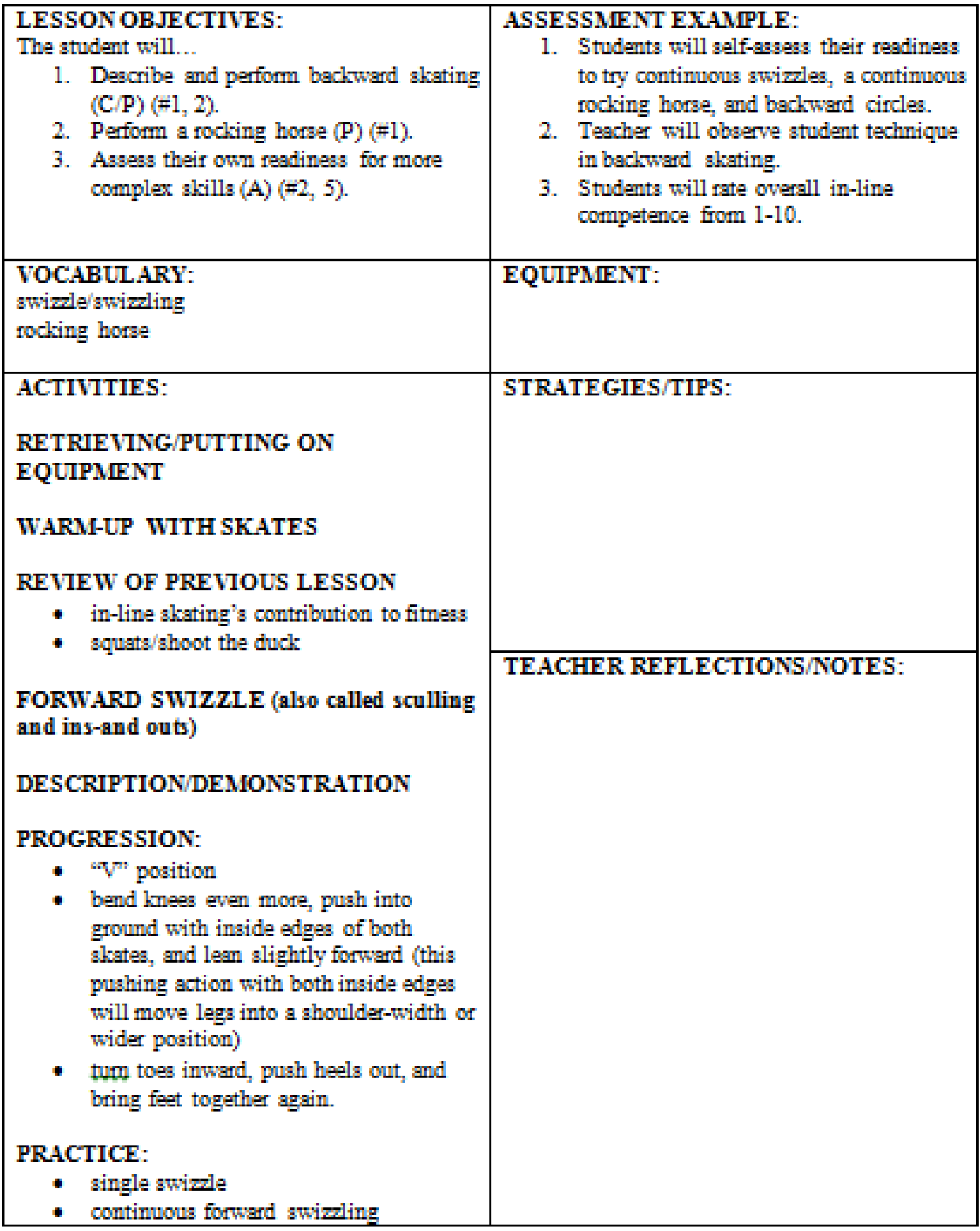




\section{LESSON \#9 (Cont.)}

\section{ASSESSMENT \#1 \\ BACKWARD/REVERSE SWTZZLE \\ DESCRIPTION/DEMONSTRATION \\ PROGRESSION: \\ - reverse "V" position \\ - reverse/backward swizzle: push into inside edges while putting more pressure on balls of feat (pushing edges away from the body will result in backwards movement) \\ - bend lnees more and push into the ground with balls of fest \\ - roll backwards off the toes on the inside edges}

\section{PRACTICE:}

- single swizzle

- continuous backward swizzling

\section{ASSESSMENT \#1}

ROCKING HORSE (alternating one forward and one backward swizzle)

\section{DESCRIPTION/DEMONSTRATION}

\section{PROGRESSION:}

- one swizzle

- one swizzle in opposite direction

\section{PRACTICE:}

- forward to backward swizzle

- backward to forward swizzle

- continuous rocking horse

\section{ASSESSMENT \#1}

\section{BACKWARD STRIDING}

- kesp left foot stationary

- stroke backward with right foot 


\section{LESSON \#9 (Cont.)}

\begin{tabular}{|l|l|}
\hline - tum clockwise, tum to right \\
continue for five strokes using edges \\
then tum to left, right foot stationary \\
and left foot stroking
\end{tabular}

Adapted with permission from Get Your Students Inline (pp. 22-23), by Skate in School. Skate in School and Rollerblade, 2016, Skate in School Minneapolis, MN \& Rollerblade, West Lebanon, NH: Skate in School. Copyright 2016 by Skate in School and Rollerblade. 


\section{LESSON \#10}

\begin{tabular}{|c|c|}
\hline $\begin{array}{l}\text { LESSON OBJECTIVES: } \\
\text { The student will... } \\
\text { 1. Students will perform leamed skating } \\
\text { skills }(\mathrm{P})(=1,2) \text {. } \\
\text { 2. Exhibit courteous and helpful behaviors } \\
\text { (A) }(=4,5) \text {. }\end{array}$ & $\begin{array}{l}\text { ASSESSMENT EXAMPLE: } \\
\text { 1. Observational and checklist of akill to } \\
\text { provide feedback to leamers. }\end{array}$ \\
\hline $\begin{array}{l}\text { VOCABULARY: } \\
\text { Review vocabulary words used during } \\
\text { previous lesson. }\end{array}$ & $\begin{array}{l}\text { EQUIPMIENT: } \\
\text { Equipment based on teacher selection of } \\
\text { enrichment activities. }\end{array}$ \\
\hline $\begin{array}{l}\text { ACTIVITIES: } \\
\text { RETRIEVIENG/PUTTING ON } \\
\text { EQUIPMENT } \\
\text { WARM-UP: SKATES ON }\end{array}$ & $\begin{array}{l}\text { STRATEGIFS/TIPS: } \\
\text { - Opportunity for teacher to assass } \\
\text { leamed skills. } \\
\text { Work individually with students to } \\
\text { foster development of leamed skills. }\end{array}$ \\
\hline $\begin{array}{l}\text { ENRICHMENT ACTIVITY(IES): } \\
\text { - Teachers discretion } \\
\text { - Enrichment list at the end of lessons }\end{array}$ & \\
\hline ASSESSMENT \#1 & TEACHER REFLECTIONS/NOTES: \\
\hline $\begin{array}{l}\text { CLOSURE } \\
\text { - retum/disinfect equipment } \\
\text { : cool-down } \\
\text { - prmmary of lesson } \\
\text { preview of next lesson }\end{array}$ & \\
\hline
\end{tabular}

Adapted with permission from Get Your Students Inline, by Skate in School. Skate in School and Rollerblade, 2016, Skate in School Minneapolis, MN \& Rollerblade, West Lebanon, NH: Skate in School. Copyright 2016 by Skate in School and Rollerblade. 


\section{LESSON \#11}

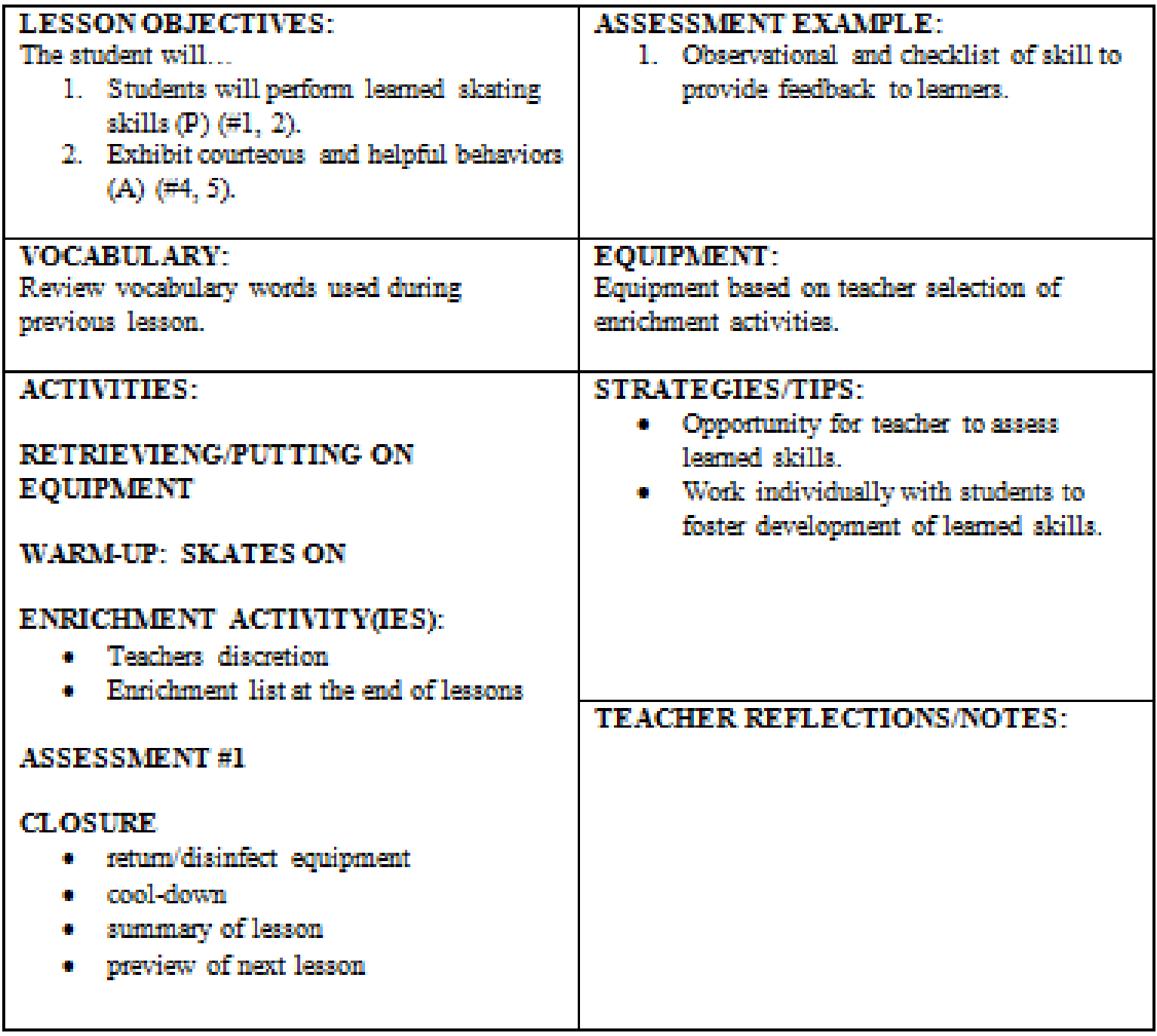

Adapted with permission from Get Your Students Inline, by Skate in School. Skate in School and Rollerblade, 2016, Skate in School Minneapolis, MN \& Rollerblade, West Lebanon, NH: Skate in School. Copyright 2016 by Skate in School and Rollerblade. 


\section{LESSON \#12}

\begin{tabular}{|c|c|}
\hline $\begin{array}{l}\text { LESSON OBJECTIVES: } \\
\text { The student will... } \\
\text { 1. Students will perform leamed skating } \\
\text { skills }(\mathrm{P})(=1,2) \text {. } \\
\text { 2. Discuss how in-line skating contributes } \\
\text { to physical fitness (C) ( }=3 \text { ). } \\
\text { 3. Exhibit courteous and helpful behaviors } \\
\text { (A) }(=4,5) \text {. }\end{array}$ & $\begin{array}{l}\text { ASSESSMENT EXAMPLE: } \\
\text { 1. Rubric of skating skills to provide } \\
\text { feadback to leamers. }\end{array}$ \\
\hline $\begin{array}{l}\text { VOCABULARY: } \\
\text { Review vocabulary words used during } \\
\text { previous lesson. }\end{array}$ & $\begin{array}{l}\text { EQUTPMENT: } \\
\text { Equipment based on teacher selection of } \\
\text { enrichment activities. }\end{array}$ \\
\hline $\begin{array}{l}\text { ACTIVITIES: } \\
\text { WARM-UP: SKATES ON } \\
\text { ENRICHMENT ACTIVITY(IFS): } \\
\text { - "Free skate:". Music will be played and } \\
\text { teacher will call out various skills for } \\
\text { students to demonstrate the leamed } \\
\text { skills during this Unit. } \\
\text { - Additional enrichment activitios can be }\end{array}$ & $\begin{array}{l}\text { STRATEGIES/TIPS: } \\
\text { - Opportunity for teacher to asseas } \\
\text { leamed skilled. }\end{array}$ \\
\hline $\begin{array}{l}\text { utilized at teacher's discretion. } \\
\text { ASSESSMINT \#1 } \\
\text { CLOSURE } \\
\text { - retum/disinfect equipment } \\
\text { - cool-down } \\
\text { UNIT WRAP-UP } \\
\text { - Discuss with students their impreasions } \\
\text { and experiences with the skating unit. } \\
\text { - Teacher ask questions about: } \\
\text { - Types of skills leamed } \\
\text { o How can skating benefit me? }\end{array}$ & TEACHER REFLECTIONS/NOTES: \\
\hline
\end{tabular}

Adapted with permission from Get Your Students Inline, by Skate in School. Skate in School and Rollerblade, 2016, Skate in School Minneapolis, MN \& Rollerblade, West Lebanon, NH: Skate in School. Copyright 2016 by Skate in School and Rollerblade. 


\section{Appendix K: Enrichment Games and Descriptions}

\section{CONES}

Cones can be used in a variety of fashions for both skill development and fun. Cones can be set up to practice turns or other skills mentioned in the skills section of the manual. Cones can be used to create a circular rink inside the gymnasium which can be used in a variety of manners: to have a free skate with music - all skaters move in the same direction; to have speed-skating races with the number of participants in each race depending upon the size of the gym and racetrack created; to have relay races using a baton; and for relay races that can incorporate skills such as back to back turns.

\section{POP CANS}

Pop cans can be set up to test the agility and maneuverability of the skater. The closer together and the faster the skater approaches increases the difficulty level. Zig zags, connecting turns, crossover turns, and the weaving of the skates are a few of the skills that can be tested.

\section{OBSTACLE COURSE}

Obstacle courses can be set up using different objects such as cones, chairs, and horizontal apparatus that are intended to be skated under, etc. The obstacle course is limited only by the imagination of the instructor.

\section{LIMBO}

Get the limbo going with some music and a pole. The pole is held by two people parallel to the ground at a height which is assumed that everyone participating can pass under without touching it. After all participants successfully skate under the pole, the height is dropped a few inches and everyone attempts again. If the skater touches the pole or loses their balance and falls while going under - they're out! Continue until one person is left. For safety make sure the people holding the pole give with it if the skater makes contact.

\section{SHOOT THE DUCK}

Shoot the duck is a game where the participants are asked to glide on one skate. All skaters begin by skating in a similar direction in a large circle to some jams. When the music stops, the participants immediately balance on one skate and coast; the contestant who coasts the longest is declared the winner. No strokes are allowed once the music stops; and the skaters cannot use their hands for locomotion either. Partner shoot the duck is also a fun game - the only difference being that two skaters must hold hands during the contest.

Reprinted with permission from Teacher Resources Instruction Manual (p. 37), by Skatetime. Skatetime, 2017, Rockford, IL: Skatetime. Copyright 2017 by Skatetime. 


\section{FOUR CORNERS ${ }^{1}$}

A cardboard box with either 4 numbers or colors corresponds to the same numbers/colors which are posted in each of the four corners of the gym. Music is played and all the students skate in the same direction. At the instructor's discretion the music is stopped - at which time all skaters must choose 1 of the 4 corners to stop at. The instructor reaches into the cardboard box and draws a number/color. All skaters in the corner that was drawn are out of the game and must leave the skating floor or sit against the wall. This process is continued until there is a single winner.

\section{FREE SKATE WITH MUSIC ${ }^{1}$}

Just like the retro days at the roller rink, turn on some music and let the students skate.

\section{INLINE HOCKEY ${ }^{1}$}

Inline hockey is an exciting and fun sport. Many schools play floor hockey and have indoor pucks and sticks. This equipment can be a fun addition to the inline unit. The equipment can be used in a variety of ways which include:

\section{PUCK HANDLING ${ }^{1}$}

With stick teach the students how to properly hold the hockey stick with both hands. Teach them proper positioning of the stick for both the forehand and backhand. Teach to skate forward and backward while handling puck. With skates during floor hockey the skates are a legal way to control, pass, or advance the puck. Have the student skate towards a puck and by turning the toes outward and using the wheels kick the puck forward. The student should be able to use both feet and then alternate.

\section{SLALOM COURSES}

The teacher can lay out several different types of slalom course. The course can be laid out with cones varying in distances and staggered off-line to allow for students to learn to vary and gauge distance and change direction.

\footnotetext{
${ }^{1}$ Reprinted with permission from Teacher Resources Instruction Manual (p. 38), by
} Skatetime. Skatetime, 2017, Rockford, IL: Skatetime. Copyright 2017 by Skatetime. 


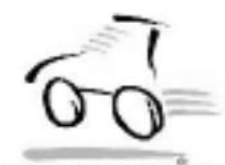

SKATETIME

School Programs

\section{Human Shuffleboard}

Materials: Roller skates, gym floor

Basic Strategy: To push your partner into the three point arc of the opposing basketball court

Game Play:

-Team will start on opposing baseline with one partner standing; the other partner is crouched with their hands around their knees

-The standing partner pushes the crouched partner, getting a moving start, the push must end before the free throw line

-The crouched partner will coast to the other side of the court and stop where their momentum ends

Scoring System:

-Anything inside the three point line is 1 point, inside the lane is worth 2 points and inside the free throw arc is worth 3 points

-Opposing teams will cancel out points, for instance, if Team A has two people in the three point arc and Team $B$ has only 1 . Team $A$ will get 1 point.

-If the coasting player loses their balance and any part of their body other than their skates touches the ground, the player will not count

-If the coasting player pushes off and gains speed the point also will not count

Skills Learned:

-Balance of both team members

-Strengthening the skating start for the pushing player

-Integrated upper and lower body movements

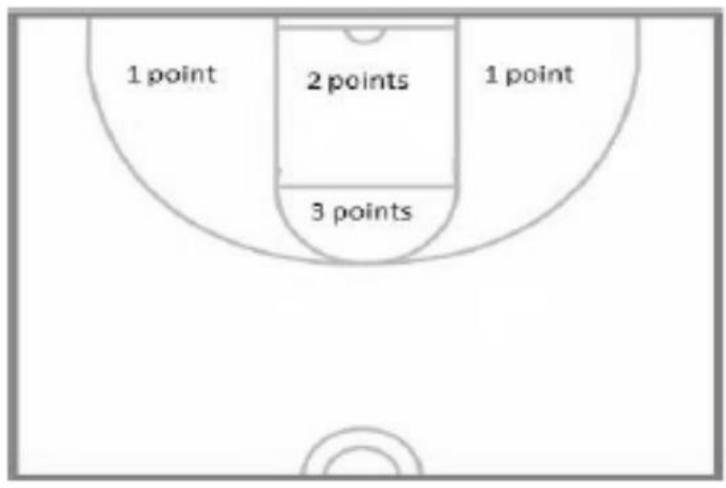

Reprinted with permission from Games and Activities (p. 1), by Skatetime. Skatetime, 2013, Rockford, IL: Skatetime. Copyright 2013 by Skatetime. 


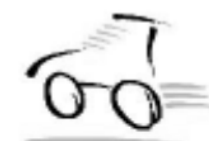

SKATETIME

School Programs

\section{Skating Noodle Tag - contributed by Zach Kelley}

Game Play:

Give 3 students a Mini-Noodle... they will be taggers.

- All skaters must move in the same skating direction.

- Taggers will skate and tag non-taggers on the shoulders with a mini-noodle.

- Skaters can only be tagged when they are inside the "Tag Zone." Place floor tape, cones, or poly spots, or poly line markers on the floor to mark the "Tag Zone." Refer to the diagram.

- If a skater is tagged... he or she must go the side road and complete 5 exercise movements of the teacher's choice (crunches, push-ups, etc...). After the student completes the exercise... he or she can stand and return to skating.

- As the activity continues, the teacher can add more noodles to the game...

- Safe skating will be enforced... skaters are not allowed to stop at any point... they must continue moving and a safe manner... any skater not demonstrating safe skating skills can be moved to the side road at any time.

- Add "Reverse" to the game once all skaters understand how the game is working.

MATS

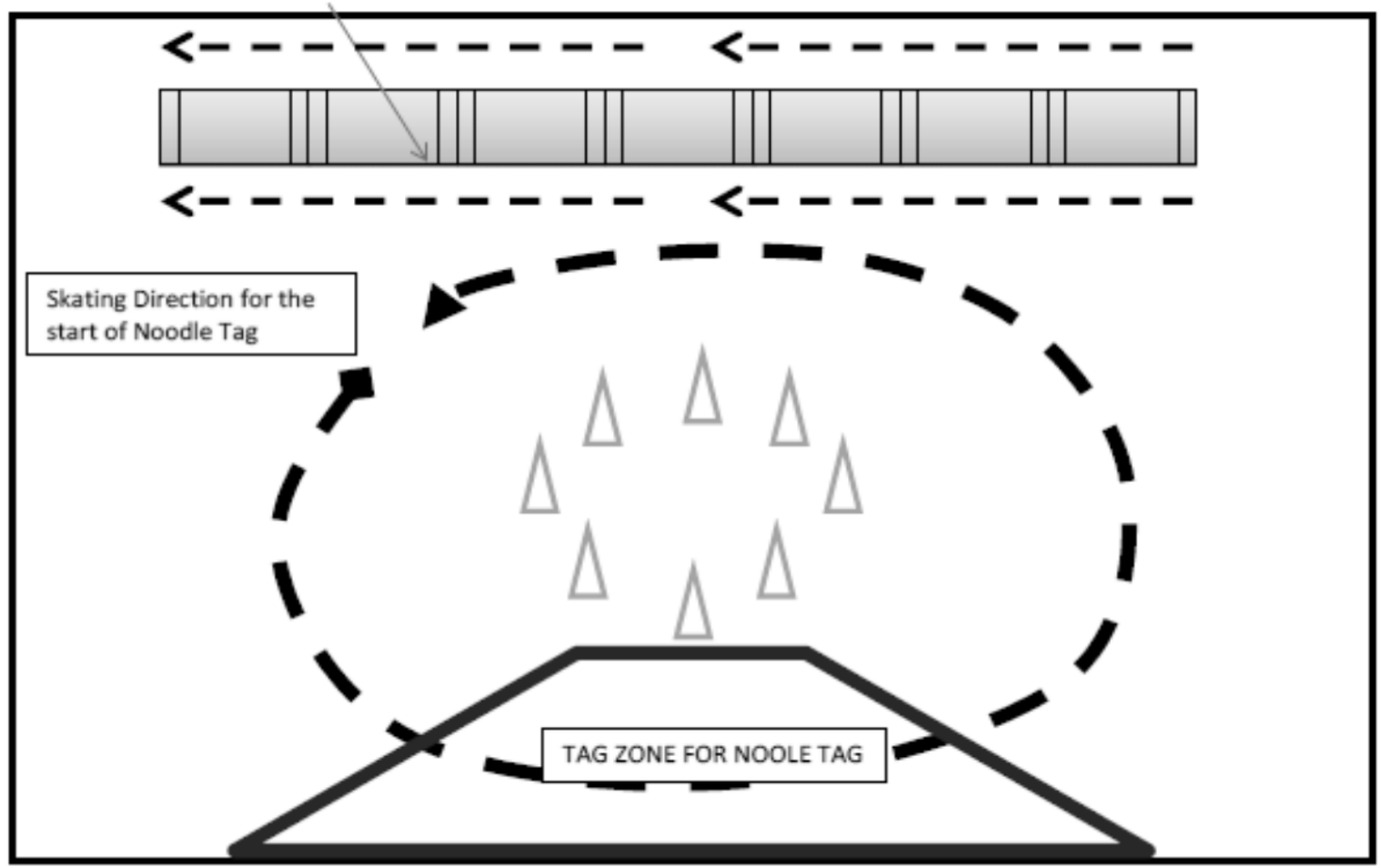

Reprinted with permission from Games and Activities (p. 2), by Skatetime. Skatetime, 2013, Rockford, IL: Skatetime. Copyright 2013 by Skatetime. 


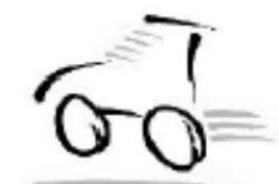

SKATETIME

School Programs

\section{Red Light/Green Light}

Materials: Roller skates, gym floor

Game Play:

- Participants line up along a baseline, standing on their own, not touching anyone or anything

- Participants progress down the court by listening and following the commands of the teacher -They can only move forward when teacher says "Green Light Go" -They have to come to a stop when teacher says "Red Light Stop"

- Once participants have come to a stop, they are allowed to get in their T-stances (don't have to act frozen) if not already, as long as they do not progress forward in the process.

- A participant completes the task (or wins, if declaring a winner) when they stop successfully $\mathrm{ON}$ (not past) the finish line (opposite baseline)

Fouls and Game Modifications:

Any foul results in that participant being sent back to the starting line and starting over.

Fouls:

- Skating forward without "Green Light Go" being said

- Not coming to a complete stop after "Red Light Stop" is said

- Falling

- Touching ground with hands

- Touching/grabbing another participant to come to a stop or prevent falling

- Running into object/wall

- Skating past finish line

\section{Modification:}

When first introducing the game, you can use a 1-3 second countdown after announcing "Red Light Stop" as they learn to stop better and more quickly.

\section{Skills Learned:}

- Students will demonstrate proper stopping technique

- Students will not to skate faster than their ability to stop under control

- Students will practice safety when moving around others

- Students will listen effectively to the teacher's commands

Reprinted with permission from Games and Activities (p. 3), by Skatetime. Skatetime, 2013, Rockford, IL: Skatetime. Copyright 2013 by Skatetime. 


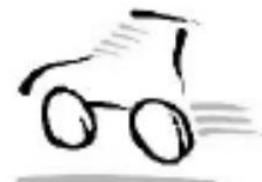

SK AT ETIME

Scheol Programs

Skatetime Basketball

Materials: Basketball, Skates, Safety Equipment, Basketball Court, Jerseys for Teams

Game Play:

- Students will participate in a $5 \mathrm{v} 5$ basketball game. Team sizes can be modified according to class size.

- Teams can be separated using teacher discretion

- Teams will play a full court $5 \mathrm{v} 5$ basketball game while the next two teams of 5 are waiting on the sideline keeping score for each basket made, and assisting their teammates on the court by passing them the ball after a made basket or rebound.

- After each change of possession (either a made basket or rebound) the player who gains control of the ball on the court MUST pass the ball to one of their teammates waiting on the sideline.

- After the ball is reentered into the playing court by one of the sideline players, the ball MUST be passed 3 times before a shot can be attempted.

- Teams will play for a 2 minute running clock time period trying to score as many points as possible curing that time.

- After 2 minutes, the two teams of 5 playing will rotate with the next two teams of 5 who were waiting on the sideline

- The two new teams of 5 will then play a $5 \mathrm{v} 5$ game of basketball for a 2 minute time period before rotating again.

Modifications:

- Larger size rubber balls instead of basketballs

- Size of teams (5v5, 6v6)

- Period of time for game play

- Number of passes before a shot can be attempted

Skills Learned:

- Students will play the game of basketball using fundamental skills of the game (dribbling, passing, shooting) while skating.

- Students will demonstrate balance while in the field of play

- Students will demonstrate safe skating throughout the game

Reprinted with permission from Games and Activities (p. 4), by Skatetime. Skatetime, 2013, Rockford, IL: Skatetime. Copyright 2013 by Skatetime. 


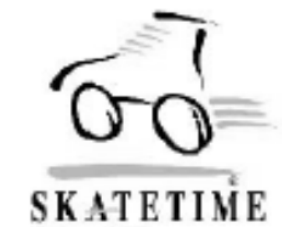

schoof Programs Skatetime Basketball
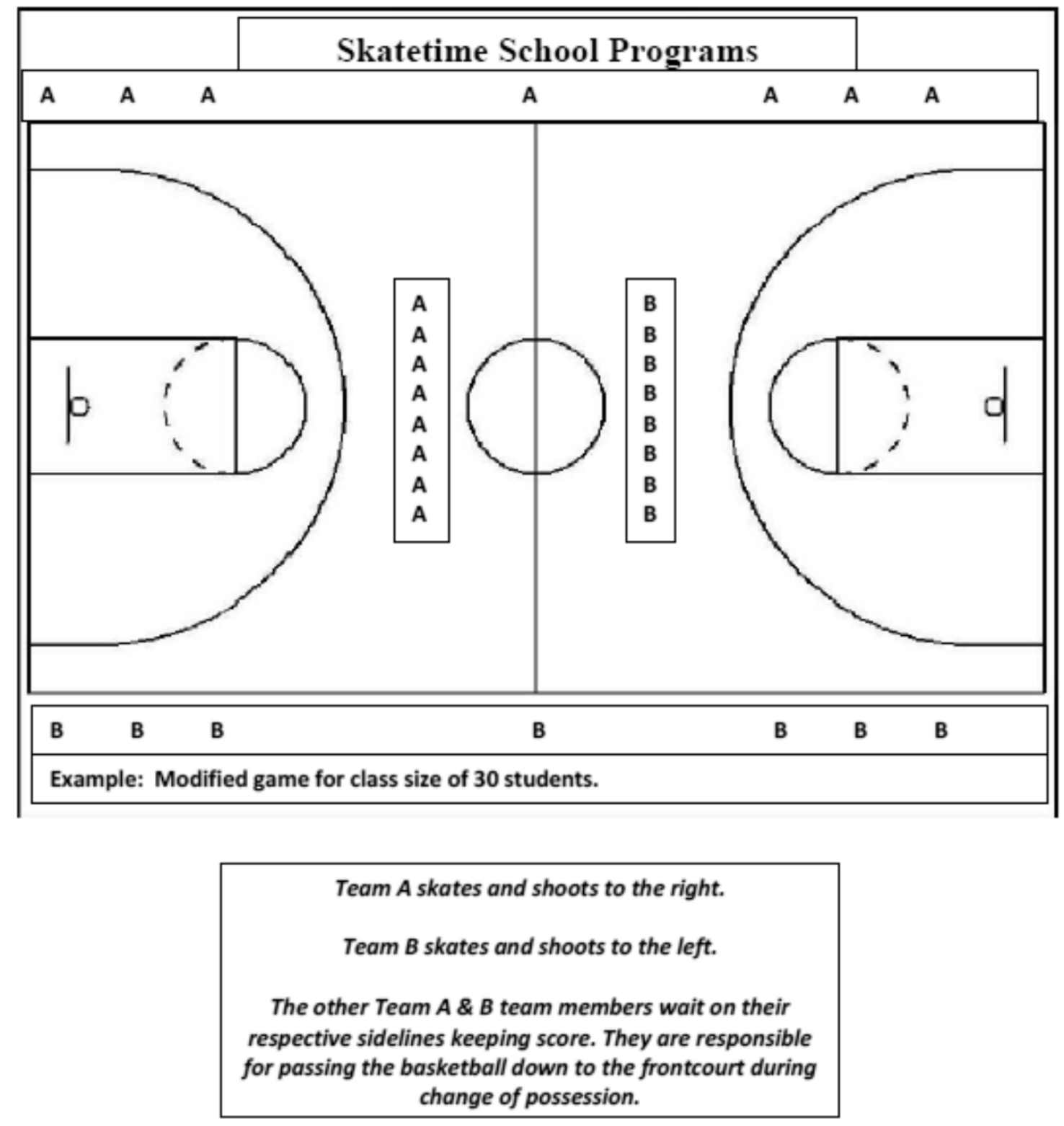

Reprinted with permission from Games and Activities (p. 5), by Skatetime. Skatetime, 2013, Rockford, IL: Skatetime. Copyright 2013 by Skatetime. 


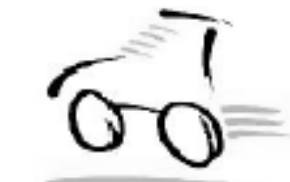

SK ATETIME

School Programs

\section{Team Handball}

Materials: Roller skates, handballs (gator balls), 2 goals, team jerseys

Game Play:

1. Two teams are spread throughout the gym and are working towards throwing the ball into the opponents goal using passing to advance the ball forward

2. Goals can be hockey goals, marked areas on the wall, cones or basketball hoops

3. Getting the ball into the designated goal area is worth 1 point

4. Players are allowed to skate with the ball.

5. Players may hold the ball for 3 seconds before passing.

6. Only one goalie allowed

7. A Player may not pass the ball to his/her self by throwing it into the air (air dribble is illegal).

8. Players are not allowed to dive for a ball that is on the ground.

9. Goalies may leave the goal area to play the ball but must then abide by all the court rules.

- Violations of above rules: Opponents receive a Free Throw On The Goal

Basic Strategy:

- Offense:

- Attempt to out-maneuver your opponents with quick passing \& deception

- Take shots skating in from outside the goal area circle

- Use set "plays" that employ quick passes and skating to beat the defense \& goalie

- Defense:

- Set up as a base on the perimeter of the goal area

- Always make the offense shoot over defensive players

- Never let an offensive player shoot uncontested at your goalie

- Teams play both "Man-to-Man" and Zone defenses

\section{Skills Learned}

- Students will learn to pass and move without the ball

- Students will demonstrate stopping and changing directions

- Students can explain the basic ideas of team handball

- Students will demonstrate safety during all portions of the game

Reprinted with permission from Games and Activities (p. 6), by Skatetime. Skatetime, 2013, Rockford, IL: Skatetime. Copyright 2013 by Skatetime. 


\section{OBSTACLE COURSE}

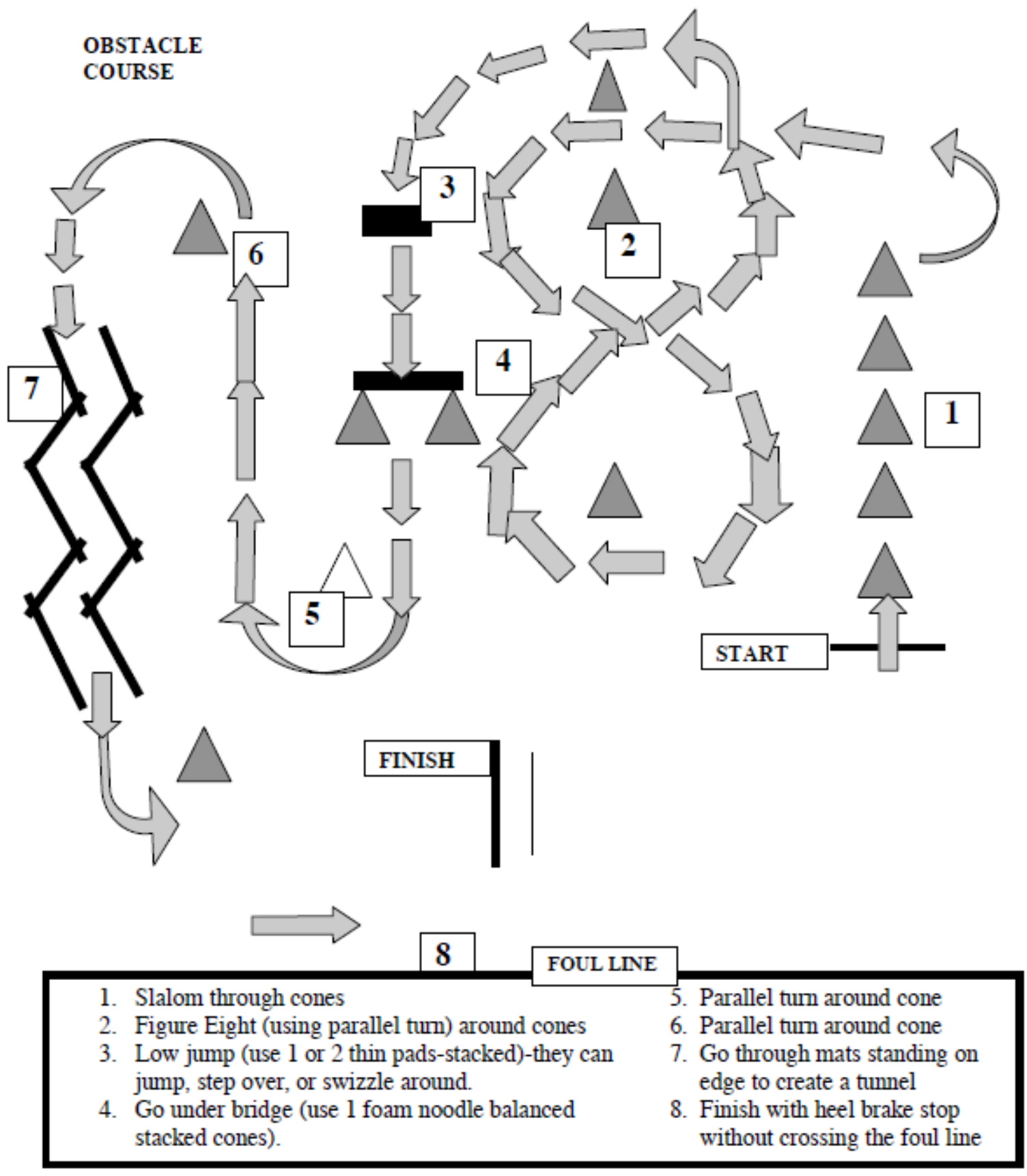

Reprinted with permission from Inline skating lesson plans intermediate \& enrichment activities Get Your Students Inline (p. 35), by Skate in School. Skate in School and Rollerblade, 2016, Skate in School Minneapolis, MN \& Rollerblade, West Lebanon, NH: Skate in School. Copyright 2016 by Skate in School and Rollerblade. 


\section{Appendix L: Skate Study Disclaimer}

This study contains copyrighted material, including but not limited to, the World Wide Web, any Mac based desktop word processing or publishing software, as well as Windows or any PC based desktop word processing or publishing software. Any reproduction without expressed permission from either the Author, Skatetime, and/or Skate in School is strictly prohibited. 